\title{
I Meilensteine in Thorvaldsens Künstlerbiografie
}

\section{Jason und die Folgen}

Am 29. August 1796 bestieg Thorvaldsen in Kopenhagen die Fregatte Thetis, die ihn nach Malta brachte. Von dort reiste der Bildhauer nach Rom weiter, wo er sein Stipendium der Kopenhagener Kunstakademie antrat. Am 8. März 1797 erreichte er schließlich Rom und feierte dieses Datum fortan als seinen zweiten Geburtstag. ${ }^{1}$ Tags darauf schrieb Lorens Henrich Fisker, der Kapitän der Thetis, an seine Frau: „Thorvaldsen ist jetzt in Rom, Gott sei mit ihm! Er ist ein honetter Kerl, aber ein fauler Hund.“2 Die angebliche Bequemlichkeit des jungen Thorvaldsen sollte besonders in posthumen Biografien als Kontrast zur späteren Schaffenskraft betont und damit zu einem festen Bestandteil der Meistererzählung seiner Künstlerbiografie gemacht werden. ${ }^{3}$

In Rom nahm sich der Archäologe Georg Zoëga seines jungen Landsmannes an. Während Fisker den Bildhauer als faul bezeichnet hatte, beklagte Zoëga dessen mangelhafte Bildung. So betrachtete er Thorvaldsen zwar als äußerst begabten Künstler, jedoch sei er „höchst unwissend in allem, was ausserhalb der Kunst liegt“". Zoëga wunderte sich darüber, dass die Akademie ihre Stipendiaten „so roh“ nach Rom schicke, wo der Künstler „sehr viele Zeit verlieren muß, um Dinge zu lernen, ohne welche er seinen hiesigen Aufenthalt nicht gehörig nützen kann, und welche er leichter und geschwinder vor der Reise hätte lernen können“. ${ }^{5}$ Weiter fragte er sich:

1 Thiele 1852-1856, Bd. 1, 33 - 46 (inkl. Thorvaldsens Reisetagebuch). Zu Thorvaldsens ,römischem Geburtstag' siehe ebd., 46; auch Repholtz 1911, 41; Baronesse Stampes Erindringer 1912, 56.

2 Lorens Henrich Fisker an Charlotte Amalie Fisker, 9. März 1797, zit. nach Thiele 1852-1856, Bd. 1, 38. Bereits in einem Brief vom 29. Dezember 1796 an seine Frau hatte Fisker Thorvaldsens Bequemlichkeit betont; TMA, Ref. Thieles Excerpter, 1796, nr. 1.

3 So bspw. bei Spender 1880, 237.

4 Georg Zoëga an Friedrich Münter, 2. Dezember 1797, zit. nach Welcker 1819, 186. Vermutlich derselbe Brief von Zoëga an Münter wird auch von Thiele 1852 - 1856, Bd. 1, 48 - 49, zitiert, jedoch mit einem leicht abweichenden Wortlaut und unter anderem Datum (4.Oktober 1797). Zu Thorvaldsens mangelhafter Bildung siehe auch Kat. Nürnberg/Schleswig 1991, 579-580.

5 Georg Zoëga an Friedrich Münter, 2. Dezember 1797, zit. nach Welcker 1819, 186. 
Ohne ein Italiänisches oder Französisches Wort zu wissen, ohne die geringste Kenntniß von Geschichte und Mythologie, wie ist es möglich, daß ein Künstler hier so studire, wie er es sollte? [...] Besonders ist ein Bildhauer, der sich doch an nichts, als an die Antiken halten kann, sehr verlegen. ${ }^{6}$

Auf den oft beklagten Bildungsmangel Thorvaldsens verweisen auch dessen einfache Urteile über Werke anderer Künstler (gut - nicht gut/schlecht), die er in Malta besichtigt hatte und in seinem Tagebuch von jener Reise erwähnte. Z Zwei Jahre nach Thorvaldsens künstlerischem Durchbruch mit der Statue Jason mit dem goldenen Vlies schrieb Zoëga 1805 über den Bildhauer:

Er ist jetzt recht in Aufnahme gekommen und erhält eine Bestellung nach der andern; Niemand bezweifelt mehr, daß er und Canova die beiden größten Bildhauer in Rom sind. Es schmeichelt mir ein wenig, das verificirt zu sehen, was ich gesagt und geschrieben habe in Zeiten, wo Niemand es recht glauben wollte. $^{8}$

Diese Briefe von Zoëga an den deutsch-dänischen Bischof Friedrich Münter veranschaulichen exemplarisch den durch Thorvaldsens Erfolg mit der Jason-Statue 1803 ausgelösten Wendepunkt in der öffentlichen Wahrnehmung des Bildhauers (Abb. 4). Es war diese Skulptur, die wegbereitend war für Thorvaldsens später als triumphal bezeichnete Künstlerbiografie sowie die Verehrung des Bildhauers, die sich über die Jahrzehnte seines Wirkens hinweg zu einem regelrechten Kult steigern sollte. Aus diesen Gründen steht die Jason-Statue hier am Anfang.

\section{Die Entstehung und frühe Rezeption der Jason-Statue}

Die hindernisreiche Entstehungsgeschichte des Jason überliefern sowohl Thiele, Thorvaldsens wichtigster zeitgenössischer Biograf, als auch Briefe von Thorvaldsen selbst an seinen früheren Lehrer Abildgaard und die Kopenhagener Kunstakademie. ${ }^{9}$ Der Bildhauer verkündete Abildgaard bereits am 4. April 1800, dass er nach der Fertigstellung seiner Raffael-Büste beabsichtige, „Hand an eine Marmorstatue in lebender Größe zu le-

7 Thorvaldsens Tagebuch von seinen Aufenthalten in Malta, Palermo und Neapel zwischen Mitte Januar und Mitte Februar 1797, das sich in Thorvaldsens Museum befindet, ist bei Thiele 1852-1856, Bd. 1, 39 - 44, abgedruckt. Siehe auch Plon 1867, $17-20$.

8 Georg Zoëga an Friedrich Münter, 27. April 1805, zit. nach Thiele 1852-1856, Bd. 1, 128; teilweise und mit leicht abweichendem Wortlaut auch zit. bei Welcker 1819, 331. Siehe auch Tesan 1991b, 225.

9 Zur Entstehungsgeschichte von Thorvaldsens Jason-Statue siehe neben Thiele 1831-1850, Bd. 1, 48-53, und Thiele 1852-1856, Bd. 1, 67 -79, ausführlich Kofoed 2009a; außerdem Fernow 1803, 313-315; Brun 1815 und 2006; Fürst 1823, 354; Danmarks Hoeder 1839, 5; „Jason“ 1855, 64-96; Müller, S. 1893, 43 - 47; Trier 1903, 59-65; Oppermann 1927, 46; Moltesen 1929, 81-96; Sass 1950, 292 - 294; von Einem 1974, 3 - 5; Wittstock 1975, 44 - 45; Jørnæs 1989c, 25; Pinelli 1991, 23; Grandesso 2015, 22 - 32. 


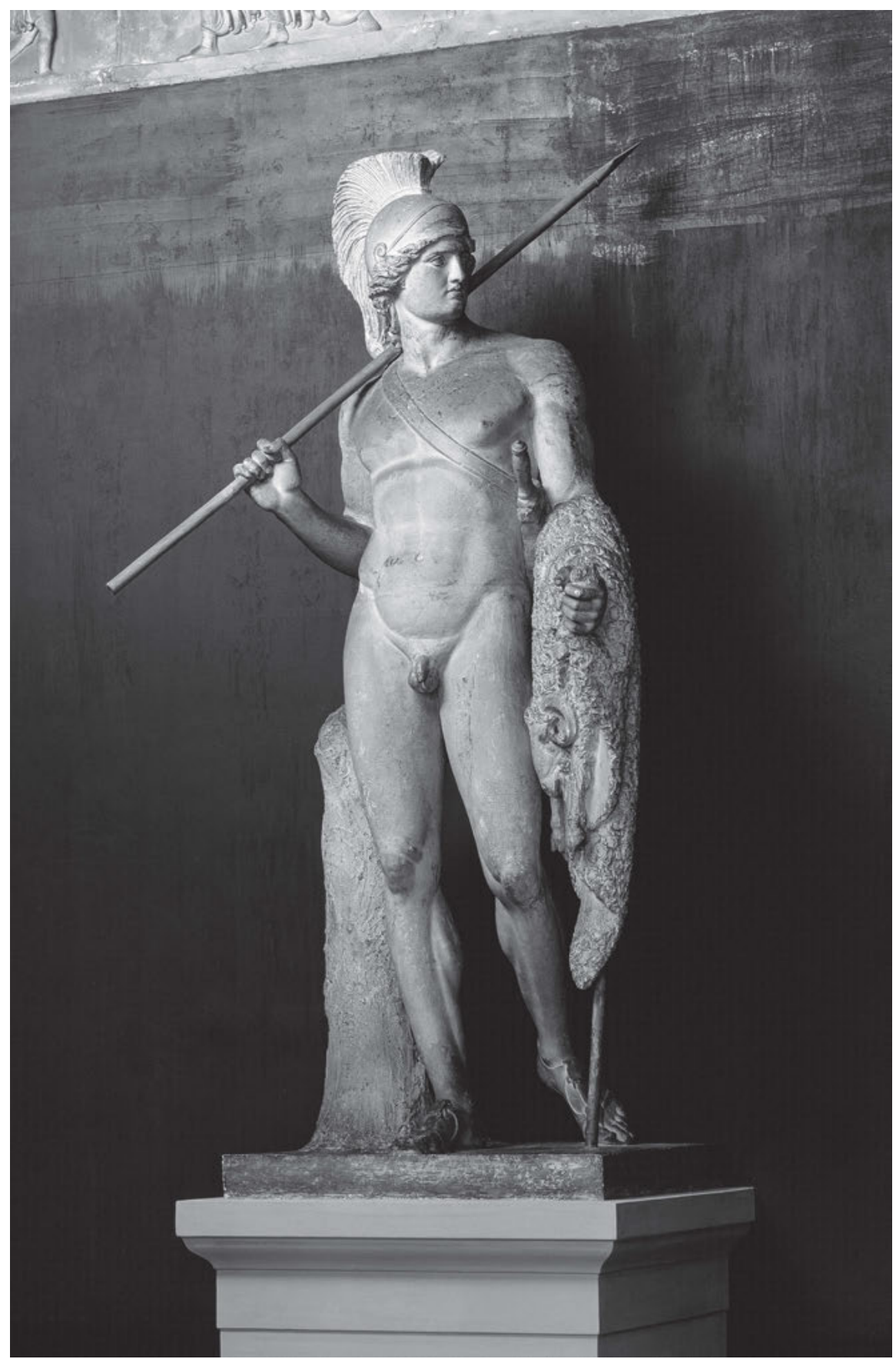

4_Bertel Thorvaldsen, Jason mit dem goldenen Vlies, 1802-1803, Gipsmodell, Höhe: 245,5 cm, Kopenhagen, Thorvaldsens Museum (Inv.-Nr. A52) 
gen“.10 Damit dürfte seine erste Jason-Skulptur gemeint sein, denn am 24. Oktober 1800 präzisierte er in einem Schreiben an die Akademie, dass ihn neben der Raffael-Büste

eine nackte Figur, in natürlicher Größe [beschäftigt], die Jason vorstellt, im Begriff zum Schiff zurückzukehren, nachdem er das goldene Vlies fortgenommen hat, das er auf dem linken Arm trägt, in der rechten Hand einen Speer haltend. ${ }^{11}$

Im darauffolgenden Frühjahr war der Entwurf für Jason fertig, woraufhin Thorvaldsen am 22. April 1801 an die Akademie berichtete: „Ich habe eine stehende Figur in natürlicher Größe modelliert, Jason mit dem goldenen Vlies darstellend, die das Glück hatte, den Beifall der Künstler zu bekommen. "12 Weiter schrieb Thorvaldsen allerdings, dass er die 36 Scudi für den Gipsabguss des Modells nicht aufbringen könne. In der Folge scheint er das Tonmodell zerstört zu haben. ${ }^{13}$

Da das Ende von Thorvaldsens insgesamt sechsjährigem Romstipendium der Kopenhagener Kunstakademie nahte, bereitete sich der Bildhauer nach jenem künstlerischen Rückschlag gedanklich auf seine Heimreise vor. ${ }^{14}$ Doch das Jason-Thema beschäftigte ihn - vermutlich unter dem Eindruck von aktuellen Werken anderer Künstler, darunter des kürzlich verstorbenen Bildhauers Domenico Cardelli und des von Thorvaldsen bewunderten Malers Carstens - weiterhin. ${ }^{15}$ Im Herbst 1802 schuf er schließlich ein überlebensgroßes Tonmodell desselben Motivs. ${ }^{16}$ In Thieles Formulierung, die der Legende des aus seiner eigenen Asche auferstandenen Phönix verpflichtet ist, klingt die zeitgenössische

10 Bertel Thorvaldsen an Nicolai Abildgaard, 4. April 1800, KB, Ref. NKS 2337, 2 (Transkript im TMA): „...] saa snart denne [Raffael-Büste] er færdig agter ieg at lægge Haand paa en Marmorstatue i levende Størrelse, [...].“

11 Bertel Thorvaldsen an die Kunstakademie Kopenhagen, 24.Oktober 1800, RA, Kunstakademiets arkiv, Akademiforsamlingen, journalsager, 1800, Ref. II, nr. 17 (Transkript im TMA): „Hvad for nærværende fornemmeligen beskæftiger mig er en nøgen Figur i naturlig Størrelse, som forrestiller Iason i Begreb at vende tilbage til Skibet efter han har borttaget det gyldne Fliis, som han bærer paa den venstre Arm holdende i den høire Haand et Spyd, [...].“ Dieser Brief ist in einer etwas ungenauen Übersetzung auch bei Thiele 1852 - 1856, Bd. 1, 68 - 69, abgedruckt; siehe außerdem Miss 2003, 11 - 12; Kofoed 2009a; Jørnæs 2011, 43.

12 Bertel Thorvaldsen an die Kunstakademie Kopenhagen, 22. April 1801, TMA, Ref. m28, nr. 1: „Jeg har modellert en staaende Figur over naturlig Størrelse forestillende Jason med det gyldne Fliis, som har havt den Lykke at finde Konst[n]ernes Bifald.“

13 Von Raczynski 1836 - 1841, Bd. 3, 272; Thiele 1852 - 1856, Bd. 1, 73; Baronesse Stampes Erindringer 1912, 92; Miss 2003, 12; Kofoed 2009a; Grandesso 2015, 23.

14 Thiele $1852-1856$, Bd. 1, 73.

15 Ebd., 67; Rosenberg 1901, 19; Moltesen 1929, 81; von Einem 1974, 22 und 29; Bryld 2003, 28-29; Miss 2003, 11; Grandesso 2015, 22 - 23.

16 Friederike Brun, 27. November 1802, zit. bei Walser-Wilhelm/Walser-Wilhelm 2002, 411; Thiele 1852 - 1856 , Bd. 1, 76; Kofoed 2009a. 
Bewunderung für dieses Werk sowie dessen entscheidende Bedeutung für Thorvaldsens Künstlerbiografie an:

Der zerschlagene Jason erhob sich nun wieder in seinen [Thorvaldsens] Gedanken, und ehe man noch eine Ahnung davon hatte, baute er in seinem Studio eine Thonmasse auf, aus welcher dieser Heros in übermenschlicher Größe hervortreten sollte. ${ }^{17}$

Die Dichterin Brun gehörte zu den Ersten, die Jason in Thorvaldsens Atelier sahen. ${ }^{18} \mathrm{Ne}-$ ben ihrem Tagebucheintrag vom 27. November 1802 stammt eines der frühesten schriftlichen Zeugnisse jener Statue vom preußischen Gesandten Wilhelm von Humboldt, der die Werkstatt des Bildhauers am 28. Januar 1803 zusammen mit Brun und seiner Ehefrau Caroline besuchte. ${ }^{19}$ Am gleichen Tag schrieb Humboldt an Goethe:

Weniger bekannt und besucht als alle diese Bildhauerwerkstätten ist die eines Dänen, Thorvaldsen, der eben jetzt einen Jason gemacht hat. [...] Das Ganze ist eine überaus kräftige und harmonische Gestalt, und die ideale Behandlung des Heros ist, ganz im antiken Sinne, sehr glücklich zwischen der gewöhnlichen Natur und der eigentlichen Göttergestalt in der Mitte gehalten. ${ }^{20}$

Während das weitere Schicksal des Jason zum Zeitpunkt dieses Briefes noch unklar war, konnte Caroline von Humboldt dem Dichter wenige Monate später berichten, dass Thorvaldsen mit der Marmorausführung der Statue begonnen habe. In einem Brief vom 20. April 1803 brachte sie ihre Bewunderung für Jason zum Ausdruck:

Ich lege Ihnen eine flüchtige Zeichnung davon bei, damit Sie eine deutlichere Idee haben mögen. Ich möchte sie [die Jason-Statue] vor Ihre Augen hinzaubern können, denn sie ist das Schönste, was neuerlich ist gemacht worden. ${ }^{21}$

\section{Schlüsselfiguren: Friederike Brun und Thomas Hope}

Brun selbst erinnert sich in mehreren Ausgaben des Morgenblatts der gebildeten Stände vom August 1812 an ihren Eindruck der Jason-Statue und an die Begeisterung der Zeitgenossen. ${ }^{22}$ Dabei scheint sie nicht zufällig auf Zoëga und Canova zu verweisen, denn Ersterer war als ein besonders kritischer Kunstkenner bekannt, und bei Letzterem handelt es

17 Thiele $1852-1856$, Bd. $1,76$.

18 Brun besuchte Thorvaldsens Atelier am 27. November 1802 und am 28. Januar 1803; siehe dazu Friederike Brun, 27. November 1802, zit. bei Walser-Wilhelm/Walser-Wilhelm 2002, 411; Brun 1815, 5; Brun 2006, 120; Wittstock 1991, 203; Kofoed 2009a.

19 Wittstock 1975, 139 und 203; Wittstock 2004, 158.

20 Wilhelm von Humboldt an Johann Wolfgang von Goethe, 28. Januar 1803, zit. nach von Einem $1974,5$. Siehe auch Wittstock 1975, 55 und 309.

21 Caroline von Humboldt an Johann Wolfgang von Goethe, 20. April 1803, zit. nach Wittstock 1975, 296. Siehe auch von Einem 1974, 5, Anm. 11; Wittstock 2004, 158.

22 Brun 1815, 16-17; Thiele 1852-1856, Bd. 1, 76; Brun 2006, 125. 
sich um den damals führenden Bildhauer. ${ }^{23}$ So wurde dessen Urteil über Jason - „Quest' opera di quel giovane danese è fatto in uno stilo nuovo e grandioso! “ - fortan in den meisten Thorvaldsen-Biografien zitiert. ${ }^{24}$ Es war schließlich auch Brun, deren finanzielle Unterstützung es Thorvaldsen ermöglichte, das neue Modell des Jason in Gips gießen zu lassen und in seinem Atelier aufzustellen. ${ }^{25}$ Der geglückte Gipsabguss wurde am 19. März 1803 mit einem ebenfalls von der Dichterin organisierten und rückblickend als „heilig“ bezeichneten Fest gefeiert, anlässlich dessen Thorvaldsen für seine Skulptur mit Lorbeeren gekränzt wurde - eine Ehre, die sich im Laufe seines weiteren Lebens zahlreich wiederholen sollte. ${ }^{26}$ Daran, dass das Tonmodell des Jason ohne Bestellung einer Marmorversion in Gips gegossen und im Atelier präsentiert wurde, zeigen sich bereits charakteristische Züge von Thorvaldsens Werkstattpraxis, auf die im Kapitel III.1 zurückgekommen wird.

Die Aufstellung des Originalmodells des Jason in Thorvaldsens öffentlich zugänglichem Atelier machte sogleich den britisch-holländischen Bankier Thomas Hope auf die Statue aufmerksam, mit deren Marmorausführung dieser den Bildhauer beauftragte. ${ }^{27}$ Hopes Bestellung erlaubte es Thorvaldsen, sich „bekannt zu machen“, wie er es in seiner von der Baronin Stampe überlieferten Lebensbeschreibung ausgedrückt hat. ${ }^{28}$ Darüber hinaus legte dieser Auftrag den finanziellen Grundstein für Thorvaldsens Verbleib in Rom, wo er während der nächsten 35 Jahre wirken sollte. ${ }^{29}$ Auf die Marmorversion des Jason musste sich Hope allerdings trotz mehrerer Mahnungen ein Vierteljahrhundert gedulden. ${ }^{30}$ Nach ihrer Fertigstellung verblieb sie während knapp hundert Jahren im Besitz der Familie Hope auf deren Landsitz Deepdene im britischen Surrey. Bei Nachlassversteigerungen im Juli und September 1917 erwarb Mario Krohn, der damalige Direktor von Thorvaldsens Museum in Kopenhagen, die Jason-Statue neben sechs weiteren Werken des nitiv in Rom zu bleiben. Zwar war die Bestellung in finanzieller Hinsicht von existenzieller Bedeutung für den Bildhauer. Doch geriet er zugleich in eine Zwangslage mit der Kopenhagener Kunstakademie, deren Stiftungsurkunde den Romstipendiaten untersagte, andere Aufträge als solche des dänischen Königs oder Staates anzunehmen. Thorvaldsens Verbleib in Rom ging daher eine bis ins Frühjahr 1804 dauernde Korrespondenz zwischen ihm und seinen Unterstützern einerseits und der Akademie andererseits voraus; siehe dazu ausführlich Bencard 2009.

30

Zu Zoëga siehe bspw. Brun 1815, 12; Melander 1991, 295; Brun 2006, 123 - 124.

Zit. nach Thiele $1852-1856$, Bd. 1, 76.

Ebd., 77; Kofoed 2009a; Jørnæs 2011, 46; Grandesso 2015, 24.

Zum Fest für Thorvaldsen siehe Brun 1833, Bd. 2, 100-102 (Zitat: 102). Siehe auch Miss 2003, 11-13; Kofoed 2009a; Jørnæs 2011, 46.

Siehe bspw. Kofoed 2009a; Jørnæs 2011, 47; Grandesso 2015, 24. Hope besuchte Thorvaldsens Atelier zwischen dem 19. und dem 21. März 1803.

Zit. nach Baronesse Stampes Erindringer 1912, 93: „[... ] og bestilte den i Marmor, hvorved der gaves mig Leilighed at giøre mig bekiendt $[\ldots]$. .“

Entgegen den meisten Überlieferungen ermöglichte es Thorvaldsen nicht Hopes Bestellung allein, defiThiele 1852 - 1856, Bd. 1, 191-194; Kofoed 2009a; Jørnæs 2011, 47. 
Bildhauers. ${ }^{31}$ Nachdem die Skulptur ab den frühen 1920er Jahren während knapp zwei Jahrzehnten in der großen Vorhalle des Museums aufgestellt war, steht sie heute in einem der kleinen Ausstellungsräume im dortigen Erdgeschoss. ${ }^{32}$

Die Begegnung zwischen Thorvaldsen und Hope wird sowohl in den Quellen als auch in der späteren Literatur oft idealisiert. In der Tat besuchte Hope Thorvaldsens Atelier in denselben Tagen, in denen sich der Bildhauer auf seine Rückkehr nach Dänemark vorbereitete, da sich sein Romstipendium dem Ende zuneigte. Dennoch scheinen das Timing und die Umstände in den Überlieferungen noch zugespitzt worden zu sein, wonach Thorvaldsen ohne eine Nachlässigkeit seines Reisegefährten Friedrich Hagemann den Besuch des Bankiers verpasst hätte. ${ }^{33}$ Gemäß den Überlieferungen hätte Thorvaldsen nämlich just an dem Tag abreisen sollen, an dem Hope sein Atelier besuchte. Doch da Hagemanns Pass nicht bereit war, habe sich die Abreise um einen Tag verschoben. Folglich wurde Hagemanns Achtlosigkeit später als schicksalshaft für Thorvaldsens gesamte Künstlerbiografie dargestellt und damit sein Weg zur Berühmtheit dramatisiert. ${ }^{34}$ Dementsprechend nannte Thiele Hopes Besuch den „entscheidenden Augenblick“ in Thorvaldsens Leben und dessen „Wiedergeburt in der Kunst“ ${ }^{“ 35}$ Ein Jahrzehnt darauf bezeichnete Andersen den Besuch des Briten in seiner „biographischen Skizze“ über den Bildhauer als „Lebens-Moment in Thorwaldsens und also auch in der Kunstgeschichte “. ${ }^{\text {. }}$ Neben dieser Gleichsetzung von Thorvaldsens Biografie mit der Geschichte der Kunst ging Andersen gar so weit, die Förderung des Bildhauers über den Wiederaufbau Kopenhagens nach der englischen Bombardierung von $1807 \mathrm{zu}$ stellen:

Der Britten Bomben hatten Kopenhagens Thürme gestürzt, die Britten haben uns Dänen unsere Flotte geraubt, aber in unserm gerechten Schmerz und Bitterkeit hierüber wollen wir gedenken, daß es ein Engländer war, der für uns und unseres Landes Größe, Dich Bertel Thorwaldsen rettete! Ein Engländer war es, der für uns nach Gottes Willen mehr aufrichtete, als wenn alle Thürme aufgebaut worden wären, der den Ruf des Namens der Nation mehr beflügelte, als alle Schiffe des Landes durch Flaggen und Kartaunen ausdonnern konnten, es war der Engländer Thomas Hope. ${ }^{37}$

Sass 1950, 294; Ravn 1964, 1-3; Bjarne Jørnæs, in: Helsted 1973, 18; Floryan 2003, 43; Kofoed 2009a. Die durch Krohn ersteigerten Werke Thorvaldsens waren neben Jason die Porträtbüsten des Ehepaars Thomas und Louisa Hope und ihren Söhnen Henry Thomas und Adrian John (Kopenhagen, Thorvaldsens Museum, Inv.-Nr. A823 - A826) sowie die Reliefs Cupido wird von Anacreon empfangen, Winter und $A$ Genio Lumen (Inv.-Nr. A827 und A828). Außerdem erwarb Krohn die Porträtbüste von Henry Philip Hope des Bildhauers John Flaxman (Inv.-Nr. G271). Kofoed 2009a. Thiele 1831-1850, Bd. 1, 50: „Dette Öieblik var det afgjörende i hans Liv, hans Gjenfödelse i Kunsten.“

Ebd. 


\section{Thorvaldsen und Canova}

Während Brun und Humboldt bereits über das Tonmodell des Jason berichteten, zog die Skulptur kurz nach ihrer Abformung in Gips umso mehr das Interesse und die Bewunderung der Zeitgenossen auf sich. Schenkt man einer oft zitierten Anekdote Glauben, eilte der Ruhm der Jason-Statue jenem des Bildhauers voraus: So berichtet Brun, dass

Thorwaldson einst bey einem Mittags-Mahl, zu welchem er sich gewöhnlich mit 30 bis 40 Künstlern zusammenfand, gefragt wurde: ,ob er denn nicht den jungen dänischen Künstler kenne, der eine so herrliche Statue gemacht habe?' So im Schoße bescheidener Stille hatte dieser große Genius seine Schwingen entfaltet. $^{38}$

Wie sowohl aus dieser Anekdote als auch aus den Briefen des Ehepaars von Humboldt an Goethe deutlich wird, war Thorvaldsen in der Zeit um 1803 ein relativ unbekannter Künstler. ${ }^{39}$ In den Quellen wird er für gewöhnlich als ,ein dänischer Bildhauer ' eingeführt. Unspezifische Formulierungen dieser Art bedurften einer Präzisierung mit Thorvaldsens Namen, damit die Leserschaft wusste, von wem die Rede ist. Dies sollte sich nun schlagartig ändern.

Schon früh wurde Thorvaldsens Talent in Verbindung zu jenem von Canova gesetzt, der damals als Referenzpunkt zur Beurteilung plastischer Werke galt. So schrieb der Bildhauer Johann Gottfried Schadow in seinem am 2. Juni 1803 in der Zeitschrift Der Freimüthige publizierten Bericht über die Jason-Statue, dem frühesten Zeugnis für deren publizistische Rezeption in Deutschland, dass einige „ein so großes Aufheben davon [machen], daß sie sogar Canova zu verstehen geben wollen, er solle darnach studieren “" ${ }^{40}$ Während die meisten Zeitgenossen nach wie vor Canova als den besten lebenden Bildhauer würdigten oder einen direkten Vergleich der beiden Künstler vermieden, räumten das Ehepaar von Humboldt und ihr illustrer Bekanntenkreis in Rom bald Thorvaldsen den ersten Rang in der neueren Skulptur ein. ${ }^{41}$ Dadurch konnte ein Nordeuropäer, also gewissermaßen einer der ihren, über die reiche italienische Kunst gestellt werden.

$\mathrm{Zu}$ diesem Kreis gehörte auch der Kunsttheoretiker und Canova-Kenner Fernow. In einem Brief vom 1. Juli 1803 schrieb er an den Altertumswissenschaftler Karl August Böttiger, dass Thorvaldsen infolge Hopes Bestellung des Jason die „Aussicht“ habe, „unter begünstigenden Umständen vielleicht dereinst Glück und Ruhm mit dem vergötterten

39 Siehe auch die Kommentare von Carl Ludwig Fernow (Fernow 1803, 313; Brief an Karl August Böttiger, 1. Juli 1803, zit. bei Wittstock 1975, 279-280), Johann Gottfried Schadow (Schadow 1803), Friederike Brun (Brun 1804, 287), Philipp Joseph von Rehfues (von Rehfues 1806, 163).

40 Schadow 1803, 346. Zur deutschen Rezeptionsgeschichte von Thorvaldsens Jason-Statue siehe auch Wittstock 1975, 203.

41 Wittstock 1975, $57-58$. 
Canova zu teilen“.42 Im November desselben Jahres veröffentliche Brun im Neuen Teutschen Merkur ein zweistrophiges Gedicht über die Jason-Statue. Den Titel „Thorwaldsons Jason“ ergänzte sie mit einem erklärenden Asterisk als Hinweis auf den

jungen dänischen [Künstler], welcher die größten Hoffnungen nicht blos erweckt, sondern bereits so sehr erfüllt hat, dass bewährte Kenner anstehen, ob nicht, in Absicht auf hohen reinen Geschmack, selbst Canova ihm weichen müsste. ${ }^{43}$

Über die Statue selbst dichtete sie in der ersten Strophe:

Trau ich dem staunenden Blick, ist's Wahrheit was mir erscheint? Ist gefüllt zwischen mir und der Antike die Kluft?

Hat der Heroen Geschlecht der Jahrtausende Gräber gesprenget; Wandelt es hehr und voll Kraft wieder auf Erden umher? ${ }^{44}$

Drei Jahre später ging Fernow in seinem Aufsatz „Über den Bildhauer Canova und dessen Werke“ noch einen Schritt weiter, indem er Jason der Perseus-Statue Canovas von 1797 „in jedem Betracht weit" vorzog (Abb. 5). ${ }^{45}$ Interessanterweise hat Fernow diesen Aufsatz über Canova ausgerechnet Brun gewidmet, der Thorvaldsen seinen künstlerischen Durchbruch zu verdanken hatte. Dementsprechend schrieb Fernow in der Dedikation:

Sie haben, durch eine im entscheidenden Moment geleistete Hülfe, der Kunst selbst in Rom einen ihrer würdigsten Zöglinge erhalten, dessen erstes Werk schon ein rühmlicher Wetkampf mit dem Künstler war, den seit zwanzig Jahren sein Zeitalter einstimmig als den ersten anerkennt. ${ }^{46}$

Die mit dem Erfolg der Jason-Staue einsetzenden Vergleiche und Gegenüberstellungen von Thorvaldsen und Canova ziehen sich durch den Großteil der Quellen und Sekundärliteratur zum dänischen Bildhauer. Sowohl Schadows Bericht als auch Bruns Epigramm und Fernows Kritik wurden kurz nach ihrem erstmaligen Erscheinen in Deutschland auf Dänisch übersetzt und in dänischen Medien veröffentlicht. ${ }^{47}$ Damit setzte die publizistische Rezeption des Jason leicht verzögert auch in der Heimat des Bildhauers ein.

Carl Ludwig Fernow an Karl August Böttiger, 1. Juli 1803, zit. nach Wittstock 1975, 280. Dieser Brief wurde auch in der August-Ausgabe des Neuen Teutschen Merkur abgedruckt; Fernow 1803, 315. Siehe auch Grandesso 2015, 31-32. Zu Fernow im Kontext seiner Zeit siehe ausführlich Tausch 2000.

Brun 1804, 287.

44 Ebd.

45 Fernow 1806, 199, Anm.

46 Ebd., 7. Siehe dazu auch Jørnæs 2011, 46.

47 Thiele 1852-1856, Bd. 1, 83; Wittstock 1975, 46. Schadows Kolportage wurde noch 1803 vom Dichter Knud Lyne Rahbek in der Zeitschrift Minerva (2, 337 -338) veröffentlicht, während die Zeitung Nyeste Skilderie af Kjøbenhavn am 9. Januar 1804 Bruns Epigramm und am 4. Juni desselben Jahres Fernows Kritik, alles in dänischer Übersetzung, abdruckte. 


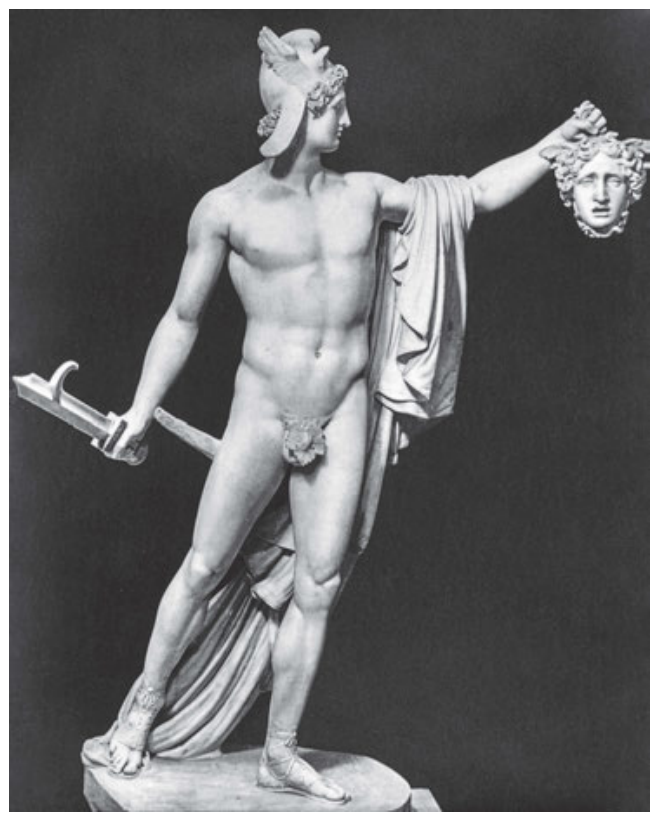

5 Antonio Canova, Perseus, 1797 - 1801, Marmor, Höhe: $235 \mathrm{~cm}$, Rom, Vatikanische Museen, Museo Pio-Clementino, Cortile Ottagono (Inv.-Nr. 969)

Wie erwähnt, hoben die dänischen und ein großer Teil der deutschen Zeitgenossen Thorvaldsen schon früh über dessen italienischen Gegenspieler. Sie betrachteten Canovas Statuen als zu bewegt und geziert, als noch zu stark der Kunst des Rokoko verhaftet. ${ }^{48}$ Demgegenüber habe Thorvaldsen die Skulptur zu Ruhe und Harmonie zurückgeführt; bisweilen wurde seine strenge Formensprache aber auch als zu kühl kritisiert. ${ }^{49}$ Das zwischenmenschliche Verhältnis zwischen Thorvaldsen und Canova scheint von rein professioneller Natur gewesen zu sein, obschon in den Quellen und der frühen Sekundärliteratur von Freundschaft bis Feindschaft alles zu lesen ist. Einzig ein etwas ungleicher Umgangston der beiden Bildhauer miteinander lässt sich feststellen: Während der generell als äußerst höflicher Mann bekannte Canova die Schöpfungen seines jüngeren Zeitgenossen in den höchsten Tönen lobte sowie seinen eigenen Schülern zu Besuchen in Thorvaldsens Ateliers riet, kritisierte dieser die in Entstehung begriffenen Werke des Ita1945-1950, 260; Ignaz Heinrich von Wessenberg, 1817, zit. bei Wittstock 1975, 367; von der Hagen 1818 -1821, Bd. 4, 285; Matthews, H. 1820, 124; „ART. IX“ 1832, 213; Oehlenschläger 1850, Bd. 4, 146; Eggers 1867, 41; Plon 1867, 216 - 217; Erinnerungen der Malerin Louise Seidler 1922, 129.

49 Siehe bspw. Oehlenschläger 1850, Bd. 4, 146; d’Angers 1856, 6; Eggers 1867, 41; Delaborde 1868, 590. 
lieners und beanstandete zudem, dass Canova seine Anregungen nicht umsetzen würde. ${ }^{50}$ Nach Canovas Tod 1822 bestand schließlich kein Zweifel mehr darüber, dass Thorvaldsen der beste Künstler der Zeit sei. ${ }^{51}$

Im oben zitierten Auszug aus Fernows Aufsatz über Canova hebt der Autor den Erfolg des dänischen Bildhauers mit Jason speziell hervor, indem er nicht nur Thorvaldsens aemulatio, das Wetteifern mit dem damals führenden Bildhauer, anspricht, sondern die Statue darüber hinaus als Thorvaldsens ,erstes Werk" bezeichnet. ${ }^{52}$ Damit sollte zweifellos sein Genie unterstrichen werden, indem dem Bildhauer schon mit seiner ersten Schöpfung der künstlerische Durchbruch gelungen sei. Entgegen dieser Aussage war Thorvaldsen allerdings bereits seit den späten 1780er Jahren bildhauerisch tätig. Sein Frühwerk umfasst neben Reliefs und kleineren Statuen vor allem Porträtmedaillons und -büsten, worunter sich auch Auftragsarbeiten für Mitglieder der Kopenhagener Kunstakademie und bekannte Persönlichkeiten aus Nordeuropa befinden..$^{53}$

\section{Die wiedergeborene Antike und die aemulatio mit Vorbildern}

Wie aus den zitierten Versen von Brun beispielhaft hervorgeht, lobten Thorvaldsens Zeitgenossen die Jason-Statue in künstlerischer Hinsicht vor allem für deren Nähe zum antiken Formideal. ${ }^{54}$ Konkret wurden Jasons Kontrapost, der ideale Körperbau des Jünglings, die zur Seite gewandte Kopfhaltung, der bestimmte Gesichtsausdruck sowie die ,gefällige Ansicht [...] von allen Seiten" bewundert. ${ }^{55}$ Bereits in einem Tagebucheintrag vom 28. Januar 1803 bezeichnet Brun das Werk als die „zuletzt fertig gewordene Antike “.56 Und auch in ihrer Kurzbiografie „Etwas über Albert Thorwaldson“, die knapp zehn Jahre später erschien, betont sie die Nähe des Jason zur Antike und nennt die Skulptur eine „Erscheinung [...], welche mehr den schönsten Zeiten hellenischer Kunst, als den unsrigen anzugehören" scheine und „den Tiefen des Alterthums" entstiegen sei. ${ }^{57}$

In dem bereits genannten Brief an Böttiger schreibt auch Fernow, dass man „,in neueren Zeiten kein Werk in so großem reinen Styl gesehen" habe. ${ }^{58}$ Thiele berichtet indessen

Thiele 1852-1856, Bd. 2, 95 - 96; Abrahams 1876, 326 - 327. Siehe auch Rosenberg 1901, 35; Hartmann 1956, 81; Salling 1972, 41-45; Jørnæs 1989c, 28; Jørnæs 2011, 124-125 und 148-149. Canova riet bspw. Gibson, so oft wie möglich Thorvaldsens Ateliers zu besuchen; Matthews, T. 1911, 49.

52 Fernow 1806, 7. Auch Neergaard 1814, 571, bezeichnet die Jason-Statue fälschlicherweise als Thorvaldsens erstes Werk in Marmor.

53 Siehe auch Skjøthaug 2015a, 268-270.

54 Siehe auch Miss 2003, 15.

55 Fernow 1806, 198 -199, Anm. (Zitat ebd.); Brun 1815, 15; Brun 2006, 125.

56 Brun 2006, 125. Siehe auch Brun 1815, 15; Wittstock 1975, 55.

57 Brun 2006, 120 und 124. Siehe auch Brun 1815, 5 und 14.

58 Carl Ludwig Fernow an Karl August Böttiger, 1. Juli 1803, zit. nach Schopenhauer 1810, 303. Siehe auch Wittstock 1975, 279. Eine ähnliche Formulierung findet sich außerdem bei Fernow 1803, 314. 
von Thorvaldsens wiederkehrender Melancholie und seinen Geldsorgen in der „Zeit, wo das Gerücht von seinem Jason siegreich von Rom aus in die Welt drang, und viele Kunstkenner schon in ihm den Schöpfer der verlornen antiken Kunst begrüßten“.59 Noch 1814 vertritt Sickler die Ansicht, dass Thorvaldsens Jason

in der gesammten neueren Sculptur nicht bloß den ersten Platz ein[nimmt], sondern [...] sich auch unmittelbar an das Vorzüglichere an[schließt], was, unter den Antiken, von der erhabenen Kunst der alten griechischen Meister bis auf unsere Zeiten gekommen ist. ${ }^{60}$

Im Zusammenhang mit diesen frühen Betrachtungen von Thorvaldsens Jason als einem Beispiel für die wiedergeborene Kunst des Altertums ist Christian Gorm Tortzens Hinweis interessant, dass in den antiken Schriftquellen keine Vorbilder für den von Thorvaldsen gewählten narrativen Moment vorkommen. ${ }^{61}$ Dargestellt ist nämlich die Szene aus der Argonautensage, als Jason das zuvor von feuerspeienden Stieren und einem Drachen bewachte, mithilfe von magischen Kräften der Königstochter Medea errungene goldene Vlies zum Schiff Argo bringt. ${ }^{62}$ Daraus wird deutlich, dass Jason für sich genommen keine Heldenfigur ist; vielmehr ist Medea stets wichtiger, wenn nicht gar tragender Teil der Geschichte. ${ }^{63}$ Es mag daher verwundern, dass Thorvaldsen die mythologische Figur des Jason für seine erste Heroendarstellung wählte. Tortzen erklärt sich Thorvaldsens künstlerische Behandlung des Argonautenführers damit, dass der Bildhauer wenig belesen war und folglich kaum die antiken Quellen beizog. ${ }^{64}$ Stattdessen dürfte er sich an Karl Philipp Moritz' Götterlehre von 1791 sowie insbesondere an Carstens' Zeichnung von Jasons Rückkehr mit dem goldenen Vlies aus der insgesamt 24 Blätter umfassenden Argonautenserie von 1797 orientiert haben. ${ }^{65}$ Carstens' Zeichnungen waren um die Jahrhundertwende also während der Entstehung der Jason-Statue - in Thorvaldsens Besitz, bis er sie 1804 dem Grafen Adam Gottlob Detlef Moltke weitergab. ${ }^{66}$

59 Thiele $1852-1856$, Bd. $1,83$.

60 Sickler $1814,7$.

61 Tortzen 2003, 19. Für weitere Ausführungen zu Jason-Darstellungen in bildender Kunst und Literatur seit der Antike siehe von Einem 1974, 8-26.

62 Galschiøt 1895, 71.

63 Siehe auch Tortzen 2003, 23; Grandesso 2015, 23.

64 Tortzen 2003, 19.

65 Asmus Jacob Carstens, Jasons Rückkehr mit dem goldenen Vlies, 1797, Zeichnung, 281 x 422 mm, Kupferstich von Joseph Anton Koch 1799, London, British Museum (Inv.-Nr. 1984,0225.3.1-24). Siehe dazu von Einem 1974, 7, 26 - 27 und 31; Kat. Nürnberg/Schleswig 1991, 389 - 390; Pinelli 1991, 23; Tortzen 2003, 23.

66 Carstens' Argonautenserie war erst im Besitz Fernows, der sie jedoch nach Carstens' Tod 1798 Joseph Anton Koch vermachte. Dieser wiederum ergänzte sie 1799 mit Landschaftsszenen und veröffentlichte sie als Radierungen. Von Koch, der im selben Haus wohnte wie Thorvaldsen, gelangten sie in den Besitz des dänischen Bildhauers, bevor sie an den Grafen Moltke übergingen. Siehe dazu von Einem 1974, 7; Kat. Nürnberg/Schleswig 1991, 390. 
Was die Formensprache des Jason betrifft, so bediente sich Thorvaldsen einer ganzen Reihe von Vorbildern aus der antiken und zeitgenössischen Kunst. ${ }^{67}$ Die wichtigsten Orientierungspunkte waren zweifellos Polyklets Doryphoros, der Apollo von Belvedere und Canovas Perseus. ${ }^{68}$ Mit dem Doryphoros ist Thorvaldsens Jason besonders durch das Innehalten in der Bewegung und die geschlossene Kontur verwandt, die ihn umgekehrt vom Apollo von Belvedere und von Canovas Perseus unterscheiden. ${ }^{69}$ Thorvaldsens offenkundige Orientierung an diesen drei berühmten Werken war zugleich ein Wetteifern mit ihnen. ${ }^{70}$ Außerdem zeigt sie, dass der Bildhauer seine Ideale entsprechend Johann Joachim Winckelmanns Lehre nicht in der Natur, sondern in der klassischen Kunst fand. ${ }^{71}$ Auch Canovas Perseus ist am Apollo von Belvedere angelehnt und nahm in den vatikanischen Museen sogar dessen Platz ein, nachdem die antike Statue 1798 unter Napoleon I. von Rom nach Paris gebracht worden war. ${ }^{72}$

Dass Thorvaldsens aemulatio eine sehr bewusste war, zeigt sich darin, dass er mit seinem Jason die genannten Skulpturen nach dem Geschmack seiner Zeit gleichsam korrigierte. ${ }^{73}$ So verlieh er seiner Statue zusätzliche Körperspannung, indem er in seiner Umsetzung des Kontraposts vom Doryphoros abwich und den Kontrast zwischen gestreckten und gebeugten Gliedern unterstrich. ${ }^{74}$ Das schlaff über Jasons linken Arm hängende Widderfell hebt die Spannung im Körper des jungen Argonautenführers zusätzlich hervor. Besonders interessant sind jedoch Thorvaldsens Abweichungen vom Perseus, denn es scheint sich dabei um eine konsequente Vermeidung der durch Fernow an Canovas Statue bemängelten Elemente gehandelt zu haben. ${ }^{75}$ So hatte Fernow die Linkslastigkeit des Per-

67 Hartmann 1956, 76, von Einem 1974, 28, und Pinelli 1991, 23 - 24, nennen unter den Antiken zudem die Dioskuren vor dem Quirinalspalast, den Ares Borghese, den Pompeius im Palazzo Spada und den Mars von der Villa Albani sowie unter den zeitgenössischen Werken Johann Tobias Sergels Diomedes-Statue von 1774, Johann Heinrich Danneckers Hektor-Statue von 1795 und Carstens' Zeichnung Ödipus bei Theseus von 1797.

68 Von Einem 1974, 28; Hartmann 1979, 48 - 51; Pinelli 1991, 23 -24; Bogh 1997, 17; Jørnæs 2011, 48; auch Jacquemont 1879, 161-162; Galschiøt 1895, 70 - 71; Grandesso 2015, 22; Kanz 2017, 170. Der Doryphoros wurde erst 1863 Polyklet zugeschrieben, war jedoch vorher durch römische Kopien im Palazzo degli Studi in Neapel, dem Braccio Nuovo in den vatikanischen Museen und den Florentiner Uffizien bekannt; siehe dazu von Einem 1974, 32.

69 Von Einem 1974, 31-33.

70 Siehe auch Wittstock 1975, 46-48; Bogh 2006, 284.

71 Siehe auch Jørnæs 1991a, 70.

72 Kephalides 1818, 157; von Einem 1974, 30 - 31; Wittstock 1975, 47; Pinelli 1991, 26-29; Wittstock 2004, 158.

73 Siehe auch Wittstock 1975, 48; Wittstock 2004, 158; Grandesso 2015, 22. Zu Thorvaldsens aemulatio mit Canova allg. siehe auch Eggers 1867, 42; Oppermann 1927, 108; Jørnæs 1989c, 28. Zur künstlerischen aemulatio und imitatio generell siehe bspw. Krieger 2007, 19-20. Von Einem 1974, 33.

75 Wittstock 1975, 48-49. Bei Jason handelt es sich nur um eines von mehreren Beispielen, mit denen Thorvaldsen auf Canovas Schaffen reagierte bzw. dieses ,korrigierte. Weitere Beispiele sind Briseis und 
seus und dessen weiche, tänzerische Erscheinung kritisiert, in der noch die Kunst des Rokoko nachwirkte. ${ }^{76}$ Beides durchbrach Thorvaldsen, indem er bei der Beinstellung seines Jason dem Apollo von Belvedere folgte sowie seiner Statue insgesamt weniger Bewegung und stattdessen eine ruhigere und strengere Erscheinung verlieh. Damit kam er nicht nur dem damals neuen Verständnis der griechischen Kunst entgegen, sondern auch Fernows Idee einer Heldenfigur. ${ }^{77}$ Denn der wohl grundlegendste Mangel des Perseus war nach Fernow, „daß er göttlich ist: er sollte nur Held sein“78 Thorvaldsens Jason bezeichnete er hingegen als eine „im ächten Heroenkarakter der Antike gebildete Figur “ ${ }^{79}$ Dieser Vergleich von Thorvaldsens Jason mit Canovas Perseus lässt vermuten, dass Fernows Kritik an Letzterem in den römischen Künstlerkreisen schon mehrere Jahre vor ihrer Publikation in den Römischen Studien 1806 Thema gewesen war. Dass Thorvaldsen seine JasonStatue vor dem Hintergrund von Fernows Kritik an Canovas Perseus gleichsam auf einen Erfolg hin kalkulierte, erscheint in Anbetracht seiner verzweifelten Lage kurz vor Ablauf seines Stipendiums durchaus naheliegend. ${ }^{80}$ Hinter der Statue dürfte folglich ein gezieltes Streben nach Ruhm gestanden haben.

\section{Die weitere Jason-Rezeption: Innovatio oder imitatio?}

Die Jason-Statue veranschaulicht, dass sich Thorvaldsen in seinem Schaffen an Bildwerken der Antike ebenso wie der Gegenwart orientierte - sei es in An- oder Ablehnung. ${ }^{81}$ Wohl um Thorvaldsens Eigenleistung zu akzentuieren, wurde diese intensive Auseinandersetzung mit Vorbildern in den Quellen jedoch teilweise negiert, zumindest aber abgeschwächt. In Bruns Augen etwa war der Jason "ganz er selbst; nur dem Apoll verwandt, doch um nichts mehr als Geschlechtsähnlichkeit “ ${ }^{82}$ Noch 1814 schrieb der Kunstsammler Tønnes Christian Bruun de Neergaard über die Jason-Statue:

Geleitet von dem griechischen Kunstgenius, hat er [Thorvaldsen], ohne griechischen Meisterstücken [sic] nachzuahmen, ein eigenes vollkommenes Werk hervorgebracht, das in unserem und den folgenden Zeitaltern neben jene gestellt werden wird. ${ }^{83}$

Achilles (1803), Hebe (1806/1816), Mars und Amor (1810), Venus (1813-1816) und die Drei Grazien (1820 - 1823); siehe dazu auch Hartmannn 1956, 81; Hubert 1964, 194; Salling 1972, 42 - 43; Tesan 1998, 18-19; Wittstock 2004, 158-161. Zudem gibt es Motive in den Werken beider Bildhauer, bei denen die Rezeptionsrichtung unklar bleibt bzw. auf antiken Vorbildern fußt. Ein Beispiel dafür sind die trauernden Genien mit der zu Boden gerichteten Fackel; siehe dazu Hartmann 1955, 225. 
Im Kontrast zu den Stimmen, die in Thorvaldsens Jason etwas vollkommen Neues und nur im Geist der Antike Verpflichtetes sahen, konstatierte Schadow bereits im Sommer 1803, dass diese Statue "gerade wie ein Abguß“ von antiken Kolossen aussehe, was in seinen Augen jedoch „ein Verdienst“ war. ${ }^{84}$ Die von Schadow beobachtete - und im Sinn des traditionellen imitatio-Primats als Lob formulierte - beinahe zu starke Orientierung der Jason-Statue an antiken Vorbildern wurde von zumindest einem zeitgenössischen Kritiker bemängelt: Der Schriftsteller Philipp Joseph von Rehfues fand 1806, dass Thorvaldsens Skulptur zwar „die erste [war], welche in dem reinen, hohen Stil der Antiken gedacht und ausgeführt war“ ${ }^{85}$ Allerdings sei sie ,vielleicht nur zu antik [gewesen], sprach mehr das Altertum, als den Künstler selbst aus ". ${ }^{86}$ Für Stig Miss könnte es sich dabei um eine Ansicht handeln, die auch der Bildhauer selbst teilte. ${ }^{87}$ Denn gemäß verschiedenen Quellen war Thorvaldsen in seinen späteren Lebensjahren nicht mehr überzeugt von seinem Jason. ${ }^{88}$ Seine Ablehnung dieser Statue soll er gegenüber dem Bronzegießer Jørgen Balthasar Dalhoff mit folgenden Worten begründet haben:

Weißt Du, warum Jason nie fertig wurde, obwohl ich das Geld für ihn erhalten hatte? [...] ich hasste die Statue, denn sie war aus Tabak gemacht. [...] Ich wollte mich zeigen, bevor ich Rom verließ. Ich lief täglich zum Vatikan und schluckte, was ich konnte von den Antiken, und sah mich auf dem Rückweg nicht um. Nun legte ich los und schnupfte den ganzen Tag [Tabak], um die Nerven zu reizen. Da war nicht das Geringste von meinen eigenen Gedanken an der ganzen Statue, $[\ldots] .{ }^{89}$

In Quellen und Sekundärliteratur wird als Grund für Thorvaldsens wachsende Abneigung gegen den Jason zudem sein Kontakt mit der Baronin Jacqueline Schubart vorgebracht, die ihn vom Tabak weg- und zum christlichen Glauben hingeführt haben soll. ${ }^{90}$ Wie nachhaltig diese Beschäftigung mit dem Christentum für den Bildhauer war, ist allerdings höchst fraglich, denn er hielt sich auch danach mit Äußerungen zu seiner religiösen Über-

Schadow 1803, 346. Siehe auch Wittstock 1975, 338.

Von Rehfues 1806, 163.

Ebd. Siehe zu Rehfues' Kritik an Thorvaldsens Jason-Statue auch Wittstock 1975, 59 und 334. Auch für Rosenberg 1901, 27, war der Jason zu nah an seinem antiken Vorbild, dem Apollo von Belvedere.

Miss 2003, 15.

Siehe bspw. Thiele 1831-1850, Bd. 1, 52; Thiele 1852-1856, Bd. 2, 109-110; auch Wittstock 1975, 49; Kofoed 2009a; Jørnæs 2011, 47-48. Siehe auch das entsprechende Zitat aus Thiele in der Einleitung des vorliegenden Buches.

89 Zit. nach Dalhoff 1915 - 1916, 222 - 223: „Veed Du, hvorfor Jason aldrig blev færdig, skønt jeg havde modtaget Penge for ham? [...] jeg hadede den Statue, for han var lavet af Tobak. [...] Jeg vilde vise mig, førend jeg forlod Rom. Jeg løb daglig til Vatikanet og slugte, hvad jeg kunde af Antikerne, og saa mig ikke om paa Tilbagevejen. Nu kilede jeg paa og snusede den hele Dag for at pirre Nerverne. Der var ikke det mindste af mine egne Tanker paa hele Statuen, [...]. “ Siehe auch Kofoed 2009a; Jørnæs 2011, 48.

90 Siehe bspw. Dalhoff 1915 - 1916, 223; Hartmann 1958, 277 - 278; von Einem 1974, 38 - 39; Wittstock 1975, 51; Jørnæs 2011, 50; Grandesso 2015, 36. 
zeugung zurück und befasste sich in seiner Kunst weiterhin hauptsächlich mit Themen aus der antiken Mythologie..$^{91}$

Es steht jedoch außer Frage, dass sich Thorvaldsen über die Jahre hinweg von seiner Jason-Statue distanzierte, obschon die Gründe dafür vermutlich nicht in jenen plakativen, sondern vor allem in materialästhetischen Vorbehalten lagen. So schrieb er nach der Fertigstellung des Jason an den Käufer Hope, dass er während der Herstellung der Marmorversion immer mehr Fehler an diesem Werk erkannt habe, die ihn an der Arbeit gehindert hätten. ${ }^{92}$ Weitere Faktoren, die zur langen Herstellungsdauer beitrugen, waren eine Phase der Krankheit, Wechsel bei den Mitarbeitern sowie der Eingang neuer Bestellungen, die Thorvaldsen jener von Hope vorzog. ${ }^{93}$ In den 1830er Jahren überarbeitete Thorvaldsen das Originalmodell des Jason erneut, nach dem 1862 posthum eine Marmorversion durch Brynjulf Larsen Bergslien unter der Aufsicht von Thorvaldsens ehemaligem Schüler Herman Wilhelm Bissen entstand. ${ }^{94}$

Auch im weiteren 19. Jahrhundert gingen die Meinungen über den Jason auseinander, was Thorvaldsens Eigenleistung betrifft. Während die Statue für Atkinson „wenig mehr als eine Zusammenstellung des alten Apollo“ ist, sieht Heinrich Pfundheller darin etwas Neues. ${ }^{95}$ Laut Letzterem fand Thorvaldsen seine Vorbilder „im fünften Jahrhundert vor Christo, an den Werken eines Phidias, Polyklet und anderer Meister des hohen erhabenen Styls“ ${ }^{96}$ Das Innovative dieses Werks sei die Rückkehr „zur vollen Einfachheit griechischer Kunst" und die Abkehr von der Theatralik, die noch Canovas Werke durchdrungen habe.$^{97}$ Gleichzeitig räumt Pfundheller ein, dass „die Arbeit noch sehr das Schwanken und Suchen des Künstlers“ zeige, und nennt sie einen „Compromiß [...] zwischen den verschiedenen Einflüssen, welche bisher auf Thorwaldsen eingewirkt hatten “ ${ }^{98}$ Dabei ist bezeichnend, dass Pfundheller unter den Vorbildern für die Jason-Statue gerade Canovas Perseus nicht erwähnte, ebenso wenig wie den Protagonisten auf Carstens' bereits angeführter Darstellung von Jasons Rückkehr mit dem goldenen Vlies. Hingegen nannte er als Thorvaldsens wichtigste Vorlagen die Figuren des Jason und des Theseus auf Carstens' Zeichnungen Die Argonauten beim Kentauren Chiron von 1792 beziehungsweise Ödipus bei Theseus von 1797 sowie den Apollo von Belvedere und - wie schon Eugène Plon - Pol-

91 Siehe dazu auch Kap. III.3.

92 Bertel Thorvaldsen an Thomas Hope, vermutlich im August 1828, TMA, Ref. m28, nr. 129.

93 Kofoed 2009a.

94 Ebd.

95 Atkinson 1873, 55: „And yet the new ,Jason' was little more than a compilation from the old Apollo.“ Pfundheller 1886, 233. Hubbard 1902, 96, betrachtet Thorvaldsens künstlerische Innovationskraft generell als gering.

96 Pfundheller 1886, 232.

97 Ebd., 233.

98 Ebd. 
lux vom Dioskurenbrunnen vor dem Quirinalspalast. ${ }^{99}$ Dass Pfundhellers durchaus idealisierender Einschätzung des Jason mit Vorsicht zu begegnen ist, zeigt ferner seine Aussage, dass die Statue in Dänemark das populärste Werk des Bildhauers geblieben sei. ${ }^{100}$ Dieser Stellenwert kam in Wirklichkeit jedoch den Reliefpendants Tag und Nacht von 1815 sowie der Christus-Statue von 1821 zu, die in verschiedenen Größen, Preiskategorien und Medien fast massenhaft reproduziert wurden (Abb. 1-3). ${ }^{101}$ Tatsächlich geriet Jason trotz seiner größtenteils enthusiastischen Rezeption durch die Zeitgenossen beim breiteren Publikum wenig später in Vergessenheit. ${ }^{102}$

Die Widersprüchlichkeit, mit der Thorvaldsens Jason seit jeher betrachtet wurde, reflektiert dessen Entstehung in einer Zeit des Umbruchs in der europäischen Bildhauerei, als man sich um die Jahrhundertwende von der römischen auf die griechische Kunst zurückbesann. ${ }^{103}$ Während dieser generellen Neuorientierung in der westlichen Kunst geschaffen, wurde Jason sowohl als eines der letzten Werke des Klassizismus wie auch als die erste Skulptur eines neuen Zeitalters der Kunst, der Romantik, betrachtet. ${ }^{104}$ Nicht ohne Grund wird Thorvaldsens Stil gelegentlich als „romantischer Klassizismus" bezeichnet. ${ }^{105}$ Konkret ist die Jason-Statue thematisch und konzeptionell noch den Heldenfiguren des 18. Jahrhunderts verpflichtet, während ihre ruhige, in sich gekehrte Erscheinung bereits in die Romantik weist. ${ }^{106}$ Gemäß Wittstock war mit Thorvaldsens Jason „der Heros des nachrevolutionären Europas geschaffen", das nach den Unruhen der Französischen Revolution einen neuen, ruhigeren Darstellungstypus von Heldenfiguren begrüßt habe. ${ }^{107}$

\section{Thorvaldsen, Prometheus}

Es war die Jason-Statue, die nicht nur Thorvaldsens Künstlerlaufbahn entscheidend prägte, sondern auch in einem der ältesten repräsentativen Porträts des dänischen Bildhauers

Pfundheller 1886, 233; Rosenberg 1901, 28. Konturstiche nach Carstens' Zeichnungen sind in Hermann Riegels Stichwerk Carstens' Werke in ausgewählten Umriss-Stichen von Wilhelm Müller (Leipzig: Dürr, 1869) enthalten. Plon 1867, 178, nennt ebenfalls Pollux vom Dioskurenbrunnen als eines der Vorbilder für Thorvaldsens Jason. Bis heute scheint nicht endgültig geklärt, welche der Figuren Pollux und welche Castor darstellt. Generell ist hier anzuführen, dass auch Castor und Pollux zu den Argonauten gezählt werden; siehe bspw. von Einem 1974, 23.

100 Pfundheller 1886, 232.

101 Siehe dazu bspw. Hagen 1844, 16; Jørnæs 2011, 86 und 153; Miss 2016, 40; zu den genannten Reliefpendants auch von Raczynski 1836-1841, Bd. 3, 288-289.

102 Kluxen 1991, 279.

103 Wittstock 1975, 50.

104 Ebd., 15 und 50; siehe auch Sass 1950, 302; Kluxen 1991, 279.

105 Siehe bspw. Wittstock 1984, 112; Kluxen 1991, 279; Tesan 1998, 33; Wittstock 2004; Jørnæs 2011, 203; Kaczmarczyk 2013. Zur Schwierigkeit von Stilbezeichnungen und spezifisch von der Benennung des Romantischen in der Skulptur ausführlich Tesan 1998, 17 - 55.

106 Wittstock 1975, 50 - 51 und 134; Jørnæs 2011, 203; siehe auch Tesan 1998, 19.

107 Wittstock 1975, 51. 


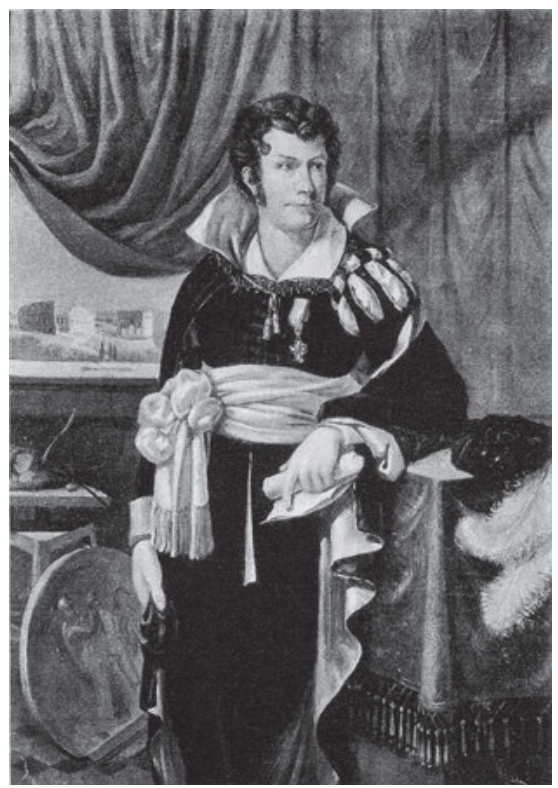

6_Jacob Edvard Munch, Bertel Thorvaldsen, 1811, Öl auf Leinwand, $140 \times 110 \mathrm{~cm}$, Oslo, Nasjonalmuseet for Kunst, Arkitektur og Design (Inv.-Nr. NG.M.03258)

vorkommt: In Jacob Edvard Munchs Gemälde von 1811 steht Thorvaldsen in einem Arbeitszimmer in Rom, ist in eine Fantasietracht gekleidet und mit dem Dannebrog-Orden geschmückt, der ihm am 28. Januar 1810 verliehen worden war (Abb. 6). ${ }^{108}$ Sein ernster Blick ist zur Seite gerichtet, sein linker Arm ruht auf einem Tisch, während er in der Hand ein zusammengerolltes Schriftstück hält. Auf seinen Beruf verweisen die Tonmodelle des Jason und des 1807-1808 modellierten Relieftondos Minerva und Prometheus sowie die Arbeitsgeräte auf dem Kavalett (Abb. 7). Die Wand hinter dem Bildhauer ist mit einer roten Draperie behangen, die über dem Fenster so weit gehoben ist, dass das Kolosseum und der Konstantinsbogen zum Vorschein kommen. Die offensichtliche Nobilitierung des Bildhauers mittels Kostüm und Draperie, der Ausblick auf römische Bauwerke als Hinweis auf Thorvaldsens Wirkungsort und künstlerische Orientierung an der Antike sowie die beiden dargestellten Plastiken machen Munchs Gemälde zu einem programmatischen Porträt des Dänen. ${ }^{109}$

108 Eine verkleinerte und leicht veränderte Replik von Munchs Thorvaldsen-Porträt befindet sich im dänischen Nationalhistorischen Museum auf Schloss Frederiksborg in Hillerød und eine Grisaille im Roskilde Museum. Annette Kanzenbach folgt der inzwischen widerlegten Deutung des Kostüms als Tracht der römischen Accademia di San Luca; Kanzenbach 2007, 232. Ferner ist bei Kanzenbach fälschlicherweise die Replik im Roskilde Museum abgebildet, bei der die Darstellung der Jason-Statue fehlt; ebd., 419, Abb. 123.

109 Zur möglichen Bedeutung des Ausblicks auf das Kolosseum siehe auch Kanzenbach 2007, 232. 
7_Bertel Thorvaldsen, Minerva und Prometheus, 1807 - 1808, Gipsmodell, Durchmesser: $147 \mathrm{~cm}$, Kopenhagen, Thorvaldsens Museum (Inv.-Nr. A319)

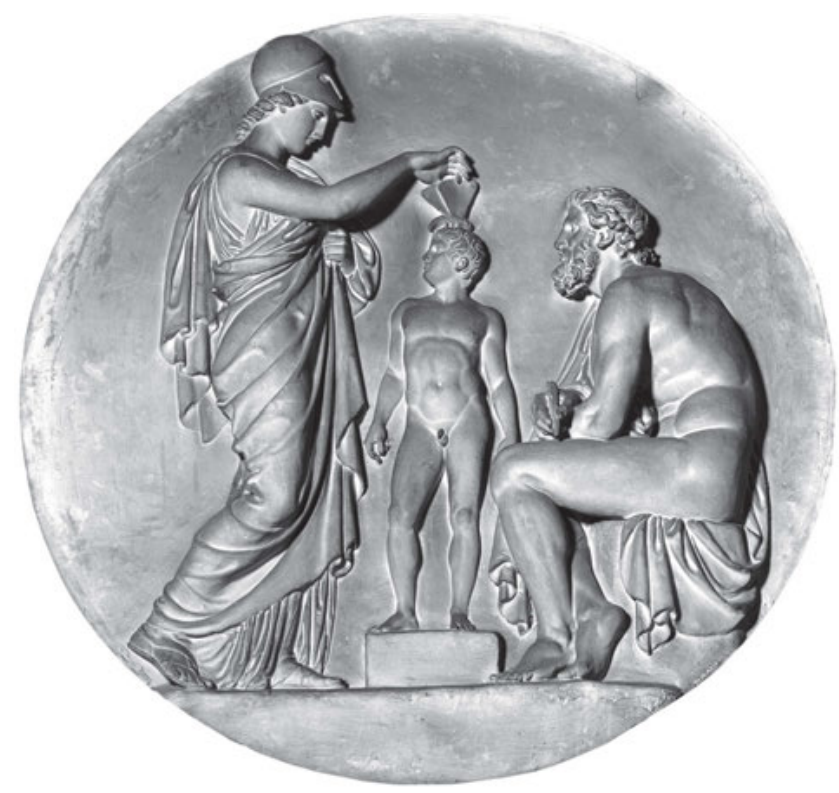

Vom genannten Relieftondo sind nur Minerva und eine durch sie beseelte Statue klar erkennbar, während deren Erschaffer Prometheus fast vollständig von der Gestalt Thorvaldsens verdeckt wird. Diese Anordnung von Thorvaldsen vor Prometheus impliziert einen seit der Renaissance verbreiteten Künstlertopos: Der zeitgenössische Bildhauer wird in direkter Nachfolge des archetypischen Schöpfergottes, Feuerbringers und Kulturstifters verstanden und inszeniert. ${ }^{110}$ Auch in schriftlichen Quellen wurde Thorvaldsen mit Prometheus verglichen. So notierte der Dichter Franz von Elsholtz nach einem Besuch in Thorvaldsens Atelier am 23. Oktober 1823 über den Bildhauer:

Und Du fürchtest den Zorn, Du zweiter, größerer Prometheus,

Nicht Minervens, - durch Dich ihres Amtes beraubt?

Wird dem Sterblichen wohl die Göttin solches verzeihen?"11

Damit deutete Elsholtz die Fähigkeit des dänischen Bildhauers an, nicht nur menschliche Figuren aus Ton zu formen, sondern diesen gleichsam Leben einzuhauchen. Außer Elsholtz ging kein Zeitgenosse so weit, Thorvaldsen als „größere[n] Prometheus“" zu bezeich-

110 Zu Prometheus im Kontext des Geniekults siehe Schmidt 1985, 254 - 261; auch Kanzenbach 2007, 233.

111 Franz von Elsholtz, „In der Werkstatt des Ritters Thorwaldson“, 23. Oktober 1823, TMA, Ref. m32, nr. 29. Der Bericht von Elsholtz' Besuch in Thorvaldsens Atelier wurde später in dessen Reiseerinnerungen publiziert; Franz von Elsholz, Ansichten und Umrisse aus den Reise-Mappen zweier Freunde, Bd. 1, Berlin und Stettin: Nicolai, 1831, 251-253. 
nen und ihn dadurch über den mythologischen Schöpfergott zu erheben. Die Gleichsetzung des dänischen Bildhauers mit Prometheus ist hingegen in zahlreichen Quellen überliefert und als solche Teil des romantischen Kults um das Künstlergenie. Beispielsweise schrieb der Opernkomponist Gaetano Donizetti eigens zu Thorvaldsens, römischem Geburtstag` vom 8. März 1836 ein Lied, das von einem Text des Dichters Scipione Barberi begleitet wurde. ${ }^{112}$ Bei Donizettis Komposition handelt es sich um nur eines von unzähligen Liedern, die über die Jahrzehnte zu Ehren des dänischen Bildhauers gedichtet wurden. Die meisten dieser Lieder wurden zu bereits existierenden Melodien geschrieben; in vereinzelten Fällen - darunter Donizetti - ist jedoch bekannt, dass nicht nur die Texte, sondern auch die Melodien in Verehrung für Thorvaldsen komponiert wurden. ${ }^{113}$ In Donizettis und Barberis Lied wird der dänische Bildhauer in allen fünf Strophen als Prometeo Dannese bezeichnet und für seine Fähigkeiten des Formens und Belebens menschlicher Figuren aus Ton gepriesen. ${ }^{114}$ Ein weiterer Topos der Thorvaldsen-Panegyrik, die in diesem Lied aufgenommen wird, ist die Gegenüberstellung von Nord- und Südeuropa als Thorvaldsens Herkunfts- beziehungsweise Wirkungsort. ${ }^{115}$ Dementsprechend wurde der Bildhauer auch in der dänischen Tageszeitung Dagen vom 27. Juli 1837 als der „nordisch-hellenische Prometheus“ bezeichnet. ${ }^{116}$

Die zeitgenössischen Äußerungen zu Thorvaldsens prometheischer Schaffenskraft verdeutlichen den topischen Zusammenhang zwischen dem mythologischen Schöpfer, der Menschen aus Lehm formte und durch Minerva beleben ließ, und dem Bildhauer, dessen Ideal eine scheinbare Verlebendigung des künstlerischen Materials darstellte. Folglich ist das Relief Minerva und Prometheus in Munchs Gemälde als Allegorie der Bildhauerei generell zu verstehen. Demgegenüber verweist die Wiedergabe des Jason auf Thorvaldsens individuelle Künstlerbiografie: Diese Statue bedeutete den künstlerischen Durchbruch des Bildhauers und legte das Fundament seines in den folgenden vier Jahr-

112

113

114

Barberi, 8. März 1836, TMA Ref. m33, nr. 78: „Con la Grazia, è con la Musa / Venga Apollo a noi cortese / Il Prometeo Dannese / Con l'alloro a coronar. // Con la creta, con li sassi / Forma umani a fare imprese / Il Prometeo Dannese / E col dito la animò. // Numi, Eroi, persone Illustri / Alla vita, al tatto ei rese / Il Prometeo Dannese / Che l['h] a fatti palpitar. // Se dal Nord tanto fuoco / A noi venne o qui s'accese / Dal Prometeo Dannese / Or l'Italia che farà. // Lo terrà per mille lustri / A dar gloria al suo paese / E al Prometeo Dannese / Mille allori porgerà.“ (Hervorhebungen durch T. S.). Weitere Vergleiche von Thorvaldsen mit Prometheus enthalten bspw. Hans Vilhelm Kaalund, „Til Thorvaldsen“, 23. September 1838, TMA, Ref. m33, nr. 7 (dieses Gedicht wurde auf der ersten Seite der Zeitung Søndagen, 36, 23. September 1838, publiziert); Wilhelm Gerhard, „An Albert Thorwaldsen“, 22. Juni 1841, TMA, Ref. m32, nr. 94; Hagen 1844, 24. Gerhards Gedicht wurde zu Ehren des Bildhauers während dessen Besuchs in Leipzig an dem von Felix Mendelssohn Bartholdy organisierten Musikfest im Hôtel de Saxe vorgetragen. Es wurde später in Schulz/Weigel 1916, 15, publiziert.

115 Siehe dazu auch Kap. I.3.

116 „Thorvaldsen“, Dagen, 177, 27. Juli 1837, 3. 
zehnten stetig wachsenden Ruhms und des damit einhergehenden Kults um ihn. Der Stellenwert der Jason-Statue für seine Künstlerlaufbahn wurde nicht nur in der eingangs zitierten Aussage des Dichters Andersen als Beginn von Thorvaldsens Berühmtheit bezeichnet; auch der Philologe Friedrich Heinrich von der Hagen hielt am 20. Mai 1816 fest: „Dieser Jason ist sein erstes großes Werk, es begründete seinen Ruhm, und Thorwaldson hat in ihm selber das goldene Vließ errungen. ${ }^{\text {"117 }}$ Der Autor Friedrich Johann Jacobsen schwärmte derweil in seinen 1820 veröffentlichten Briefen an eine deutsche Edelfrau von jener Skulptur, die seit ihrer Entstehung „die Welt mit dem Ruhm seines [Thorvaldsens] Namens erfüllte, und Könige und Fürsten in seine Werkstatt rief ". ${ }^{118}$ Und nach Thorvaldsens Schüler Ponciano Ponzano y Gascón hatte es die Jason-Statue ihrem Erschaffer ermöglicht, „unsterblichen Ruhm“ zu erlangen. ${ }^{119}$ Schließlich scheint der Erfolg der Jason-Statue auch andere Künstler wie Christian Daniel Rauch oder Manuel Vilar zur Behandlung des Argonautenthemas angeregt zu haben. ${ }^{20}$

\section{Jason und die celebrity-Kultur des frühen 19. Jahrhunderts}

Die rege publizistische und künstlerische Rezeption von Thorvaldsens Jason-Statue wurde durch frühe Nachzeichnungen sowie druckgrafische Vervielfältigungen begünstigt. ${ }^{121}$ Gerade Letztere trugen entscheidend zur Erweiterung des Publikums und damit zur Bekanntheit von Kunstwerken und deren Erschaffern bei. Im selben Jahr wie Munchs Gemälde entstand das Stichwerk der ebenfalls in Rom lebenden Künstlerbrüder Riepenhausen und des Kupferstechers Mori nach Thorvaldsens Skulpturen. ${ }^{122}$ Den Auftakt dieser Sammlung von insgesamt 32 Konturstichen bildet der aus zwei verschiedenen Blickwinkeln wiedergegebene Jason (Abb. 8 und 9). Die doppelte Abbildung dieser Statue untermalt in erster Linie deren epochale Bedeutung für Thorvaldsens Künstlerbiografie. Darüber hinaus reflektiert sich darin ein bereits nach der Mitte des 18. Jahrhunderts einsetzendes neues Verständnis der Kunstbetrachtung, wonach nicht mehr nur die Hauptansicht von plastischen Werken im Zentrum der Aufmerksamkeit stand, sondern die

117 Von der Hagen 1818 - 1821, Bd. 2, 335.

118 Jacobsen $1820,97$.

119 Zit. nach Hartmann 1971, 38: „[... Giasone che diede a Thorwaldsen la possibilità di acquisire fama immortale [...].“

120 Grandesso 2015, 32.

121 Es wurde bereits erwähnt, dass Caroline von Humboldt ihrem Brief vom 20. April 1803 an Johann Wolfgang von Goethe eine eigene Nachzeichnung der Jason-Statue beigelegt hatte. Außerdem ist bekannt, dass die in Rom lernenden Schüler des schwedischen Bildhauers Johan Tobias Sergel für diesen Nachzeichnungen von Thorvaldsens Skulpturen anfertigten und ihn so über das Schaffen des Dänen informierten; Wittstock 1975, 79.

122 Riepenhausen/Riepenhausen/Mori 181la, 2 - 3. Siehe auch Neergaard 1814, 569; Wittstock 1975, 79 - 80; Jørnæs 1991a, 69; Springer, P. 1991, 217; Jørnæs 2011, 70. 


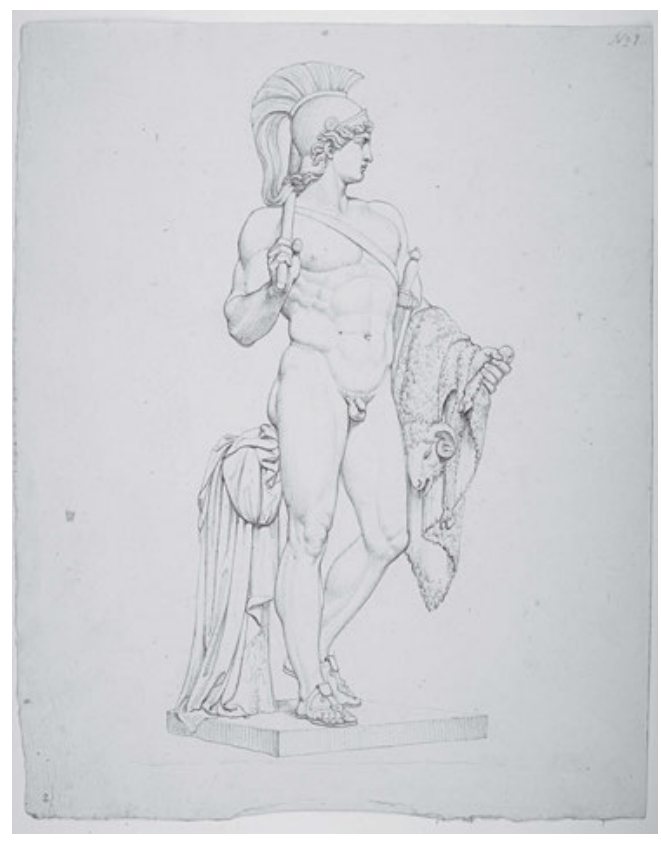

8__Ferdinando Mori, Jason mit dem goldenen Vlies, zwischen 1803 und 1811, Bleistift auf Papier, $260 \times 210 \mathrm{~mm}$, Kopenhagen, Thorvaldsens Museum (Inv.-Nr. D159)

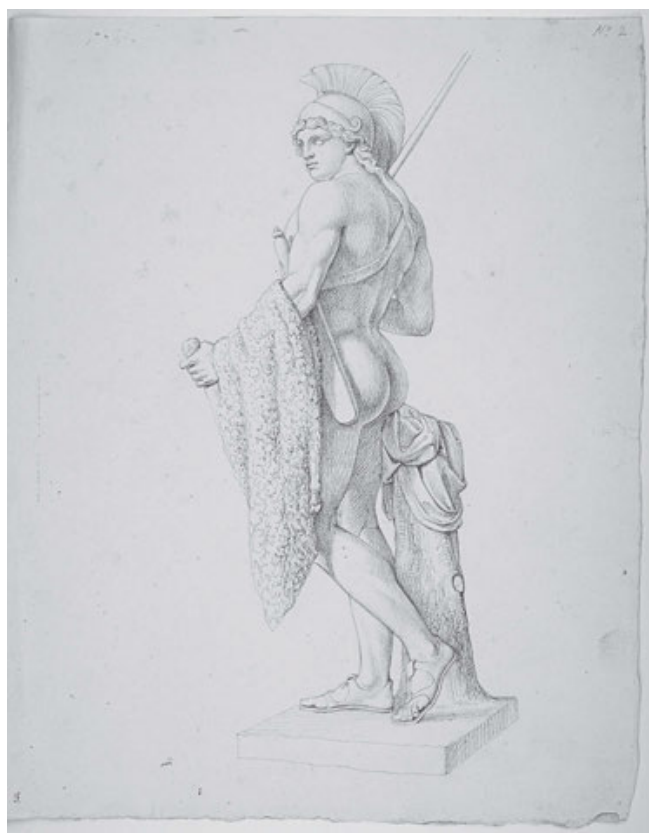

9__Ferdinando Mori, Jason mit dem goldenen Vlies, zwischen 1803 und 1811, Bleistift auf Papier, $264 \times 208$ mm, Kopenhagen, Thorvaldsens Museum (Inv.-Nr. D160)

Skulptur als Ganze. ${ }^{123}$ In diesem Zusammenhang ist beispielsweise auch Fernows oben zitiertes Lob der Mehransichtigkeit des Jason, dessen "gefällige Ansicht [...] von allen Seiten“, zu verstehen. ${ }^{124}$

Gemäß Thiele hatte der Maler und Kupferstecher Koch bereits im Sommer 1809 gegenüber Thorvaldsen die Idee geäußert, dessen neuste Entwurfszeichnungen als Radierungen in einem Heft zu veröffentlichen. ${ }^{125}$ Wenige Monate später war von einer druckgrafischen Vervielfältigung der Skulpturen des Dänen anstelle der Entwurfszeichnungen die Rede. ${ }^{126}$ Beide Pläne wurden schließlich nicht von Koch verwirklicht, sondern 1811 laut Thiele auf den Wunsch und mittels eigener Finanzierung des Bildhauers - von den

124 Fernow 1806, 198-199, Anm.

125 Thiele 1852 - 1856, Bd. 1, 186; auch Marini Clarelli 1989, 308.

126 Thiele 1852-1856, Bd. 1, 189, gemäß dem Brief von Herman Schubart an Bertel Thorvaldsen, 1. Januar 1810, TMA, Ref. m2 1810, nr. 1 . 
Riepenhausen und Mori. ${ }^{127}$ Eine spätere Ausgabe, die vermutlich 1817 oder 1818 erschien, wurde mit Umrissstichen nach den jüngsten Arbeiten des Bildhauers ergänzt. ${ }^{128}$ Das erste Heft dieser Konturstiche brachte der Baron Schubart bereits Ende 1811 mit sich nach Kopenhagen und soll es seinen Landsleuten bei allen möglichen Gelegenheiten vorgezeigt haben. ${ }^{129}$ Darin spiegelt sich die Bedeutung wider, die Umrissstichen für die systematische Bekanntmachung und Ruhmessteigerung von Thorvaldsen und seinem Schaffen in dessen Heimat zukam.

Der Bildhauer selbst war schon früh mit der Gattung des Konturstichs vertraut, wie sein Besitz der von John Flaxman 1792/1793 gezeichneten und von Tommaso Piroli gestochenen Illustrationen zu Dichtungen von Homer und Aischylos belegt. ${ }^{130}$ Ferner ist bekannt, dass er Pausen nach diesen Stichen anfertigte und sich so Flaxmans äußerst linearen Zeichenstil aneignete, was sich in seinen klar konturierten Skulpturen und Reliefs niederschlug. ${ }^{131}$ Neben Flaxmans Illustrationen zu Homer und Aischylos besaß Thorvaldsen auch die 1804 publizierten Umrissstiche nach antiken Vasen aus der Sammlung des britischen Diplomaten in Neapel, Sir William Hamilton. ${ }^{132}$

Dass sich Thorvaldsen der zentralen Bedeutung von Konturstichen für die großflächige Verbreitung seiner Arbeiten sehr bewusst war, zeigt beispielsweise seine Mitsprache bei entstehenden Stichwerken. ${ }^{133}$ Es kann darüber hinaus angenommen werden, dass er die Herstellung von Umrissstichen aktiv vorantrieb, denn sie scheinen so gefragt gewesen zu sein, dass der Bildhauer gemäß einer Tagebuchnotiz seines Landsmannes Peder Brønnum Scavenius 1819 in Rom eine eigene Werkstatt mit Kupferstechern betrieb. ${ }^{134}$ Interessant ist in diesem Zusammenhang ferner Thieles Aussage, dass Thorvaldsens bildhauerische Produktivität den Zweck der druckgrafischen Vervielfältigung seiner Werke ab einem bestimmten Zeitpunkt erübrigt habe - in anderen Worten: Thorvaldsen habe selbst mehr produziert, als mit industrieller Vervielfältigung möglich war. ${ }^{135}$ Damit spricht Thie-

Thiele 1852 - 1856, Bd. 1, 190; auch Marini Clarelli 1989, 308.

Riepenhausen/Riepenhausen/Mori 1811b (obwohl auch bei dieser Ausgabe 1811 als Publikationsjahr vermerkt ist, muss man aufgrund der darin abgebildeten Werke davon ausgehen, dass sie frühestens 1817 erschienen ist). Siehe auch Wittstock 1975, 80.

Thiele 1852-1856, Bd. 1, 214; auch Wittstock 1975, 79.

Jørnæs 1991a, 68 - 69; Jørnæs 2011, 35.

Jørnæs 1991a, 69 und 72. Eine weitere Verbindung von Thorvaldsen zu Flaxman war seine Übernahme von Flaxmans Atelier nach seiner Ankunft in Rom 1797. Die beiden Bildhauer begegneten sich jedoch nie persönlich.

Jørnæs 1991a, 69. Die erwähnten Umrissstiche nach Hamiltons Vasen: Outlines from the Figures and Compositions upon the Greek, Roman, and Etruscan Vases of the Late Sir William Hamilton. With Engraved Borders Drawn and Engraved by the late Mr. Kirk, London: William Miller, 1804.

Siehe dazu die entsprechenden Ausführungen in der Einleitung.

Peder Brønnum Scavenius, 31. März 1819, RA, Peder Brønnum Scavenius’ privatarkiv (Digitalisat im TMA); auch Wittstock 1975, 121; Springer, P. 1991, 217.

Thiele 1852 - 1856, Bd. 2, 141-142. 
le zum einen die fabrikähnliche Werkstattorganisation des Dänen an, die im Kapitel III.1 betrachtet wird, und nährte zum anderen das öffentliche Bild von Thorvaldsen, dessen Fleiß und Schnelligkeit im Modellieren zuweilen mit Zauberei assoziiert wurden. ${ }^{136}$

Obschon man die Vervielfältigung von Thorvaldsens Werken in Form von Konturstichen nicht nur begrüßt, sondern auch gewünscht hatte, wurde rasch Kritik an deren künstlerischer Qualität laut. Besonders deutlich hatte sich Neergaard 1814 über das Heft der Riepenhausen und Mori ausgesprochen: Demnach entbehrten Moris Werke der für Umrissstiche besonders wichtigen korrekten Wiedergabe von Proportionen, Licht und Schatten, wohingegen Neergaard die Arbeit der Brüder Riepenhausen für gut befand. ${ }^{137}$ Ein weiterer Kritikpunkt war das Fehlen von Jugendarbeiten Thorvaldsens, da man „den ausgezeichneten Künstler auch als Jüngling kennen zu lernen“ wünschte. ${ }^{138}$ Daraus geht erneut die zentrale Rolle hervor, die Konturstiche für die Bekanntmachung von Künstlern, in diesem Fall von Thorvaldsen in Dänemark, spielten. Schließlich hatte der Kritiker auf detailliertere Informationen zu den einzelnen Werken gehofft, besonders was die Käuferschaft betraf. ${ }^{139}$ Die Mängel wogen nach Neergaard gerade deshalb so schwer, da Konturstiche „die ganze Welt [durchwandern], und nach ihnen [...] der Maler und Bildhauer allenthalben beurtheilt [wird]; nur nach ihnen werden ihre Vorzüge und Fehler ermessen“. ${ }^{140}$ Aus diesem Zitat wird ebenfalls die damals kaum überschätzbare Bedeutung der druckgrafischen Vervielfältigung von Kunstwerken für die Sichtbarkeit von Künstlern deutlich, wenn auch Neergaards Gewichtung der Stiche als alleiniger Basis zur Beurteilung von Kunstwerken allzu stark erscheint.

Die von Neergaard angesprochene Mobilität von Stichwerken machte die druckgrafische Vervielfältigung zu einem wichtigen Bestandteil der frühen celebrity-Kultur, wie auch in der Einleitung ausgeführt wurde. In Stichen konnten sowohl künstlerische Schöpfungen als auch Porträts ihres Erschaffers reproduziert und großflächig in Umlauf gebracht werden, weshalb sie ein zentrales Instrument zur Stilisierung und Verbreitung der Künstlerpersona waren und damit wesentlich zum Kult um diese beitrugen. Zweifellos gilt dies auch für die druckgrafische Vervielfältigung von Thorvaldsens Jason-Statue, die das Werk und dessen fulminanten Erfolg weit über die römischen Grenzen hinaus bekannt machte und dadurch seine Rezeption wesentlich steigerte, was sich wiederum auf Thorvaldsens frisch errungenen Ruhm auswirkte und den Grundstein für dessen internationale Berühmtheit legte.

137 Neergaard 1814, 569-571.

138 Ebd., 569-570.

139 Ebd., 570.

140 Ebd., 574. 


\section{Der Alexanderzug des "nordischen Phidias“}

Kurze Zeit nach Munchs Bildnis von Thorvaldsen entstand 1815 mit jenem des Malers Carl Christian Vogel (von Vogelstein) ein weiteres Porträt, das den Bildhauer zusammen mit dem Modell seiner epochalen Jason-Statue wiedergibt (Taf. I). Thorvaldsen erscheint hier auf einem roten Stuhl sitzend, in die Tracht der römischen Accademia di San Luca gekleidet und wie bei Munch mit dem Kreuz des Dannebrog-Ordens geschmückt. ${ }^{141}$ Die Beine und Arme sind gekreuzt, und an der linken Hand des Bildhauers ist dessen oft getragener antiker Goldring in Schlangenform erkennbar. ${ }^{142}$ Mit seinen klaren Augen blickt Thorvaldsen in die Ferne, während sein feines, gewelltes Haar einen Kontrast zu den markanten Gesichtszügen schafft und diese dadurch hervorhebt. Bei dieser Darstellungsweise handelt es sich um das typische Bild des Dänen, das sich durch den Großteil sowohl der gemalten Porträts als auch der Schriftquellen zieht.

In Vogels Porträt steht links hinter dem Bildhauer das Tonmodell des Jason, dessen Oberkörper vom einfallenden Tageslicht erhellt wird. An die Wand ist das Schlüsselstück von Thorvaldsens 1812 modelliertem, monumentalem Relieffries Einzug Alexanders des Großen in Babylon gelehnt (kurz: Alexanderzug; Abb. 10). Der Erschaffer der beiden dargestellten Werke erscheint im Zentrum des Blicks von Jason einerseits und Alexander dem Großen andererseits. Vogel hat Thorvaldsen hier mit seinen bis dahin wichtigsten Schöpfungen porträtiert und damit ein nicht weniger programmatisches Bildnis als Munch geschaffen: Während Thorvaldsen mit der Jason-Statue der künstlerische Durchbruch gelungen war, brachte ihm der Alexanderzug den Übernamen patriarca del bassorilievo ein und erhob ihn - zumindest in der Gattung des Reliefs - unbestritten über den bis dahin kaum erreichten Canova. ${ }^{143}$ Das vorliegende Kapitel beleuchtet die Entstehung und Rezeption dieses Relieffrieses sowie dessen Bedeutung für Thorvaldsens Künstlerbiografie, Selbstdarstellung und den Personen- und celebrity-Kult um den Bildhauer.

141 Siehe auch Müller, S. 1893, 118; Sass 1963-1965, Bd. 1, 258; Bjarne Jørnæs, in: Helsted 1973, 10; Kanzenbach 2007, 306; Salling 2012, 166. Thorvaldsen war am 6. März 1808 zum Mitglied und Professor der Accademia di San Luca und am 28. Januar 1810 zum Ritter des Dannebrog-Ordens ernannt worden; siehe dazu TMA, Ref. m29 II, nr. 3 und Ref. m29 II, nr. 5.

142 Zu Thorvaldsens Schlangenring siehe Melander 2008.

143 Siehe bspw. Friedrich von Raumer an Louise von Raumer, 12. Dezember 1816, zit. bei Wittstock 1975, 331; Kephalides 1818, 158; Kruseman 1826, 86; Thiele 1852 - 1856, Bd. 1, 225; d’Angers 1856, 7; Plon 1867, 34; Lücke 1883, 56; Pfundheller 1886, 237; von Thürheim 1914, 91; Erinnerungen der Malerin Louise Seidler 1922, 129; Hartmann 1965, 6; Wittstock 1975, 92 - 93; Jørnæs 1989b, 45; Tesan 1991b, 225; Jørnæs 2011, 76; Grandesso 2015, 108. Hans West hatte Thorvaldsens Fähigkeiten in der Reliefbildhauerei bereits 1810 über jene von Canova erhoben; siehe dazu Wittstock 1975, 94. 


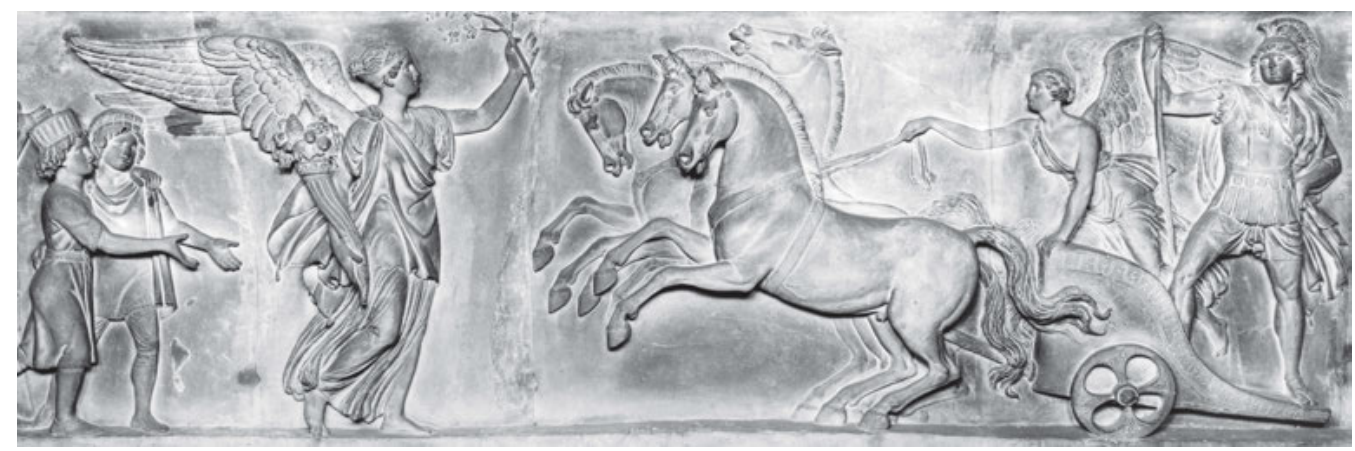

10_Bertel Thorvaldsen, Einzug Alexanders des Großen in Babylon (Alexanderzug), 1812, Gipsmodell, $1,06 \times 34,46$ m, Detail, Kopenhagen, Thorvaldsens Museum (Inv.-Nr. A503)

\section{Der Alexanderzug für den Quirinalspalast}

Thorvaldsens Einzug Alexanders des Großen in Babylon war eine Auftragsarbeit für die Neudekoration diverser Räume im Quirinalspalast. Diese Umgestaltung erfolgte im Hinblick auf den für 1812 geplanten Besuch Napoleons I. zu dessen zweiter Kaiserkrönung im Petersdom in Rom. Der Russlandfeldzug, der in Napoleons Niederlage enden sollte, verhinderte jedoch den Besuch in der Ewigen Stadt. ${ }^{144}$ Mit dem Umbau des Quirinalspalastes war indessen bereits 1811 unter der Leitung des Architekten Raffaele Stern begonnen worden. ${ }^{145}$ Zwischen März und Juni 1812 modellierte Thorvaldsen seinen Alexanderzug, der im November desselben Jahres im sogenannten Salone d'Onore, dedicato alla Virtù (heute Sala delle Dame) angebracht wurde..$^{146}$

Die Erzählung des Alexanderzuges basiert größtenteils auf Quintus Curtius Rufus' Geschichte Alexanders des Großen, von der sich eine Kopie in Thorvaldsens Bibliothek befand ${ }^{147}$ Eine Quelle für die Darstellung der Babylonier war vermutlich Carsten Niebuhrs

144 Wittstock 1975, 102. Bereits 1814 bestellte Napoleon eine Kopie des Alexanderzuges für den geplanten Temple de la Gloire in Paris, heute Kirche La Madeleine, die jedoch trotz erfolgter Anzahlung nicht mehr ausgeführt wurde; siehe dazu Calmeyer 1990, 98; Jørnæs 2011, 76; Grandesso 2015, 117.

145 Hartmann 1965, 3; Wittstock 1975, 102; Jørnæs 1991b, 35; Jørnæs 2011, 74; Grandesso 2015, 109.

146 Gohr 1977a, 83; Calmeyer 1990, 97; Jørnæs 1991b, 36 - 37; Grandesso 2015, 109.

147 Bertel Thorvaldsen an Raffaele Stern, nach dem 23. Dezember 1813, Kopie im TMA, Ref. m28A I, nr. 37. Thorvaldsens Alexanderzug basiert im Wesentlichen auf folgender Textstelle bei Curtius 1954, 5, 3, 215 -217: „Als Alexander nun nach Babylon vorrückte, zog ihm Mazäus, der aus der Schlacht sich in diese Stadt geflüchtet hatte, mit seinen halberwachsenen Kindern entgegen und ergab sich ihm mitsamt der Stadt auf Gnade oder Ungnade. Daß er ihm so entgegenkam, war Alexander willkommen, denn eine Belagerung der so stark befestigten Stadt hätte viel Mühe gekostet. [...] Daher nahm er ihn zwar mitsamt seinen Kindern gnädig auf; alsdann aber ließ er das Heer schlagbereit sich in Bewegung setzen, als ginge es in die Schlacht; er selbst ritt als Führer voran. / Ein Großteil der Babylonier stand auf den Mauern, voll Neugier, den neuen König kennenzulernen; mehr noch zogen ihm entgegen. Unter diesen 
11_Bertel Thorvaldsen, Einzug Alexanders des Großen in Babylon (Alexanderzug), 1812, Gipsmodell, $1,06 \times 34,46$ m, Detail, Rom, Palazzo del Quirinale

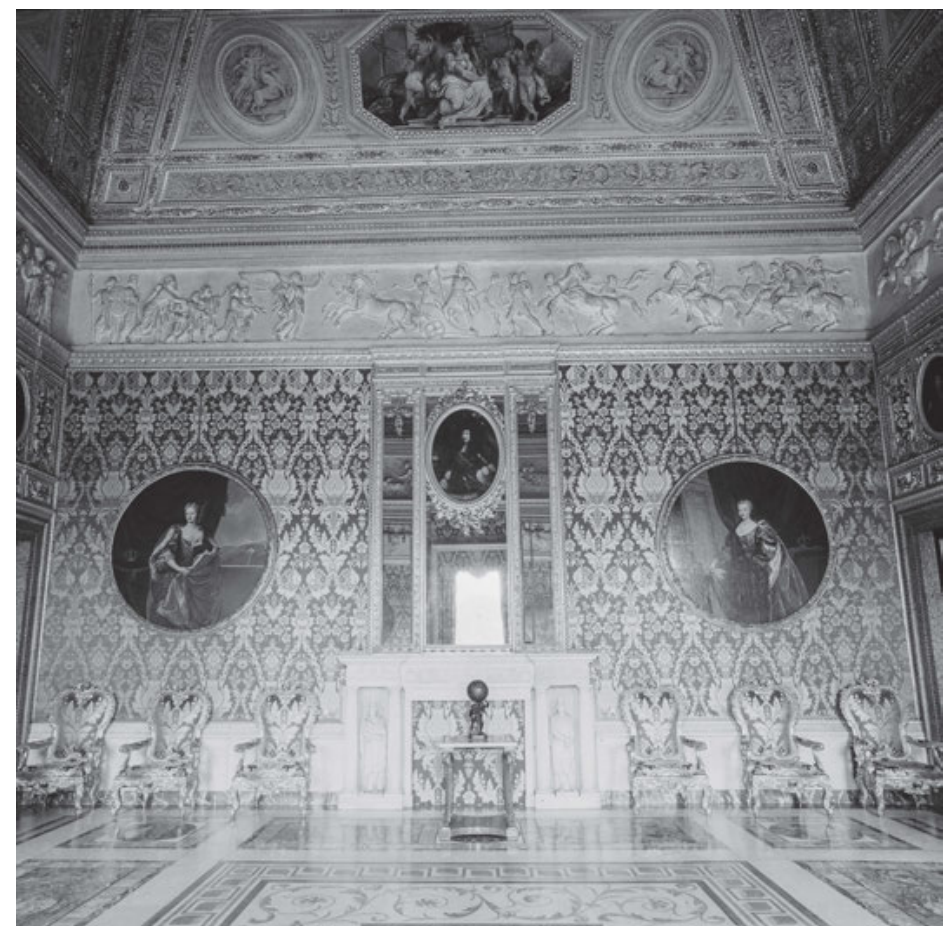

Reisebeschreibung nach Arabien und andern umliegenden Ländern von 1778; außerdem stand Thorvaldsen mit dem schwedischen Archäologen Johan David Akerblad ein bereister Berater zur Seite. ${ }^{148}$ Das Zentrum von Thorvaldsens Fries bestimmt - zumindest in thematischer Hinsicht - der durch die Friedensgöttin empfangene Alexander der Große auf dem von Viktoria gelenkten Triumphwagen (Abb. 11). Direkt hinter der Friedensgöttin geht der sich ergebende babylonische Feldherr Mazäus mit seinen Kindern dem Makedonierkönig entgegen. Auf diese Gruppe folgt das babylonische Volk, das mitsamt Pferden, Löwen und Schafen herbeigeströmt ist, um Zeuge von Alexanders Einzug zu sein und den Herrscher mit Gaben zu empfangen. Auf dieser Seite des Frieses, die die meisten Relieffelder einnimmt, verweisen verschiedene Elemente auf Babylon als Schauplatz des Ge-

war auch Bagophones, der Hüter der Burg und der königlichen Schatzkammer; um sich an Beflissenheit von Mazäus nicht ausstechen zu lassen, hatte er den ganzen Weg mit Blumen und Kränzen bestreuen und rechts und links vom Wege silberne Altäre aufstellen lassen, die mit Weihrauch und dazu Essenzen aller Art überladen waren. Als Geschenkgaben folgten ihm Herden von Vieh und Pferden, und sogar Löwen und Panther trug man in Käfigen herbei." Siehe auch Hagen 1844, 14; Wittstock 1975, 86; Gohr 1977a, 81; Jørnæs 1989b, 46; Jørnæs 1991b, 37; Noll 2005, 45; Jørnæs 2011, 74. 
schehens, wie die berühmte Stadtmauer, der für den Euphrat stehende Fluss und der legendäre Turm. Die etwas kürzere rechte Seite des Frieses hinter Alexander auf dem Triumphwagen wird von zahlreichen Kriegern zu Pferd und zu Fuß bestimmt, denen ein mit Spolien beladener Elefant folgt. An diesen schließen zwei weitere Krieger sowie ein Selbstbildnis von Thorvaldsen an, worauf später eingegangen wird (Abb. 12). Beide Enden des Frieses sind von Palmen geziert, die zum einen als Abschluss dienen und zum anderen die Möglichkeit einer räumlichen Verbindung bieten. ${ }^{149}$

Der knapp 35 Meter lange Relieffries ist in vier Abschnitte gegliedert, die den vier Wänden der Sala delle Dame entsprechen, wobei die Figurengruppe um Alexander den Großen das Zentrum der den Fenstern gegenüberliegenden Wand bestimmt. ${ }^{150}$ Der Alexanderzug war Teil eines umfassenderen ikonografischen Programms des ehemaligen Salone d'Onore, dedicato alla Virtù: So stand nicht nur Alexander der Große für Herrschertugenden, sondern vor allem auch Felice Gianis Deckenfresken mit Darstellungen der Fortitudo, Justitia, Prudentia und Magnanimitas verwiesen auf das Motto des Saales. ${ }^{151}$ Außerdem schmückte Paul Duqueylars Gemälde Trajan verteilt die Zepter Asiens die Decke des Salone d'Onore. ${ }^{152}$ Indem Duqueylar dem antiken Herrscher die Gesichtszüge Napoleons verlieh, brachte er die beiden Potentaten in eine direkte Verbindung miteinander. Ferner bestand eine Parallele zwischen Duqueylars Gemälde und Thorvaldsens Relieffries, da sowohl Trajan als auch Alexander der Große - und ebenso Napoleon - auf bedeutende Feldzüge in Asien zurückblicken konnten. ${ }^{153}$

149 Die früheste Beschreibung des Alexanderzuges stammt von Thorvaldsen selbst; Bertel Thorvaldsen an Raffaele Stern, nach dem 23. Dezember 1813, Kopie im TMA, Ref. m28A I, nr. 37: „Alessandro sul Cocchio guidato della Vittoria, appresso di Lui due Scudieri, e poi il Suo Cavallo Bucefalo, ed appresso li Generali. Seguito di Cavalleria e Fanteria; un Elefante sopra di cui sono messi le spoglie accanto un Prigioniere, e seguito dell'Armata che viene fra glalberi delle palmi. - Il fiume Tigri [sollte Euphrat sein] che divide L'Armata della Citta sulla riva un Pescatore, una Barca di Trasporto per la Citta. Il fiume Tigri sedendo col remo in mano dell'altro mano spighi di grano a canto un Tigre dietro di Lui un indizio della Torre di Babele; un Pastore che manda le Pecore in dono ad Alessandro, gente che s'affaccia sul muro di Babilonia, per vedere entrare il nuovo sovrano, ed altri, che aspettano fuori delle mura. Un ara di profumi prossimo alla porta; Li Caldei, che sortono della Citta di Babilonia per andare incontro ad Alessandro vicino porte leoni Pantere, e Cavalli che si portano in Dono ad Alessandro, ci Suonatori con e lori instromenti, Bagofano Tesorieri di Dario fà mettere su glaltare d’argento con di profumo. le Donne ghirlande che spargono de fiore per dova ha da passare Alessandro. Mazio che va incontro con i Figliuoli per rendere la Citta di Babilonia ad Alessandro - La Pace, che trattiene il Cocchio di Alessandro." Siehe auch Thiele 1852-1856, Bd. 1, 226.

150 Siehe auch Gohr 1977a, 82.

151 Hartmann 1965, 4; Calmeyer 1990, 97 und 116; Jørnæs 1991b, 37; Jørnæs 2011, 74.

152 Jørnæs 1991b, 37. Duqueylars Gemälde befindet sich heute in einem anderen Saal des Quirinalspalastes.

153 Gohr 1977a, 83; Calmeyer 1990, 97; Jørnæs 1991b, 37 - 38. 


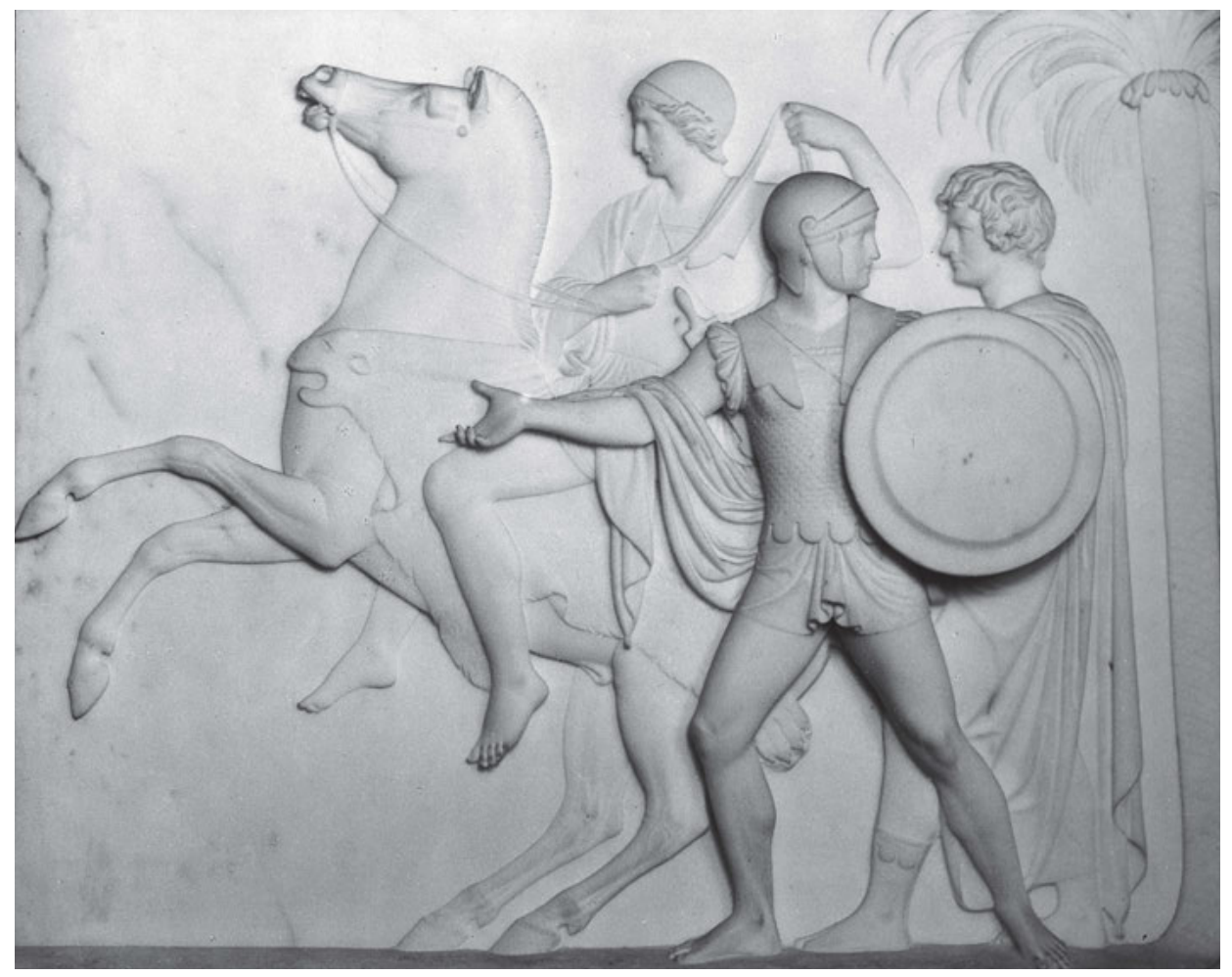

12_Bertel Thorvaldsen, Einzug Alexanders des Großen in Babylon (Alexanderzug), 1822, Marmor, 0,55 × 22,94 m, Detail, Kopenhagen, Thorvaldsens Museum (Inv.-Nr. A508)

\section{Eine Kritik an Napoleon I.?}

Der Alexanderzug gibt exemplarisch Einblick in Thorvaldsens Umgang mit Aufträgen aus verschiedenen politischen und religiösen Lagern: Da seine Haltung gegenüber dem französischen Kaiser zwiespältig gewesen zu sein scheint, können ideologische Widersprüche nicht ausgeschlossen werden. Tatsächlich wird angenommen, dass er die gegen Napoleon opponierende Gruppierung um Germaine de Staël unterstützte. ${ }^{154}$ Weiter ist bekannt, dass er im Jahr 1809 Aufträge für Napoleons Schwester Elisa Bonaparte - gemäß Schubart aus „politischem Vorurteil“ - abgelehnt hatte. ${ }^{155}$ Umgekehrt führte er um 1830 für den Politiker und Kunstsammler Alexander Murray eine Büste aus, die Napoleons Apotheose

155 Herman Schubart, 20. Mai 1809, zit. nach Hartmann 1958, 281: „par ce préjugé politique“. Siehe auch Wittstock 1975, 103. 
zeigt. ${ }^{156}$ Ferner schuf er in den späten 1820er Jahren das Grabmal für Napoleons Adoptivsohn Eugène de Beauharnais in der St.-Michaels-Kirche in München (Abb. 83). ${ }^{157}$ Eindeutige Äußerungen zum politischen Geschehen - ebenso wie zu seiner religiösen Überzeugung - sind von Thorvaldsen selbst kaum überliefert. ${ }^{158}$ Vor einem ähnlichen Hintergrund sind Thorvaldsens Aufträge sowohl für die katholische als auch für die protestantische Kirche zu sehen. In diesem Zusammenhang erscheinen Hubbards Bemerkungen, Thorvaldsen sei den „Weg des geringsten Widerstandes“ gegangen und wäre mit etwas mehr Willen ein ausgezeichneter Diplomat gewesen, in seinem zuweilen recht reißerischen Aufsatz über den Bildhauer doch nicht ganz unzutreffend. ${ }^{159}$ Thorvaldsens Zurückhaltung seiner persönlichen Meinung und seine opportunistischen Tendenzen sind als ein Aspekt seiner Selbstvermarktung zu verstehen und trugen im Endeffekt wesentlich zur breiten Sichtbarkeit des Bildhauers bei, was sich wiederum auf seinen celebrity-Status auswirkte.

Im Kontext des bei den Zeitgenossen offenbar bekannten Widerspruchs zwischen Thorvaldsens eigener Überzeugung einerseits und dessen künstlerischer Unterstützung napoleonischer Propaganda andererseits ist auch die folgende Aussage von der Hagens vom 14. Dezember 1816 zu verstehen:

[...] und trefflich ist die unfreiwillige Freude Babylons dargestellt (einige Freiheitsliebende entrudern schnell über den Tigris): nur Alexander selber auf seinem Triumpfwagen [sic] möchte nicht genügen, weil er eigentlich doch die Krone sein sollte. ${ }^{160}$

In der - nicht nur durch von der Hagen kritisierten - übermäßig theatralischen, fast karikierenden Darstellung des für Napoleon stehenden Alexander sieht Wittstock eine mögliche Distanzierung des Künstlers von der napoleonischen Politik, sofern es sich denn um eine bewusste Übertreibung durch Thorvaldsen handelte. ${ }^{161}$ Letzterer Vorbehalt ist berechtigt, denn die Alexanderfigur ist keine gänzlich originale Schöpfung, sondern an die Gestalt des Hektor in Thorvaldsens Relief Hektor mit Paris und Helena von 1809 angelehnt (Abb. 13). Trotzdem lässt sich nicht verneinen, dass die Änderungen für die Alexanderfigur - etwa die stärkere Drehung von Körper und Kopf sowie die ausladende Gestik -

Kopenhagen, Thorvaldsens Museum (Inv.-Nr. A909 und A867). Siehe auch Grandesso 2015, 117. Siehe dazu Kap. III.2.

Siehe auch Calmeyer 1990, 107; Jørnæs 2011, 76 und 187. Laut Wittstock 1975, 104, war Thorvaldsen überzeugter Republikaner und Atheist, wofür es jedoch keine eindeutigen Belege gibt.

Hubbard 1902, 96: „He moved in the line of least resistance-made friends of Protestant and Catholics alike; $[\ldots]$. He kept clear of all factions, and with a modicum more of will, might have been a very prince of diplomats."

60 Von der Hagen 1818-1821, Bd. 2, 335 (Hervorhebung durch T. S.); der Fluss wird fälschlicherweise als Tigris statt als Euphrat bezeichnet. Mit einer sehr ähnlichen Formulierung äußerte sich kurz darauf auch Per Daniel Amadeus Atterbom über den Alexanderzug; siehe dazu Calmeyer 1990, 107.

Wittstock 1975, 107. 
13__Bertel Thorvaldsen, Hektor mit Paris und Helena, 1809, Gipsmodell, 69,7 ×93 cm, Kopenhagen, Thorvaldsens Museum (Inv.-Nr. A499)

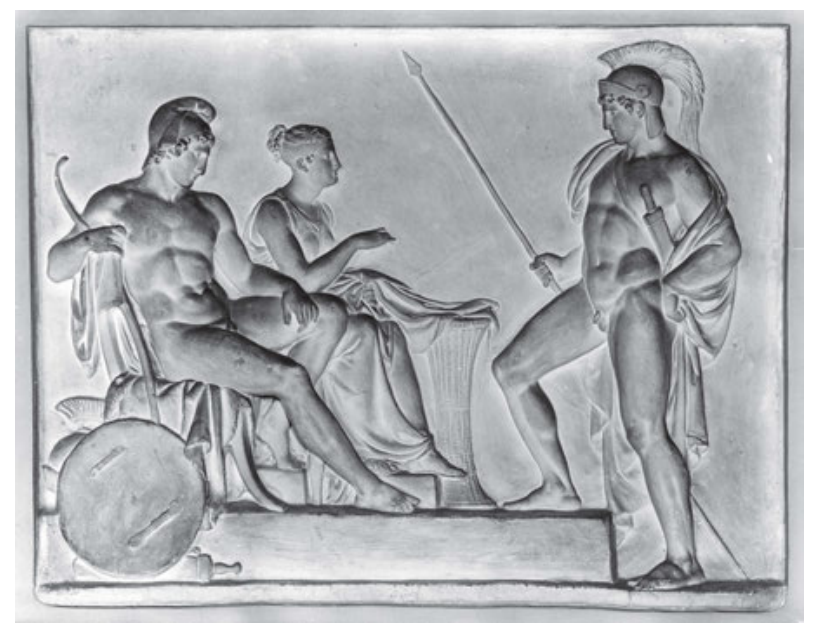

deren Theatralik deutlich steigern. Es ist denn auch diese Gestalt, die der Bildhauer in den späteren Marmorversionen des Alexanderzuges für die am Comer See gelegene Villa Carlotta des Grafen, Kunstsammlers und Thorvaldsen-Verehrers Giovanni Battista Sommariva und für Schloss Christiansborg in Kopenhagen überarbeitete und von ihrer pathetischen Erscheinung befreite. ${ }^{162}$ Während Alexander auf der ersten Fassung im Quirinalspalast breitbeinig auf dem Triumphwagen steht, die linke Hand in die Hüfte gestützt und den Blick zum Himmel gerichtet, verändern sich seine Kopfhaltung und die Stellung seiner Beine und Arme in den nachfolgenden Versionen, wodurch die Drehung in Alexanders Körper stetig abgeschwächt wurde. ${ }^{163}$

Nicht nur in der übermäßigen Theatralik der Gestalt Alexanders des Großen und in der „unfreiwilligen Freude“ der Babylonier sehen manche Autoren eine versteckte Kritik am französischen Kaiser. Nach Wittstock könnte man das Zusammentreffen von Alexander dem Großen und der Friedensgöttin in der Hauptszene als Missbilligung des Krieges und als Aufruf zum Frieden interpretieren. ${ }^{164}$ Ferner dürfte der mit Kriegsbeute beladene Elefant jede Betrachterin und jeden Betrachter an die napoleonischen Raubzüge in Rom in den späten 1790er Jahren erinnert haben. ${ }^{165}$ Aufgrund dieser Beobachtungen lässt sich

164 Wittstock 1975, 107; auch Noll 2005, 45. Eine ähnliche Aussage sieht Wittstock auch darin, dass Thorvaldsen seine Friedensgöttin (1799/1800, Standort unbekannt) und den Friedenbringenden Mars (1808, später Teil der Gruppe Mars und Amor, 1810, Kopenhagen, Thorvaldsens Museum, Inv.-Nr. A7) ohne Auftrag schuf.

165 Siehe bspw. Calmeyer 1990, 111. 
dennoch nicht entscheiden, ob Thorvaldsen die ursprüngliche Alexanderfigur bewusst in jener überspitzten Weise darstellte und in den späteren Fassungen abschwächte oder ob er lediglich die in der Hektik der Gipsausführung für den Quirinalspalast unterlaufenen Fehler korrigierte. ${ }^{166}$ Dass es sich hingegen klar um eine Korrektur handelte, dafür spricht die Tatsache, dass sich der Bildhauer in Porträts stets mit einem Ausschnitt aus den späteren Versionen des Alexanderzuges abbilden ließ (Taf. I und III, Abb. 25 und 29). Insgesamt erscheint eine Lektüre des Alexanderzuges als subtile Kritik am französischen Kaiser fraglich. Dies weniger, weil sich Thorvaldsen kaum zur politischen Situation äußerte, als vielmehr weil sich der Bildhauer dadurch selbst kritisieren würde: Denn indem sich Thorvaldsen mit seinem eigenen Bildnis im Fries verewigt hat und sich mehrfach zusammen mit diesem Werk porträtieren ließ - auf beides wird zurückgekommen -, verglich und nobilitierte er sich mit Alexander dem Großen, der wiederum für Napoleon steht. ${ }^{167}$

Dies zeigt sich auch in Thorvaldsens eigenem Urteil über seinen Relieffries, der seine „liebste Arbeit“ gewesen sei und „wahrscheinlich auch das Beste, was ich gemacht habe“ ${ }^{168}$ In einer sehr ähnlichen Formulierung wie diesen von Thiele überlieferten Worten versuchte der Bildhauer mit Brief vom 16. Oktober 1813 den bayerischen Kronprinzen Ludwig, ab Oktober 1825 König Ludwig I., für seinen Relieffries zu gewinnen:

Es ist nicht allein eine meiner Lieblingsarbeiten, sondern auch gewiß eine der besten, welche ich jemals verfertigt habe. Weder Eigennutz, noch irgend eine Nebenabsicht brachten mich auf diesen Gedanken, diese Arbeit für Eure königliche Hoheit zu machen. Bloß die Liebe zu meiner Kunst hatt [sic] auf eine solche Art diesen Wunsch in mir erregt, daß ich meine Arbeit selbst unentgeldlich machen will, und bloß die Kosten des Marmor und den Taglohn meiner Arbeiter Eurer königlichen Hoheit berechnen will.

Mit Gewißheit kann ich behaupten, daß seit der Zeit der Griechen und Römer keine Arbeit in Relief von dieser Ausdehnung in Marmor verfertigt worden. Den Gedanken, daß diese Arbeit in den Händen [sic] eines Fürsten komme, der Talent und Verdienst zu schätzen weiß, ist die Triebfeder meines Vorschlags, und ich darf mich schmeicheln, daß Höchstdieselben ihn genehmigen werden. [...] Mein sehnlicher Wunsch ist es, daß diese Arbeit, die bis jezt nur in den [sic] so leicht zerstörten Gips existirt, in ein dauerhaftes Material, als ein feststehendes Denkmahl meines geringen Talents übertragen werden möchte. ${ }^{169}$

Der eher bescheidene Anfangston wird durch diesen letzten Satz aufgehoben und veranschaulicht Thorvaldsens Selbstbewusstsein als Künstler. Wohl wegen des napoleonisch-

Siehe auch Wittstock 1975, 108; Gohr 1977a, 82; Calmeyer 1990, 104. Ein klarer Fehler in der Originalfassung unterlief Thorvaldsen mit der Darstellung des Flusses Tigris anstelle des Euphrat.

167 In diesem Zusammenhang sei auf Claudia Hattendorffs Untersuchung zur Napoleon-Ikonografie verwiesen, in der die Autorin feststellt, dass sich kritische Darstellungen des französischen Kaisers auf dem europäischen Festland, im Gegensatz zu England, erst nach 1812 merklich häuften; Hattendorff 2012, 9.

168 Zit. nach Thiele 1852-1856, Bd. 1, 245.

169 Bertel Thorvaldsen an Ludwig von Bayern (später Ludwig I.), 16. Oktober 1813, München, Geheimes Hausarchiv München, Nachlass König Ludwig I., Ref. I A 40 IV (Transkript im TMA). 
propagandistischen Entstehungs- und Verwendungskontextes des Alexanderzuges hatte Ludwig von Bayern kein Interesse an einer Marmorversion dieses Werks. ${ }^{170}$ Hingegen dürfte seine Bestellung eines rund 86 Meter langen Monumentalfrieses bei Johann Martin von Wagner für die in Planung befindliche Walhalla bei Regensburg direkt auf Thorvaldsens Relief zurückgehen. ${ }^{171}$ Auch in Wagners Anpreisung seines eigenen Werks diente der Alexanderzug als Referenzpunkt:

Meines Wissens ist dieses [der Walhallafries] der größte und bedeutendste Fries, welcher seit der alten Griechen und Römer Zeit bis jetzt in Marmor ist ausgeführt worden. - Der Triumphzug Alexanders von Thorwaldsen hat kaum ein Viertheil der Länge. Noch ist zu bemerken, daß ich diesen 400 Palm langen Frieß durchaus eigenhändig modelliert, ohne mir von irgend jemand auch nur im Geringsten daran arbeiten oder helfen zu lassen, so wie Thorwaldsen und Hr. Schwanthaler zu thun pflegen. ${ }^{172}$

Dass Wagner sein eigenes Werk stark idealisierte, zeigt seine Herabstufung der Dimensionen von Thorvaldsens Alexanderzug. Entgegen Wagners Ausführungen darf zudem davon ausgegangen werden, dass die Arbeit am Walhallafries ebenfalls arbeitsteilig organisiert war: Gemäß Günter Lorenz zeichnete Wagner die Entwürfe, nach denen er die Bozzetti und originalgroßen Gipsmodelle formte. ${ }^{173}$ Die Ausführung der Platten in Marmor übernahmen indessen Gehilfen, die Wagner bezeichnenderweise aus Thorvaldsens Ateliers anwarb.

\section{Mythen um die Entstehung des Alexanderzuges}

Obwohl die Arbeitsteilung in Thorvaldsens Werkstätten weithin bekannt war, wurden die Entstehungsumstände des Alexanderzuges stark mythisiert. So war Thorvaldsen laut Thiele „noch durch Fieber geschwächt“, als er den Auftrag erhielt. ${ }^{174}$ Dennoch habe er „die Arbeit mit einer solchen Kraft und Begeisterung“ angepackt, „daß dieses Kunstwerk, welches den Triumph Alexander's vorstellte, und auf den Napoleon's anspielen sollte, in der Wirklichkeit sein eigener wurde“. ${ }^{175}$ Thieles Dramatisierung erinnert an seine Erwähnung von Thorvaldsens finanziellen Nöten und melancholischen Phasen während der Schaffung der Jason-Statue, mit der ihm sozusagen aus dem Nichts der künstlerische Durch-

170

172

72

173

174 Thiele $1852-1856$, Bd. 1, 219.

175 Ebd., 219-220. In diesem Zusammenhang sei erwähnt, dass sich Napoleon offenbar gerne in der Nachfolge Alexanders des Großen sah: Zwischen 1800 und 1815 war die wohl bekannteste gemalte Darstellung des Makedonierkönigs, die 1529 von Albrecht Altdorfer geschaffene Alexanderschlacht, im Besitz des französischen Kaisers; siehe bspw. Noll 2005, 45. Altdorfers Gemälde befindet sich heute wieder in der Alten Pinakothek in München (Inv.-Nr. 688). 
bruch gelungen war. ${ }^{16}$ Gerade Thorvaldsens Hang zu Melancholie und Launenhaftigkeit spielt neben der von Thiele genannten körperlichen Schwächephase auch in den idealisierenden Berichten über die Entstehungsgeschichte des Alexanderzuges eine Rolle. Wie beispielsweise Wilhelm von Schadow in seiner autobiografischen Novelle Der moderne Vasari von 1854 mit Bezug auf jenen Relieffries erzählt, war Thorvaldsen bis zu diesem Auftrag

[g]eizig und freigiebig, faul und ungeheuer thätig, wie die Umstände es erforderten oder die Laune es ihm eingab [...]. Es war, als ob ein hungriger Löwe nach langem Schlafe erwacht und auf seine Beute stürzt; nie habe ich einen ähnlichen Grad von Aufschwung gesehen; auch gehörte seine isländische Natur dazu, um dies auszuhalten. ${ }^{177}$

Weiter verweist Schadow auf die kurze Dauer, die dem Bildhauer für die Ausführung des Alexanderzuges zur Verfügung stand. Thorvaldsens Arbeitsweise beschreibt der Autor in folgenden Worten:

\begin{abstract}
Er hatte das Modell in unglaublich kurzer Zeit gemacht und die Composition zwar sehr geistreich, aber ganz flüchtig und klein mit Bleistift gezeichnet. Auf seiner sehr großen Schieferplatte entwarf er mit dem Griffel ganz roh zwei, drei Figuren, etwa zwei Drittel Lebensgröße, warf dann die Ballen Thon an die Tafel und war regelmäßig jeden Abend mit einer solchen Gruppe fertig. Ohne weitere vorbereitende Studien, vollendete er ganz ununterbrochen das kolossale Werk. Die Gipsformer gossen bei Nacht, was er am Tage modellirt hatte und nur zwei solcher Schiefertafeln waren in Gebrauch. Solche Klarheit der Vorstellung, solche Kenntnisse, solche vollendete Meisterschaft und zugleich solche Körperkraft setzten Männer von Fach in Erstaunen, und man wird dabei unwillkürlich an Michel Angelo erinnert, welcher die Decke der Sixtina in zweiundzwanzig Monaten gemalt haben soll. ${ }^{178}$
\end{abstract}

In der Tat hatte Thorvaldsen für die Ausführung des Relieffrieses nur drei Monate Zeit, was für eine solch monumentale Schöpfung sehr wenig ist und seine Arbeit allein schon deswegen zu einer außerordentlichen Leistung macht. Die Monumentalität des Alexanderzuges wird in Ditlev Martens' 1828-1829 entstandenem Gemälde von Thorvaldsens größtem römischem Atelier inszeniert, das im dritten Teil ausführlich besprochen wird (Taf. II). Die Dimensionen und räumliche Wirkung dieses ehemaligen barberinischen Stallgebäudes wurden von Zeitgenossen mit einem Tempel und einer Kirche verglichen. ${ }^{179}$ Doch gemäß Martens' Gemälde reichte auch die gesamte Länge dieses Raumes für die Aufstellung von Thorvaldsens Relieffries nicht aus, sodass ein Teilstück noch rechts im Bild platziert werden musste.

176 Thiele $1852-1856$, Bd. 1, 83. Siehe auch Kap. I.1.

177 Von Schadow 1854, 71-72. Thorvaldsens unbeständige Arbeitsweise kommt auch in Briefen von Christian Gottlieb Schick an Caroline von Humboldt (5. Juli 1811) und von Caroline von Humboldt an Friederike Brun (12. Oktober 1818) zur Sprache; zit. bei Wittstock 1975, 342, bzw. Foerst-Crato 1975, 173.

178 Von Schadow 1854, 72.

179 Siehe dazu Kap. III.2. 
Durch die Erwähnung von Thorvaldsens kränklicher Verfassung, der kurzen Ausführungszeit des Relieffrieses und der angeblichen Arbeitsweise ohne Vorstudien wird die herausragende Leistung des Bildhauers in den Quellen ins fast Übermenschliche erhoben. ${ }^{180}$ Dies gilt umso mehr, wenn die ohnehin sehr knappe Entstehungsdauer des Alexanderzuges in manchen Überlieferungen noch verkürzt wurde, wie es in den Berichten von der Hagens sowie des Mediziners Ludwig Hermann Friedländer geschah. Letzterer schrieb in seinen 1819 - 1820 publizierten Reiseerinnerungen:

[...] sein Siegereinzug Alexanders in Babylon, dieses ungeheure, binnen acht Wochen, ohne vorherigen Entwurf einer Zeichnung, fertig modellirte Werk, ist allein eines ewigen Lorbeers würdig. Wenn von allen Kunstdenkmalen neuerer Zeit bloß dieses erhalten würde, so müßte die späte Nachwelt unsern Tagen denselben Zoll der Bewunderung darbringen, wie dem Zeitalter eines Phidias und Polyclet. ${ }^{181}$

Während Friedländer die Entstehungszeit des Alexanderzuges von den tatsächlichen drei auf zwei Monate verkürzt hat, sind es bei von der Hagen noch wenige Tage:

Seine [Thorvaldsens] erhobenen Bildwerke sind gerade seine trefflichsten, und sein Einzug Alexanders in Babylon ist wol sein größtes und bedeutendstes Werk. In wenig Tagen war es entworfen und ausgeführt. ${ }^{182}$

\section{Kopien oder verschiedene Originale?}

Das früheste Zeugnis zu Thorvaldsens Alexanderzug stammt vom Architekten Malling, der bereits am 20. März 1812 noch während der Entstehung des Werks an den dänischen Kronprinzen Christian Frederik, ab Dezember 1839 König Christian VIII., schrieb:

Eine wichtige Arbeit, die ihm von der französischen Regierung übertragen wurde, und die mit Recht ein klassisches Werk genannt werden kann, das Thorw. Ruhm vermehren wird, ihm einen noch höheren Rang als Künstler geben und sozusagen die goldene Epoche der Griechen ins gegenwärtige Zeitalter zurückrufen wird, ist ein Basrelief für das Throngemach im früheren päpstlichen, jetzt kaiserlichen Palast auf dem Monte Cavallo, [...]. Als Sujet hat Th. Alexanders triumphalen Einzug in Babylon gewählt. Th. Wert ist hinreichend bekannt und seine vortreffliche Anordnung von Basreliefs vollständig als die voll-

180 Siehe auch Wittstock 1975, $83-84$.

181 Friedländer 1820, 306. In einer Rede kurz nach Thorvaldsens Tod im März 1844 ließ Thiele schließlich sämtlichen Werken des Bildhauers die Ehre von unsterblichen Schöpfungen zukommen; Just Mathias Thiele, Rede am Stiftungstag der Kopenhagener Kunstakademie, 31. März 1844, zit. nach Thiele 1852-1856, Bd. 3, 185: „Ein halbes Jahrhundert genügte, um Hunderte von Werken hervorzubringen, von welchen jedes einzelne wiederum genügt haben würde, einen Künstler berühmt zu machen." Eine sehr ähnliche Formulierung findet sich auch bei Otto 1869, 665. Entgegen den hier zitierten, enthusiastischen Urteilen über den Alexanderzug verlief die Rezeption dieses Werks zunächst stockend, was sich mit den politischen Umständen um 1812 und dem damit einhergehenden Fehlen eines größeren internationalen Publikums erklären lässt; siehe dazu Wittstock 1975, 81 - 82 und 206-207; Springer, P. 1991, 215.

182 Von der Hagen 1818 - 1821, Bd. 2, 334. 
kommenste ihrer Art erkannt; wieviel mehr müssen seine Landsleute beklagen, falls der französische Kaiser sich alleine mit diesem chef doeuvre brüsten, alleine im Besitz des einzigen Exemplars sein sollte. ${ }^{183}$

Mit dem letzten Satz spielte Malling wohl auf den Umstand an, dass Dänemark erst kleinere Werke von Thorvaldsen besaß und damit anderen europäischen Ländern nachstand. Dies wurde noch 1817 vom Arzt Rasmus Emil Bruun beanstandet, wonach Dänemark „in seinen Werken [...] danach streben sollte, ihn [Thorvaldsen] zu besitzen“" ${ }^{184}$

Malling führte den oben zitierten Brief an den dänischen Kronprinzen mit der Anregung einer Bestellung des Alexanderzuges für die königliche Residenz auf Schloss Christiansborg fort. Dabei versuchte er Christian Frederik mit dem Argument der tieferen Kosten einer Kopie zu überzeugen: „[D] a die französische Regierung die Komposition bezahlt“, wären nur noch die Kosten für Material, Arbeit und Transport zu übernehmen. ${ }^{185}$ Bevor jedoch das dänische Königshaus die Bestellung einer Marmorversion des Alexanderzuges aufgeben konnte, erhielt Thorvaldsen am 31 . Dezember 1817 einen entsprechenden Auftrag des Grafen Sommariva. ${ }^{186}$ Dadurch fühlten sich die Dänen noch stärker unter Druck, da nun nicht mehr nur eine Gipsversion im Quirinalspalast, sondern auch eine Marmorfassung in einer italienischen Privatresidenz existieren würde. Dementsprechend bat der Autor Lauritz Kruse, der die Verhandlungen zwischen Christian Frederik und Thorvaldsen führte, den Bildhauer am 4. April 1818, dem Kronprinzen

begreiflich zu machen, [...] daß Sie die Bearbeitung des Frieses für Dänemark als das eigentliche Original, und die für Sommariva als die Copie desselben angesehen haben (weil nun doch eins diesen Namen haben soll), und daß Sie aus dem Grunde ihm denselben für einen so billigen Preis [16.000 Scudi] überlassen konnten. ${ }^{187}$

183 Peder Malling an Christian Frederik von Dänemark (später Christian VIII.), 20. März 1812, zit. nach Linvald/Fabritius 1965, 91-92: „Et vigtigt Arbeide, som er ham overdraget af den franske Regiering, og som med Rette kan kaldes et klassisk Værk, der vil forøge Thorw. Hæder, vil give ham en endnu høiere Rang som Kunstner og saa at sige kalde Grækernes gyldne Periode tilbage i den nærværende Tidsalder, er et Basrelief til Throngemakket i det forhen pavelige, nu keiserlige Palais paa Monte-Cavallo, [...]. Til Sujet har Th. valgt Alexanders Triumphindtog i Babylon. Th. Værd er noksom bekiendt og hans fortreffelige Anordning af Basreliefs tilfulde erkiendt for det fuldkomneste i sin Art; hvormeget mere maatte hans Landsmænd beklage, dersom de Franskes Keiser alene skulde bryste sig af dette chef doeuvre, alene være i Besiddelse af det eneste Exemplar.“

184 Bruun, R.E. 1817, 538 und 543 (Zitat): „I hans Værker skulde hans Fædreland stræbe at besidde ham; $[\ldots]$. “

185 Peder Malling an Christian Frederik von Dänemark (später Christian VIII.), 20. März 1812, zit. nach Linvald/Fabritius 1965, 92: „Det 2det Exemplar er naturligviis mindre bekosteligt end det første, da den franske Regiering betaler Compositionen.“

186 Giovanni Battista Sommariva an Giovanni Raimondo Torlonia, 31. Dezember 1817, KB, Ref. NKS 1557, folio (Transkript im TMA); auch Thiele 1852-1856, Bd. 1, 306.

187 Lauritz Kruse an Bertel Thorvaldsen, 4. April 1818, TMA, Ref. m5 1818, nr. 19: „[...] saa stræb at giøre ham begribeligt, [...] at De bestandig har anseet Forarbeidelsen [det] af Frisen til Dannemark, som den 
Wenige Tage später äußerte Christian Frederik selbst in einem Brief an Thorvaldsen nicht nur den Wunsch nach einem Original, sondern forderte den Bildhauer auf, „einen neuen Fries in derselben Größe zu komponieren und in Marmor auszuführen, in dessen Besitz dann Dänemark alleine kommt“. ${ }^{188}$ Schließlich ließ sich der Kronprinz von Thorvaldsen und dessen Gönner Schubart doch von einer Betrachtung des Alexanderzuges für Schloss Christiansborg als Original überzeugen und beauftragte den Bildhauer mit der Marmorausführung des Relieffrieses, die von 1822 bis 1838 dauern sollte. ${ }^{189}$ Der Fries, der das Vorzimmer des Empfangssaales von Christiansborg schmückte, wurde beim Brand des Schlosses 1884 fast vollständig zerstört. ${ }^{190}$ Die erhalten gebliebenen Stücke des Reliefs wurden schließlich in Thorvaldsens Museum überführt, wo sie sich bis heute befinden. ${ }^{191}$

Zusätzlich zum Quirinalspalast, Schloss Christiansborg und der Villa Carlotta wurde der Alexanderzug - in jeweils den Räumen angepasster Größe und zugunsten der Originalität teils leicht verändert - in Gips für das Palais Leuchtenberg in München (zerstört), die Frankfurter Familie Bethmann-Hollweg, die Villa Torlonia in Rom und den Palazzo Reale in Neapel sowie in Terrakotta für die ehemals im englischen Warwickshire gelegene Hams Hall ausgeführt. ${ }^{192}$ Darüber hinaus arbeitete Thorvaldsens langjähriger Mitarbeiter

egentlige Original, og den som Sommariva skal have, som Copien deraf. Siden dog den eene skal hedde saadan. og at De kun paa den Grund har overladt ham den for en saa billig Pris." Deutsche Übersetzung nach Thiele 1852-1856, Bd. 1, 309.

188 Christian Frederik von Dänemark (später Christian VIII.) an Bertel Thorvaldsen, 7. April 1818, TMA, Ref. m5 1818, nr. 21: „[...] at componere og udføre en nye Frise af samme Størrelse i Marmor, hvilken Danmark da ene kom til at besidde." Siehe auch Thiele 1852 - 1856, Bd. 1, 310.

189 Bertel Thorvaldsen bzw. Herman Schubart an Christian Frederik von Dänemark (später Christian VIII.), beide 9. Mai 1818, beide RA, Kongehusarkivet (Transkripte im TMA). Siehe auch Thiele 1852 - 1856, Bd. 1, 311; Springer, P. 1991, 216; Grandesso 2015, 119. Im Jahr 1831, also während der Ausführung des Alexanderzuges für Schloss Christiansborg, erwarb die dänische Königsfamilie ferner Martens' oben erwähntes Gemälde, das den monumentalen Relieffries in Thorvaldsens größtem römischem Atelier zeigt; siehe auch Thimann 2018, 79, sowie Website des Statens Museum for Kunst in Kopenhagen (https://collection.smk.dk/\#/detail/KMS196; zuletzt aufgerufen am 8. April 2020).

190 Jørnæs 1991b, 39; Grandesso 2015, 119.

191 Inv.-Nr. A831-A850.

192 Siehe bspw. Jørnæs 1989b, 46; Tesan 1998, 71; Jørnæs 2011, 76; Grandesso 2015, 119; spezifisch zu der 1920 abgerissenen Hams Hall siehe Kofoed 2015b. Der Auftraggeber des 1835/1836 ausgeführten Alexanderzuges für die Villa Torlonia war Alessandro Torlonia. Thorvaldsens Relieffries war auch hier Teil eines umfassenderen Bildprogramms im ovalen Alexandersaal, das dem Namen entsprechend ausschließlich Szenen aus dem Leben des Makedonierkönigs gewidmet war. Aufgrund der Namensgleichheit von Auftraggeber und historischer Figur diente Thorvaldsens Relieffries hier zur Gegenüberstellung der beiden Männer, wobei der römische Bankier durch seine Wohltätigkeit als der edlere der beiden erschien; zum Alexanderzug in der Villa Torlonia siehe Noll 2005, 46; auch Grandesso 2015, 119. In der Tat war der Makedonierkönig seit jeher eine zwiespältige Figur und wurde bald als Tugendbeispiel, bald als gewaltsamer Herrscher rezipiert; siehe dazu Noll 2005, 8. 
Pietro Galli ab 1822 an einer verkleinerten Marmorfassung des Alexanderzuges, die heute in Thorvaldsens Museum zu sehen ist (Taf. XIII und Abb. 12). ${ }^{193}$ Für das in Carrara gelegene Geburtshaus von Luigi Bienaimé, einem weiteren engen Mitarbeiter Thorvaldsens, entstand eine ebenfalls verkleinerte Terrakotta-Version des Relieffrieses. ${ }^{194}$ Ferner scheint ein Steinschneider namens Pistrini eine kleine Replik des Alexanderzuges in Pietre dure hergestellt zu haben, die ihrerseits als Vorlage für Kopien in Stuckmarmor gedient haben soll. ${ }^{195}$ Schließlich zierte der Alexanderzug bald nach seiner Entstehung auch diverse Objekte aus Kunsthandwerk und Populärkultur. ${ }^{196}$

Neben diesen Ausführungen von Thorvaldsens Relieffries in verschiedenen Dimensionen und Materialien wurde das Werk auch in Umrissstichen vervielfältigt. Dies geschah nebst den einleitend genannten Euvreverzeichnissen von Riepenhausen und Mori, Lahde, Carnevalini und Missirini auch durch einen Anonymus (um 1825) sowie durch Francesco Garzoli (1829), Samuel Amsler (1835) und schließlich Pietro Antonio Leone Bettelini und Domenico Marchetti (1838) als Teil von umfassenderen Stichwerken nach Thorvaldsens Schöpfungen. ${ }^{197}$ Am Beispiel der plastischen und druckgrafischen Kopien, Repliken und Reproduktionen des Alexanderzuges zeigt sich nicht nur die zentrale Rolle der großflächigen Verbreitung von Thorvaldsens Werk für seine Sichtbarkeit und den stetig wachsenden Kult um ihn, sondern auch das veränderte Verhältnis zwischen Künstler und Publikum und die damit aufs Engste verknüpfte Loslösung des Kunstwerks von seiner Ortsgebundenheit. ${ }^{198}$

\section{„der Antike ebenbürtig“}

Gerade Letzteres kommt auch in Mallings obigem Brief an den dänischen Kronprinzen deutlich zum Ausdruck, wonach Teile des Alexanderzuges zur Dekoration „verschiedener

193 Siehe auch Springer, P. 1991, 217; Tesan 1998, 71; Grandesso 2015, 119.

194 Grandesso 2015, 119.

195 Springer, P. 1991, 217.

196 Eggers 1867, 45.

197 Thorwaldson's Basrelief im Quirinal. Alexanders des Großen Einzug in Babylon, Frankfurt a. M.: Wenner, um 1825 (Allegorische Darstellungen und Grabmäler von A. Thorwaldson); Il trionfo di Alessandro. Inciso a semplici contorni da Francesco Garzoli, inventato e scolpito dal celebre artista cav. Alberto Thorwaldsen, colle illustrazioni del chiarissimo abate Misserini, Roma: Tipografia Aurelj, 1829; Alexander des Grossen Einzug in Babylon. Marmorfries im Königlich Dänischen Schloss Christiansburg. Nach Zeichnungen von Friedrich Overbeck, in Kupfer gestochen von Samuel Amsler, nebst Erläuterungen von Ludwig Schorn, München: Verlag der literarisch-artistischen Anstalt, 1835; Basreliefs von Albert Thorwaldson: 1. Alexanders des Großen Einzug in Babylon, in 18 Blättern. 2. Allegorische Darstellungen und Grabmäler, in 6 Blättern. Nebst beigefügter Erläuterung. Nach Zeichnungen von Friedrich Overbeck in Rom, in Kupfer gestochen von Pietro Bettelini und Domenico Marchetti, Frankfurt am Main: Karl Jügel, 1838.

198 Siehe auch Tesan 1998, 53. 
14__Ditlev Martens, Der Antikensaal in der Kunstakademie Kopenhagen, 1824, Öl auf Leinwand, 92,8 $\times 74,5 \mathrm{~cm}$, Kopenhagen, Thorvaldsens Museum (Inv.-Nr. B259)

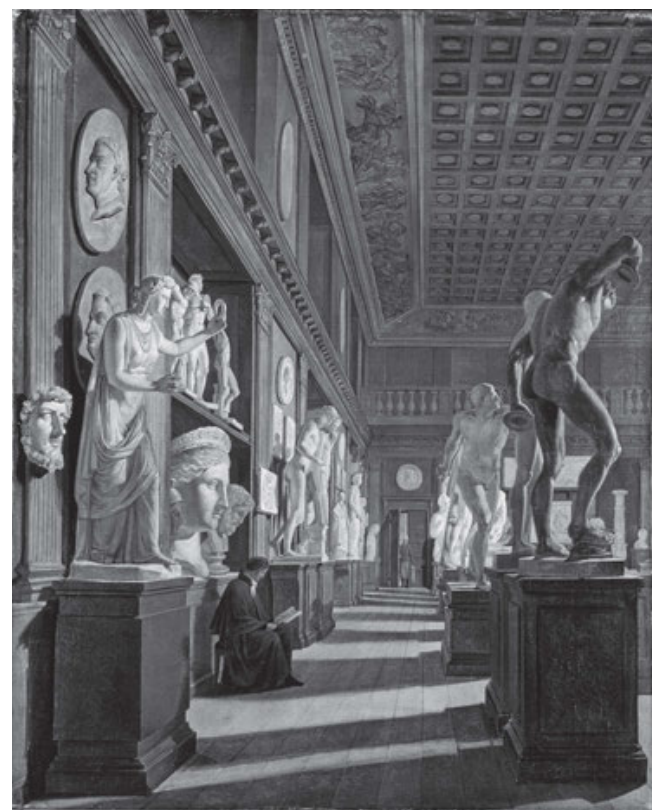

anderer Orte“ geeignet seien, „sogar als Studium der Schüler der Akademie“. ${ }^{199}$ Mit diesem Vorschlag appellierte der Architekt an Christian Frederiks Funktion innerhalb der Kopenhagener Kunstakademie, deren Präsident der Kronprinz von 1808 bis zu seiner Thronbesteigung 1839 war. ${ }^{200}$ Mallings Idee sollte mehr als ein Jahrzehnt später in Martens' Antikensaal in der Kunstakademie Kopenhagen malerisch umgesetzt werden: Wie der Bildtitel sagt, zeigt das Gemälde den großen Saal auf Schloss Charlottenborg, das seit 1754 Sitz der Königlichen Dänischen Kunstakademie ist (Abb. 14). Die stimmungsvolle Lichtführung unterstreicht die Materialität der teilweise patinierten Gipsabgüsse ebenso wie die Erhabenheit des Raumes. Zu sehen sind zuvorderst rechts im Bild etwa der tanzende Satyr aus den Florentiner Uffizien, prominent im unteren Regal die kolossale Juno Ludovisi und daneben die Metrodoros-Büste aus den Kapitolinischen Museen in Rom sowie im Bildmittelgrund rechts der freistehende Borghesische Fechter und links an der Wand die Ildefonso-Gruppe aus dem Madrider Prado. Schließlich befindet sich auf dem oberen Re-

199 Peder Malling an Christian Frederik von Dänemark (später Christian VIII.), 20. März 1812, zit. nach Linvald/Fabritius 1965, 92: „[...] som Decoration paa andre forskiellige Steder, selv som Studium for Academiets Elever."

$200 \mathrm{Zu}$ Christian Frederiks Funktion innerhalb der Kopenhagener Kunstakademie siehe bspw. http://arkivet.thorvaldsensmuseum.dk/people/kunstakademiet (zuletzt aufgerufen am 4. Dezember 2019). 
galbrett die Anatomiefigur des Dänen Andreas Weidenhaupt aus dem Jahr 1772. Der Decke entlang läuft - als fiktives Element - Thorvaldsens Alexanderzug. ${ }^{201}$

Der Antikensaal auf Schloss Charlottenborg diente in erster Linie den jungen Künstlern zum Studium. ${ }^{202}$ Mit der Integrierung des Alexanderzuges in diesen bedeutsamen Raum an der Kopenhagener Kunstakademie zeichnete Martens das Werk als der antiken Plastik ebenbürtig aus - wenn nicht gar dieser überlegen, betrachtet man die Anbringung des Relieffrieses über allen anderen Exponaten erhöht an der Decke. ${ }^{203}$ Darüber hinaus wies der Maler den Alexanderzug, gleich der genannten Anatomiefigur, als wichtige zeitgenössische Vorlage für das Kunststudium aus. Während die Akademie in Wirklichkeit keine Version des Alexanderzuges besaß, beherbergte sie seit den 1820er Jahren eine sich kontinuierlich vergrößernde Sammlung von Gipsabgüssen nach Thorvaldsens Werken: Sie wurden nicht nur auf den jährlichen Ausstellungen gezeigt, sondern dienten den Schülern als Studienobjekte. ${ }^{204}$

1828 wurde der Antikensaal umgebaut, um den ab diesem Jahr in Kopenhagen eintreffenden Gipsabgüssen nach Thorvaldsens Werken neben den Antiken einen hellen und zeitgemäßen Ausstellungskontext zu bieten. Zudem wurden ab 1833 ein Raum und der vom Antikensaal dorthin führende Korridor einzig Thorvaldsens Werken gewidmet und den Schülern der Akademie als Studienräume zur Verfügung gestellt. ${ }^{205}$ In diesen Umbauten kommt der stetig wachsende Kult um den Bildhauer deutlich zum Ausdruck. Darüber hinaus nahm bereits diese frühe Präsentation von Thorvaldsens Werken den musealen Kontext vorweg, der sich ab den späten 1830er Jahren im Bau eines eigenen Museums für den Bildhauer verwirklichen sollte. Zur Modernisierung der Skulpturgalerien auf Schloss Charlottenborg gehörte auch die Einführung von drehbaren Podien, wie sie etwa in den Gemälden von Peter Herman Rasmussen 1837 und Julius Exner 1843 zu sehen sind (Abb. 15 und 16). ${ }^{206}$ In der von Rasmussen und Exner festgehaltenen Präsentation einiger Statuen auf Drehgestellen spiegelt sich das neue, im vorangegangenen Kapitel angesprochene Verständnis der Kunstbetrachtung wider, bei dem das Interesse des Publi-

201 Zur Identifikation der dargestellten Werke siehe auch Kat. Kopenhagen 1974, 29; Kat. Köln 1977, 341; Mildenberger 1991, 195. Weidenhaupts Anatomiefigur befindet sich nach wie vor in der Kopenhagener Kunstakademie (Inv.-Nr. KS 453).

202 Kat. Kopenhagen 1974, 29; Mildenberger 1991, 195.

203 Siehe zu dieser Deutung auch Mildenberger 1991, 195.

204 Johansson 2001, 142 - 150; Miss 2008, 34; Kronberg Frederiksen 2014c. Visualisierungen des Studiums nach Thorvaldsens Werken existieren bspw. von Martinus Rørbye (1825 und 1826), Joachim Ferdinand Richardt (1839), Carl Anton Schmidt (um 1842 - 1844) sowie von einem anonymen Maler (um 1829).

205 Kronberg Frederiksen 2014c; Kronberg Frederiksen 2017.

206 Kronberg Frederiksen 2014c. Eine ähnliche Ansicht hielt auch Peter Henrik Gemzøe 1835 in einer Zeichnung fest, deren Verbleib jedoch unbekannt ist (eine Fotografie davon befindet sich im Bildarchiv von Thorvaldsens Museum). 


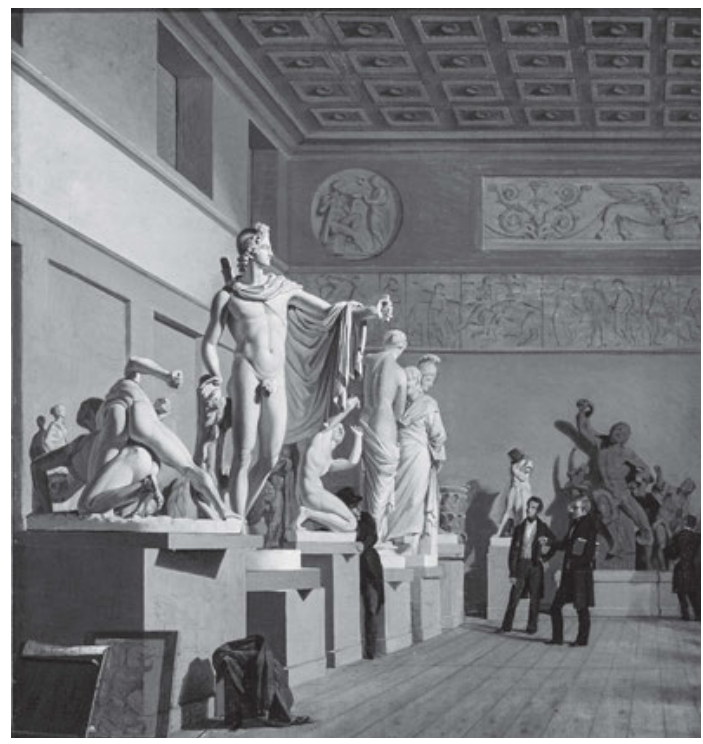

15_Peter Herman Rasmussen, Antikensaal auf Charlottenborg nach dem Umbau von 1828, 1837, Öl auf Leinwand, Maße unbekannt, Dänemark, Privatbesitz

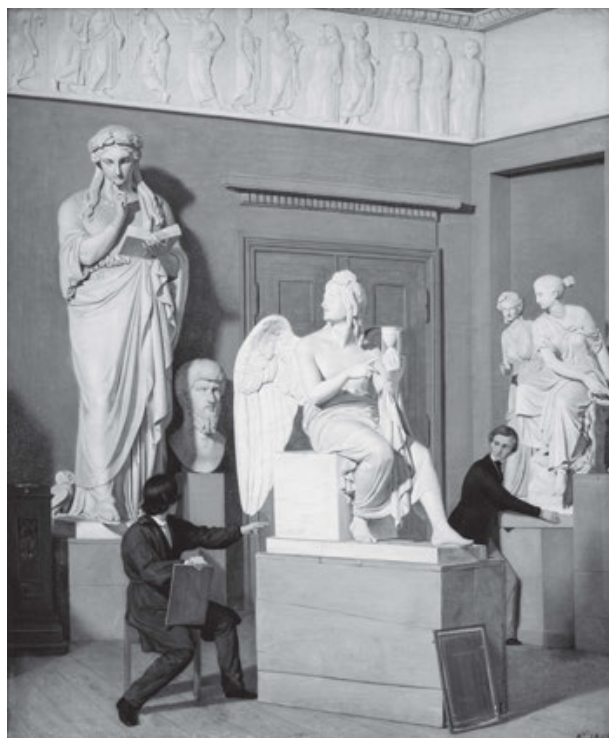

16__Julius Exner, Im Skulpturensaal der Kunstakademie, 1843, Öl auf Leinwand, $74,4 \times 63,8 \mathrm{~cm}$, Kopenhagen, Statens Museum for Kunst (Inv.-Nr. KMS3110)

kums der Skulptur in ihrer Gesamtheit galt. ${ }^{207}$ Rasmussens und Exners Darstellungen zeigen zudem nicht nur die helle Ausmalung des umgebauten Raumes, sondern auch die Integration von Werken Thorvaldsens in den Antikensaal. 1846, zwei Jahre vor der Eröffnung von Thorvaldsens Museum, wurde dessen Galerie auf Charlottenborg für das Publikum geschlossen und diente fortan als Werkstatt der Bildhauer, die nach Thorvaldsens Tod vereinzelte seiner Werke für sein Museum in Marmor ausführten. Der Antikensaal wurde in den Jahren 1880 bis 1883 schließlich in einen Festsaal umgewandelt. ${ }^{208}$

Wie Martens' Gemälde des Antikensaals auf Schloss Charlottenborg bildhaft veranschaulicht, wurde Thorvaldsens Alexanderzug bereits kurz nach seiner Entstehung als der antiken Kunst gleichwertig gepriesen. Am 15. Dezember 1812 schrieb Malling erneut an den dänischen Kronprinzen:

Überall wird dieses Basrelief bewundert als das einzige seiner Art, das seit den im Minervatempel in Athen abgebildeten Olympischen Spielen der Griechen hervorgebracht wurde, wovon Paris heute einen 
Gipsabguss nach den antiken originalen Fragmenten besitzt [= Parthenonfries]. Thorw's scheint sogar eine lebendigere Bewegung in den abwechslungsreichsten Stellungen auszudrücken. Überall ist die Anordnung des ganzen Sujets so ausgezeichnet meisterhaft, dass sie sich fühlen lässt, aber nicht beschreiben. [...] Der Gedanke ist schön, dass Dänemark einen Th. hervorbrachte, der Griechenlands Phidias und Praxiteles den Rang streitig machte und die Palme von seinem gleichzeitigen, vergötterten Canova erringt. ${ }^{209}$

Mallings Urteil über den Alexanderzug war nur der Beginn einer Flut von ähnlichen Lobpreisungen dieses Relieffrieses. So bezeichnete der Bildhauer Rauch, ein Protegé und Weggefährte Thorvaldsens, das Werk in einem Brief vom 29. September 1813 an den Archäologen Friedrich Gottlieb Welcker als „das Beste, was in neuerer Zeit in dieser Kunst hervorgebracht ist". ${ }^{210}$ Die sich von 1818 bis 1823 in Rom aufhaltende Malerin Louise Seidler nannte den Alexanderzug „der Antike ebenbürtig“. ${ }^{211}$ Und Wilhelm von Schadow betrachtete das Relief als Thorvaldsens bestes Werk, das dank den Marmorausführungen „seinen Ruhm für alle Zeiten bewahren“ werde, und dies, „obgleich er selbst wenig daran gemeißelt“. ${ }^{212}$ Mit dieser Bemerkung verwies Schadow - wie bereits Wagner im obigen Zitat - auf die arbeitsteilige Organisation in Thorvaldsens Werkstätten und zeigte damit Sinn für eine Realität, die in vielen Kommentaren zu Thorvaldsens Schaffen ausgeblendet ist. Besonders enthusiastisch reagierten ferner die Schriftsteller Franz Grillparzer und Atterbom auf den Alexanderzug: So war dieses Werk für Grillparzer „ein Basrelief, dergleichen ich kaum unter den Antiken gesehen habe. [...] was helfen die Worte, wo man kaum dem Sehen traut“.213 Laut Atterbom übertraf Thorvaldsen mit seinen Reliefs schließlich nicht nur Canova, sondern die griechische Kunst selbst. ${ }^{214}$ Gerade solche Stimmen, wonach der Alexanderzug die antike Kunst übertreffe, entfalteten eine neue Dimension in

209 Peder Malling an Christian Frederik von Dänemark (später Christian VIII.), 15. Dezember 1812, zit. nach Linvald/Fabritius 1965, 99: „Overalt beundres dette Basrelief som det eneste i sin Art, der er frembragt siden Grækernes olympiske Lege afbildet i Minervatemplet i Athen, hvoraf Paris paa nærværende Tid besidder Gibsafstøbning efter de antique originale Fragmenter. Thorw’s synes endog at udtrykke en mere levende Bevægelse i de meest afvexlende Stillinger. Overalt er Anordningen af det hele Sujet saa udmærket mesterlig, at det lader sig føle, men ikke beskrive. [...] Tanken er skiøn, at Danmark frembragte en Th., der giorde Grækenlands Phidias og Praxiteles Rangen stridig og tager Palmen fra sin samtidige forgudede Canova." Siehe auch Wittstock 1975, 318 - 319. Eine ähnliche Formulierung findet sich bei Rasmus Emil Bruun, laut dem jedoch Thorvaldsen schon seit seinem Durchbruch mit der Jason-Statue über allen anderen zeitgenössischen Künstlern stand; Bruun, R. E. 1817, 535 - 536.

210 Christian Daniel Rauch an Friedrich Gottlieb Welcker, 29. September 1813, zit. nach Haufe 1965, 196. Eine sehr ähnliche Formulierung benutzte vier Jahre später auch Caroline von Humboldt in einem Brief an Wilhelm von Humboldt, 3. Juni 1817, zit. bei Wittstock 1975, 300.

211 Erinnerungen der Malerin Louise Seidler 1922, 123.

212 Von Schadow 1854, 72. Zur Arbeitsteilung in Thorvaldsens Werkstätten siehe Kap. III.1.

213 Grillparzer 1893, 218. Siehe auch Wittstock 1975, 286.

214 Atterbom 1968, 207. Eine ähnliche Einschätzung findet sich bei Petersen 1893, o. S., der Thorvaldsens Leistung über jene von Phidias auf der Grundlage der für heutige Begriffe etwas gesuchten Ansicht er- 
der damals schon nicht mehr aktiv diskutierten, aber spürbar nachwirkenden Querelle des Anciens et des Modernes. ${ }^{215}$ Im späten Klassizismus scheint die Antike zwar als ästhetisches Vorbild allen künstlerischen Schaffens anerkannt worden zu sein, das aber idealerweise übertroffen werden sollte. Indem Thorvaldsen nun mit seinem Alexanderzug die antiken Vorbilder nicht nur erreicht, sondern überboten habe, handelt es sich bei diesem monumentalen Werk gleichsam um einen doppelten Triumph des Bildhauers. ${ }^{216}$

Nebst unzähligen Lobeshymnen gab es auch vereinzelte kritische Stimmen zu Thorvaldsens Alexanderzug. Während die hohe künstlerische Qualität dem Relieffries insgesamt nicht abgesprochen wurde, betraf die Kritik vor allem einzelne Elemente in der Darstellung. Bemängelt wurde beispielsweise die geringe Variation in den Gruppen von Reitern, die den Maler Ludwig Emil Grimm „von jeher mit Langeweile erfüllt [hat], wie denn überhaupt der bis über die Wolken erhobene Thorwaldsen mein Lieblingsbildhauer nicht ist“ ${ }^{217}$ Ein grundsätzlicher Mangel an Variation wurde auch von der Autorin Charlotte A. Eaton kritisiert. ${ }^{218}$ Für den Autor Stendhal, der zu den kritischsten Zeitgenossen zählte, war Thorvaldsens Alexanderzug indessen zu grob und zu wenig erhaben. ${ }^{219}$ D'Angers betrachtete zwar seinen dänischen Kollegen ebenfalls als einen der vorzüglichsten Reliefplastiker seit den Griechen, bemängelte jedoch zugleich die fehlende Lebendigkeit und Bewegung im Alexanderzug und setzte diese Schwächen den Qualitäten des Parthenonfrieses gegenüber. ${ }^{220}$ In Stendhals und d'Angers Vorbehalten spiegelt sich die einleitend erwähnte kritischere Haltung der französischen als speziell der skandinavischen und deutschen Zeitgenossen gegenüber Thorvaldsens Kunst wider.

\section{Thorvaldsen als neuer Phidias}

Der Autor Gustav Gardthausen fasste die Wirkung des Alexanderzuges 1844 folgendermaßen zusammen: „Das Parthenon[,] es wird zu Rom bewundert.“221 Damit verglich auch er Thorvaldsens Relieffries mit dem damals Phidias zugeschriebenen Parthenonfries. Dieses monumentale Werk war zu Beginn des 19. Jahrhunderts in Lord Elgins Auftrag zusammen mit weiteren Fragmenten der Baudekoration des Parthenons von Athen nach London überführt und 1816 ans British Museum verkauft worden. ${ }^{222}$ Die erste Präsentati-

hebt, dass sich der Ruhm des Letzteren über mehrere Jahrhunderte aufgebaut habe, während sich Thorvaldsen die Anerkennung seiner Zeitgenossen innerhalb weniger Jahrzehnte sichern konnte.

Die Querelle des Anciens et des Modernes, die sich bis zu Petrarca zurückverfolgen lässt, hatte ihren diskursiven Höhepunkt im Frankreich des 17. und 18. Jahrhunderts erreicht; Fumaroli 2001, 7.

216 Für das Gespräch hierüber danke ich Stefan Rebenich.

217 Grimm, L.E. 1911, 240 - 241.

218 Eaton 1852, 302-305.

219 Stendhal 1932, 109. Siehe auch Hartmann 1965, 5.

220 D’Angers 1856, 7 und 13-14.

221 Gardthausen 1844, 11.

222 Siehe bspw. Melcher 1999, 272 - 273. 


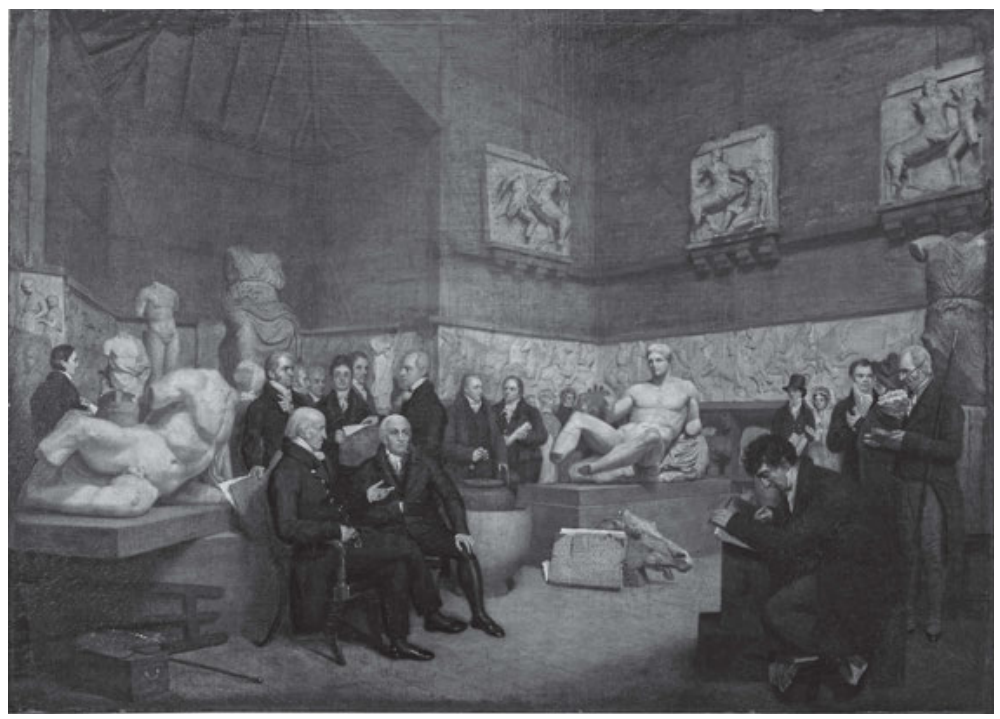

17_Archibald Archer, Der provisorische Elgin-Saal, 1819, Öl auf Leinwand, $94 \times 132,7 \mathrm{~cm}$, London, British Museum (Inv.-Nr. Painting.30)

onsweise des Parthenonfrieses ist in einem 1819 ausgeführten Gemälde von Archibald Archer gezeigt, das mit dem allen Wänden des Saals entlang laufenden Fries durchaus Ähnlichkeit hat mit Martens' Darstellung des Alexanderzuges in Thorvaldsens großem Atelier in Rom von 1828 - 1829 (Taf. II und Abb. 17). ${ }^{223}$ Die Überführung der Elgin Marbles machte nicht nur das europäische Publikum mit der Kunst der griechischen Klassik bekannt, sondern festigte die generelle Verschiebung des ästhetischen Interesses im späten Klassizismus von der hellenistischen hin zum strengeren Stil der klassischen Antike. ${ }^{224}$

Thorvaldsen kannte den Parthenonfries vermutlich aus Gipsabgüssen und Kupferstichen. ${ }^{225}$ Spezifisch für die Hauptszene um Alexander den Großen dürfte er sich zudem an der 1766 von Domenico Cunego gestochenen Reproduktion nach Gavin Hamiltons Gemälde Achilles schleift den toten Hektor hinter seinem Wagen her aus dessen sechsteiliger Serie zum Trojanischen Krieg orientiert haben. ${ }^{226}$ Doch gemäß dem Grafen Conrad Rant-

223 Im Kontext dieses Topos sei ferner Lawrence Alma-Tademas Gemälde Phidias zeigt seinen Freunden den Parthenonfries von 1868 im Birmingham Museum erwähnt; siehe dazu bspw. Prettejohn 2009.

224 Von Einem 1974, 24; Wittstock 1975, 51. Zum Klassizismus in Dänemark siehe bspw. Eckart 1868, 16 - 17; Pfundheller 1886, 218 -221; Jørnæs 1991a, 67-69; Bukdahl 2006, 62 -63; Jørnæs 2011, 18-19; Friborg 2014.

225 Lücke 1883, 58; Pfundheller 1886, 237; Hartmann 1979, 94; Jørnæs 1991b, 37; Grandesso 2015, 108 - 109.

226 Berlin, Staatliche Museen zu Berlin, Kupferstichkabinett, Inv.-Nr. 591-96. 
zau war der Alexanderzug nicht etwa aus intensivem Studium und viel Fleiß erwachsen: „Thorvaldsen hat mir oft gesagt, er wüsste selbst nicht, wie es entstanden sei, und erst da Overbeck die Zeichnungen der Figuren machte, erkannte er die Vollkommenheit seines eigenen Werkes. “227 In diesem Zitat klingt erneut die schon von Neergaard konstatierte zentrale Bedeutung von Nachzeichnungen und Umrissstichen zur Beurteilung von Kunstwerken an. ${ }^{228}$ Indem Pfundheller schließlich die Mangelhaftigkeit solcher Reproduktionen betont, die auch Thorvaldsen als Vorlagen dienten, mythisiert er dessen herausragende Leistung noch im späten 19. Jahrhundert: „Sein künstlerisches Gefühl leitete ihn allein und ließ ihn das Richtige finden. "229 Was auf den ersten Blick als reines Lob für den Dänen erscheint, kann direkt mit Phidias in Verbindung gebracht werden, der in antiken Quellen für seine phantasia gepriesen wird. Demnach habe seine Kunst nicht nur aus Nachahmung (mimesis, imitatio) bestanden; vielmehr habe er mit der Darstellung von Dingen und Erscheinungen überzeugt, die er nicht selbst gesehen habe. ${ }^{230}$ In diesem Zusammenhang erhält auch Atterboms eingangs zitierte Bezeichnung von Thorvaldsen als einem „echte[n] Sohn der Phantasie“ eine zusätzliche Bedeutungsebene, die ihn ebenfalls mit Phidias verbindet. ${ }^{231}$

Der Rückbezug auf die griechische Kunst und namentlich auf den Parthenonfries sowie dessen vermeintlichen Schöpfer Phidias zieht sich wie ein roter Faden durch die lobende wie kritische - Rezeptionsgeschichte von Thorvaldsens Alexanderzug. ${ }^{232}$ Dabei ist Phidias' Rolle bei der Schaffung der Parthenonskulpturen bis heute nicht endgültig geklärt. Einzig Plutarch nennt in seinem Perikles $(13,4)$ Phidias als Aufseher des gesamten skulpturalen Programms am Parthenon. ${ }^{233}$ Hier liest man zudem, dass die Arbeiten von zahlreichen Steinmetzen ausgeführt worden seien, was Phidias' genaue Rolle im Unklaren lässt. Obwohl der Ruhm des griechischen Bildhauers auf freistehenden Kolossalstatuen wie dem Zeus in Olympia oder der Athena Parthenos basierte, scheint Phidias im frühen 19. Jahrhundert den Künstlern und deren Publikum gleichsam als Verkörperung der Hochklassik und als Referenzfigur für jegliche plastische Schöpfung gedient zu haben. ${ }^{234}$ Dieser Rückgriff auf herausragende Künstler längst vergangener Epochen zur Würdigung

Conrad Rantzau, 14. Juli 1819, zit. nach Wittstock 1975, 329. Siehe in ähnlichem Zusammenhang auch Wittstock 1975, 85.

229 Pfundheller 1886, 237.

230 Zur antiken Phidias-Rezeption unter dem Aspekt der phantasia siehe Männlein-Robert 2003.

231 Atterbom 1820, 185: „fantasiens omedelbara son“. Deutsche Übersetzung nach Mildenberger 1991, 191, der Atterboms Brief jedoch aus einer anderen Quelle zitiert und fälschlicherweise mit dem Jahr 1811 versieht. Siehe auch Jørnæs 2011, 100, sowie die Einleitung des vorliegenden Buches.

232 Siehe auch Lücke 1883, 58; Pfundheller 1886, 237 - 239; Oppermann 1927, 88; Gohr 1977a, 82; Jørnæs 1991b, 37; Melcher 1999, 272; Kanzenbach 2007, 306; Grandesso 2015, 108 - 109.

233 Prettejohn 2009, 106.

234 Siehe bspw. ebd.; Schmälzle 2012, 105. 
zeitgenössischen Schaffens - Phidias ist dafür nur ein Beispiel - ist im größeren Kontext des romantischen Geniekults zu sehen, indem er lebende Künstler als Fortführung einer glorreichen Vergangenheit inszenierte. ${ }^{235}$

Thorvaldsen war schon seit dem Erfolg seiner Jason-Statue mit Praxiteles und Phidias verglichen worden: So nannte die Gräfin Charlotte Schimmelmann ihn bereits am 15. Dezember 1803 in einem Brief an ihren Bruder, den Baron Schubart, „unsern Praxiteles“.236 Schubart wiederum bezeichnete Thorvaldsen ab dem folgenden Jahr regelmäßig als „unseren Phidias“ (vor Phidias) oder „unseren dänischen Phidias“ (vor Danske Phidias, nostro Fidia Danese) sowie „unseren Praxiteles“ (vor Praciteles) oder „unseren dänischen Praxiteles“ (vor Danske Praxiteles). ${ }^{237}$ Und wenn Thieles Zuschreibung eines Briefes vom 10. Januar 1804 korrekt ist, sah auch die Baronin Schubart in Thorvaldsen den „Praxiteles seines Jahrhunderts“. ${ }^{238}$ Die Stilisierung Thorvaldsens zum ,neuen Phidias' scheint somit wesentlich von Schubarts Kreis ausgegangen und in der Folge von verschiedenen Zeitgenossen übernommen und weitergeführt worden zu sein. ${ }^{239}$ Besonders die enthusiastische Rezeption von Thorvaldsens Alexanderzug festigte schließlich die Benennung des Bildhauers als ,dänischer Phidias', wohingegen sich der Vergleich mit Praxiteles allmählich verlor.

Jenes Lob wies indessen wenig individuelle Prägung auf, sondern war vielmehr ein Gemeinplatz: So hatte schon Winckelmann, der um die Mitte des 18. Jahrhunderts die Kunst der griechischen Klassik als ästhetische Norm durchgesetzt hatte, Michelangelo als „Phidias neuerer Zeiten“ bezeichnet. ${ }^{240} \mathrm{Zu}$ Thorvaldsens Lebzeiten galten ferner auch dessen Lehrer Johannes Wiedewelt als ,dänischer Phidias', Canova als ,neuer Phidias` und

235 Siehe auch Graepler 2008, 33.

236 Charlotte Schimmelmann an Herman Schubart, 15. Dezember 1803, zit. nach Thiele 1852-1856, Bd. 1, 96.

237 Siehe bspw. Herman Schubart an Bertel Thorvaldsen, 2. Juli 1804, TMA, Ref. ml 1804, nr. 13; Herman Schubart an Bertel Thorvaldsen, 26. November 1804, TMA, Ref. ml 1804, nr. 22; Herman Schubart an Bertel Thorvaldsen, 28. Dezember 1804, TMA, Ref. m1 1804, nr. 24; Herman Schubart an Bertel Thorvaldsen, 1. Juli 1805, TMA, Ref. C482v; Herman Schubart an Carl Frederik Ferdinand Stanley, 30. September 1805, KB, Ref. NKS 1976, 2 (Transkript im TMA); Herman Schubart an Carl Frederik Ferdinand Stanley, 11. November 1805, KB, Ref. NKS 1976, $2^{\circ}$ (Transkript im TMA); Herman Schubart an Bertel Thorvaldsen, 18. Januar 1808, TMA, Ref. m2 1808, nr. 1; Herman Schubart an Bertel Thorvaldsen, 8. April 1811, TMA, Ref. m3 1811, nr. 11; Herman Schubart an Bertel Thorvaldsen, 27. September 1812, TMA, Ref. m26 I, nr. 93. Ähnliche Bezeichnungen sind schon früh auch vom dänischen Architekten Stanley überliefert: Carl Frederik Ferdinand Stanley an Herman Schubart, 9. Oktober 1804, KB, Ref. NKS 1976, 2० (Transkript im TMA); Carl Frederik Ferdinand Stanley an Bertel Thorvaldsen, 20. November 1804, TMA, Ref. ml 1803, nr. 18.

238 Zit. nach Thiele 1852-1856, Bd. 1, 90: „[...] il deviendra le Praxiteles de son siècle [...].“

239 So bspw. von Bernhard Severin Ingemann, 18. Februar 1819, zit. bei Wittstock 1975, 311; Jerdan 1820, 93.

240 Winckelmann 2007, 29. 
Johan Tobias Sergel als ,schwedischer Phidias. ${ }^{241}$ Es ließen sich zweifellos noch zahlreiche weitere Beispiele anführen, die die Topik des Phidias-Vergleichs bestätigen würden. Dieser Vergleich hatte zwar bereits seit der im 15. Jahrhundert erfolgten Neubewertung von Phidias als dem größten antiken Bildhauer existiert, entwickelte sich aber erst im Zusammenhang mit den Winckelmann'schen Idealen zu jener Erscheinungsform, womit die genannten Bildhauer in den Jahrzehnten um 1800 nobilitiert wurden. ${ }^{242}$ Vor diesem Hintergrund kann festgehalten werden, dass es in den Quellen zu Thorvaldsen kaum um stilistische Vergleiche zwischen seinem Alexanderzug und dem Parthenonfries geht, obwohl sich durchaus Parallelen in der Reliefbehandlung und einzelnen Bildelementen finden lassen. ${ }^{243}$ Anders jedoch als im Parthenonfries, dessen Einzelszenen größtenteils nahtlos ineinander übergehen, ist die Erzählung im Alexanderzug in sogenannte „Handlungszentren" gegliedert, was zusätzliche Unterteilungen durch Architektur oder Landschaften erübrigt hätte. ${ }^{244}$ Dennoch hat Thorvaldsen, wie erwähnt, entsprechende Elemente plastisch leicht angedeutet und damit auf den Schauplatz Babylon verwiesen.

\section{Thorvaldsen im Profil}

Unter der Palme, die den Alexanderzug abschließt, hat sich Thorvaldsen selbst hinter dem Schild eines Kämpfers stehend im Profil dargestellt (Abb. 12). Gedeutet wird dieses Selbstbildnis als Zuschauer und Augenzeuge von Alexanders Einzug oder Betrachter des eigenen Werks. ${ }^{245}$ Zweifellos trifft beides zu, denn indem Thorvaldsen auf den Umzug blickt, betrachtet er zugleich seine eigene Schöpfung. Zudem weist er sich als Teil des gezeigten Triumphzuges aus, der sowohl jener von Alexander dem Großen als auch sein eigener war. Überdies kann dieses Betrachten eines Eroberungs- und Raubzuges mit der subjektiven Erfahrung des Bildhauers in Verbindung gebracht werden: Thorvaldsen war zu einer Zeit in Rom angekommen, als in Napoleons I. Auftrag Hunderte von Kunstwerken ein-

$241 \mathrm{Zu}$ Wiedewelt als ,dänischem Phidias' siehe Wittstock 1975, 34. Winckelmanns Freund Wiedewelt hatte zusammen mit Abildgaard, die an der Kopenhagener Kunstakademie beide Thorvaldsens Lehrer waren, zu den zentralen Figuren bei der frühen Vermittlung des Klassizismus in Dänemark gehört. Zu Canova als ,neuem Phidias' siehe bspw. Carl Julius Weber, Reise in Italien in den Jahren 1807-1808, Stuttgart: Hallberger, 1844, 55, zit. nach Wittstock 1975, 365: „Thorwaldsen möchte ich noch mehr Kraft zusprechen als dem Phidias der Neuern, Canova [...]“; zu Sergel als ,schwedischem Phidias siehe Jakob Jonas Björnstål an Carl Christoffer Gjörwell, 22. Oktober 1773, zit. nach Jakob Jonas Björnståls Briefe 1781, 208: „[...] Sergel, welchen ich allzeit den schwedischen Phidias nenne [...].“

242 Diese Ehre war zuvor Polyklet zugekommen. Zu Phidias', Wiederentdeckung' in der Renaissance siehe Pfisterer 1999, bes. 63-66, 69 und 75. Interessanterweise war es mit Jacopo Bellini nicht ein Bildhauer, sondern ein Maler, der 1441 als erster Künstler als ,neuer Phidias‘ bezeichnet wurde; siehe dazu ebd., 75. Siehe auch Wittstock 1975, 88; Gohr 1977a, 82; Hartmann 1979, 93 - 97; Grandesso 2015, 114. Gohr 1977a, 82 .

245 Molbech 1841, 66 und 75; Hammerich 1876, 47; Trier 1903, 97; Oppermann 1927, 86; Calmeyer 1990, 113; Jørnæs 1991b, 40. 


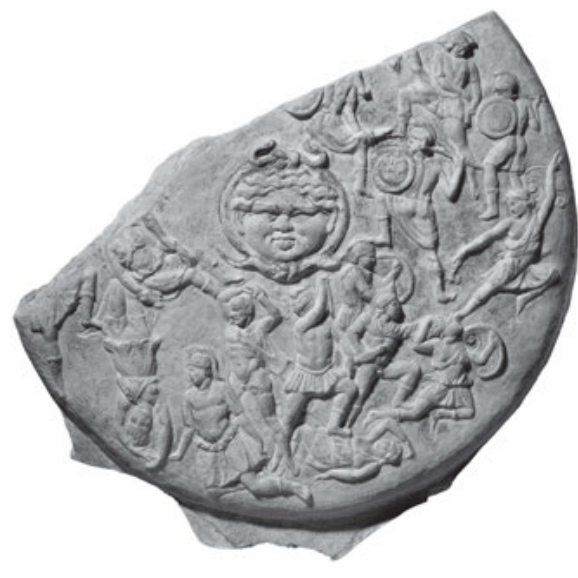

18_Phidias, Schild der Athena Parthenos (sog. Strangford Shield), römische Kopie des griechischen Originals, um 200-300 n. Chr., Marmor, 43,18 $\times 45,72 \mathrm{~cm}$, Detail, London, British Museum (Inv.-Nr. 1864,0220.18)

gepackt, aus Rom abtransportiert und nach Paris gebracht wurden. ${ }^{246}$ Nach Peter Calmeyer porträtierte sich Thorvaldsen in der Nähe des mit Spolien beladenen Elefanten und nicht in der idyllischen Flusslandschaft, da er vor Jahren den genannten Raubzug selbst miterlebt hatte. ${ }^{247}$ Brisant ist dabei jedoch, dass dieser Raubzug unter demselben Herrscher stattfand, für den später der Relieffries geschaffen wurde.

Diese Interpretationen sind zwar durchaus plausibel, greifen aber zu kurz. Außer Acht geblieben ist in der bisherigen Forschung Thorvaldsens Position in unmittelbarer Nähe zum Schild des Kriegers. Dass diese Position kaum zufällig gewählt ist, lässt ein Blick in die Geschichte des Künstlerselbstbildnisses vermuten: Phidias hatte seine eigene Gestalt in das Relief integriert, das den Schild der Athena Parthenos schmückte (Abb. 18). ${ }^{248}$ Dabei handelt es sich um eines der ältesten bekannten Selbstbildnisse überhaupt. Unabhängig vom Parthenonfries, dessen Autorschaft ungeklärt bleibt, lässt sich Thorvaldsens Alexanderzug mit Phidias folglich über den Aspekt der künstlerischen Selbstdarstellung, zusätzlich betont durch die Nähe zu einem Schild, verbinden.

Obwohl Thorvaldsen seinen Relieffries für Stern detailliert beschrieb und das Werk Ludwig von Bayern mit unmissverständlicher Selbstzufriedenheit anpries, erwähnte er sein eigenes Bildnis an keiner Stelle. Doch gerade im Kontext der celebrity-Kultur sowie von Thorvaldsens künstlerischem Selbstverständnis ist dieses Element von besonderer Signifikanz. Gemäß Braudy kann Alexander der Große als erste Berühmtheit (famous perEbd.

248 Holsten 1978, 9; Melcher 1999, 270. Die Selbstdarstellung des ägyptischen Bildhauers Ni-ankh-Ptah im Grab des Ptah-hotep in Sakkara um 2650 v. Chr. gilt als das älteste Selbstporträt überhaupt. Das zweitälteste Selbstbildnis eines mit Namen bekannten Künstlers ist Phidias' Bild auf dem Schild der Athena Parthenos. Siehe zu diesen frühen Selbstdarstellungen Goldscheider 1936, 8-11. 
son) der Geschichte betrachtet werden, die jenen gesellschaftlichen Status bewusst pflegte. ${ }^{249}$ Dies geschah mithilfe von zur Ruhmesverbreitung eingesetzten Missionaren, der Gründung mehrerer Städte namens Alexandria sowie seinem Profilporträt auf Münzen, Medaillen und Siegeln. ${ }^{250}$ Mehr noch: Alexander der Große gilt als Wegbereiter der Bildform des Profilporträts, was Thorvaldsens Selbstbildnis im Alexanderzug zusätzliches Gewicht verleiht und den Bildhauer nicht nur mit Phidias, sondern auch mit Alexander selbst verbindet. ${ }^{251}$

In dem einleitend angesprochenen Kontext der Stilisierung des Äußeren von celebrities sind gerade auch Profilporträts von zentraler Bedeutung, da sie die dargestellte Person an wenigen Merkmalen erkennen lassen. ${ }^{252}$ Eine herausragende Form von Profilporträts bilden die in der kunsthistorischen Forschung nach wie vor zu wenig beachteten Silhouetten- oder Schattenporträts in unterschiedlichen Medien, die in der Mitte des 18. Jahrhunderts in Paris als eine allen Gesellschaftsschichten zugängliche und selbst herstellbare Bildform entstanden. ${ }^{253}$ Sie spielte vor allem in der Erinnerungskultur eine wichtige Rolle, indem Schattenrisse von verstorbenen Angehörigen hergestellt und eingerahmt wurden. Parallel dazu wuchs aber auch ihre Bedeutung für die sich gleichzeitig entwickelnde celebrity-Kultur und wurde zu einer Spezialisierung innerhalb der Porträtkunst.

Der Bildtypus des Schattenporträts erreichte Dänemark in den 1780er Jahren und war besonders in der ersten Hälfte des 19. Jahrhunderts bis zur Etablierung der Bildnisfotografie eine beliebte Form des Porträtierens. ${ }^{254}$ So ist für den Silhouettisten Niels Christian Fausing bekannt, dass er in den späten 1830er Jahren mehrere Serien von Schattenporträts dänischer Berühmtheiten anfertigte und verlegte, darunter zwei Silhouettenschnitte von Thorvaldsen als ganzfigurige Abbildung und als Büste. ${ }^{255}$ Ferner besitzt Thorvaldsens frühestes Selbstbildnis von 1787 die Form eines mit Tinte gemalten Schattenporträts, und auch in späteren Jahren stellte sich der Bildhauer auf mindestens zwei weiteren Zeichnungen im Profil dar (Abb. 19-21). Die Modelle in Profilporträts, wie sie von Thorvaldsen auch in Zeichnungen, Stichen, Reliefs, Medaillen und in Wachs existieren, erscheinen los-

249 Zum Berühmtheitsstatus Alexanders des Großen und dessen Pflege siehe Braudy 1986, 32 - 51.

250 Ebd.; Greer 2008, 33.

$251 \mathrm{Zu}$ Alexander dem Großen und seiner Bedeutung für die Bildform des Profilporträts siehe Greer 2008, 33.

252 Kanz 2008, 6-7; Mole 2007, 79; Bond 2008, 86; Greer 2008, 33; Mole 2008, 68 und 73; Lilti 2014,302 und 347; McPherson 2017, 129.

253 Christensen 2010, 104.

254 Ebd., 103.

255 Ochsner 1963, 99-102; Duus 1998, 75 - 77 und 158-160; Christensen 2010, 104. Zur Zuschreibung dieser Silhouettenschnitte siehe Ochsner 1963, 112 - 115. Die Silhouettenschnitte von Thorvaldsen befinden sich in der Königlichen Bibliothek in Kopenhagen. 


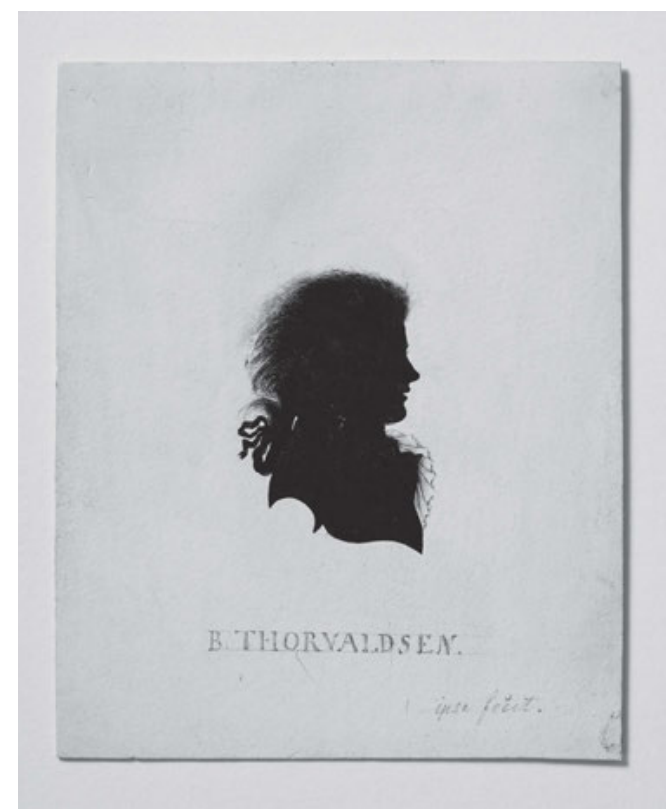

19_Bertel Thorvaldsen, Selbstbildnis (Silhouette), um 1787, Tinte auf Karton, $115 \times 94 \mathrm{~mm}$, Kopenhagen, Thorvaldsens Museum (Inv.-Nr. C758)

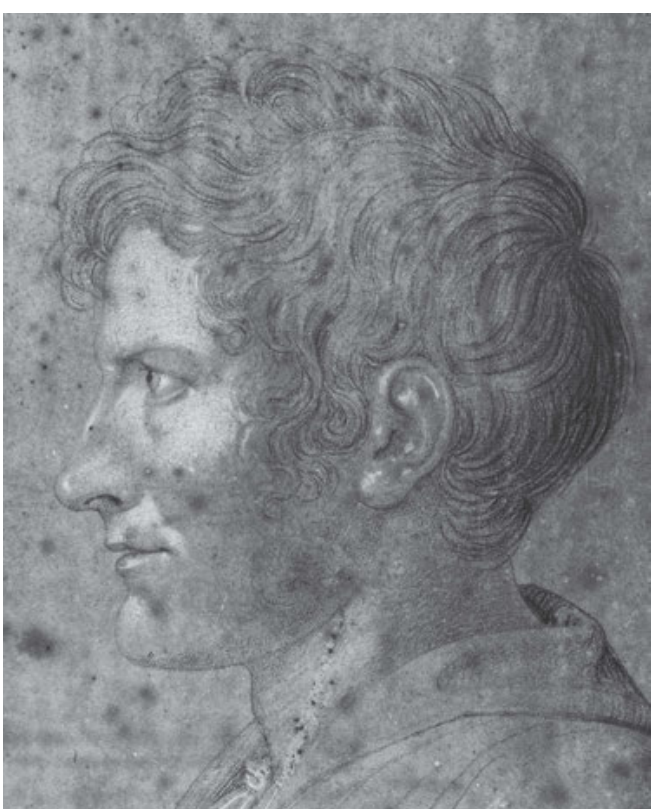

20__Bertel Thorvaldsen, Selbstbildnis, 1811, schwarze und weiße Kreide auf Papier, $275 \times 227 \mathrm{~mm}$,

Kopenhagen, Thorvaldsens Museum (Inv.-Nr. C759)

gelöst von jeglichem räumlichen und thematischen Kontext, was ihnen den Wert von Allgemeingültigkeit und Zeitlosigkeit verleiht. ${ }^{256}$

Nicht zufällig fiel die Popularität des Silhouettenporträts in dieselbe Zeit wie jene der antiken Legende von Butades und seiner Tochter als Motiv der Malerei. ${ }^{257}$ Gemäß Plinius dem Älteren hielt Butades' Tochter das Schattenbild ihres Geliebten auf einer Wand fest, woraufhin Butades jene Umrisse mit unterschiedlich gefärbtem Ton füllte und das Bildnis des jungen Mannes als Relief modellierte. ${ }^{258}$ Diese Legende galt nicht nur als Ursprung der Relief- und der Zeichenkunst, sondern darüber hinaus der polychromen Plastik und vermutlich des Profilporträts. ${ }^{259}$ Vor dem Hintergrund dieses Ursprungsmythos der Relief-

Im Zusammenhang mit Byron siehe Greer 2008, 34. Ein wohl 1813 von Giovanni Antonio Santarelli geschaffenes Wachsporträt von Thorvaldsen befindet sich in dessen Museum in Kopenhagen (Inv.-Nr. G258).

257 Christensen 2010, 105; Kanz 2008, 6. In den Jahrzehnten um 1800 wurde diese Legende in zahlreichen Gemälden dargestellt, so auch in Dänemark durch Christoffer Wilhelm Eckersberg (1811) und Heinrich Eddelien (1831).

258 Plinius 1978, 109:151.

259 Siehe auch Christensen 2010, 104. 
21__Bertel Thorvaldsen, Selbstbildnis, nach 1817, Bleistift, Feder und Tinte auf Papier, $156 \times 157 \mathrm{~mm}$, Kopenhagen, Thorvaldsens Museum (Inv.-Nr. C485)

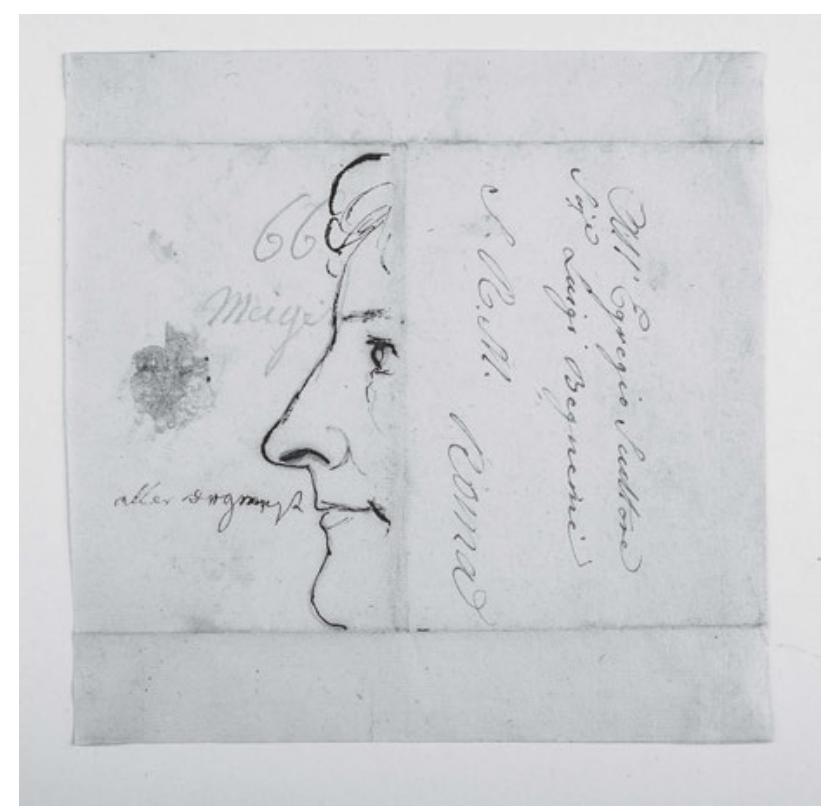

kunst handelt es sich bei Thorvaldsens Profilansicht innerhalb seines monumentalen Alexanderzuges - und dies an einem politisch so zentralen Ort wie dem Quirinalspalast in Rom - um weit mehr als ein Assistenzselbstbildnis: Es ist Thorvaldsens selbstbewusste Einschätzung des Werts seiner Kunst.

Das Selbstbildnis im Alexanderzug für den Quirinalspalast ist keineswegs ein Einzelfall in Thorvaldsens Oeuvre. ${ }^{260}$ Gerade in der zwischen 1818 und 1827 ausgeführten Marmorversion desselben Reliefs für Sommariva in der Villa Carlotta zeigt sich eine weitere Variante eines Assistenzselbstbildnisses (Abb. 22). Generell sind die Figuren in dieser Fassung des Alexanderzuges weniger gedrängt wiedergegeben, damit sie in die vom Salone d'Onore abweichenden Maße des Marmorsaales in der Villa Carlotta passten. ${ }^{261}$ Das letzte Teilstück präsentiert den Bildhauer zusammen mit dem Auftraggeber, beide in antike Gewänder gekleidet. Thorvaldsen nimmt Sommariva bei der Hand und weist mit seiner Rechten auf den Triumphzug. Durch diese Gestik scheint sich der Künstler zugleich selbst dem Siegeszug - der auch sein eigener war - anzuschließen. Es handelt sich bei diesem Teilstück um eine eigens für den Marmorsaal von Sommarivas Villa Carlotta geschaffene und offenbar vom Auftraggeber ausdrücklich gewünschte Ergänzung des Originalfrie- 


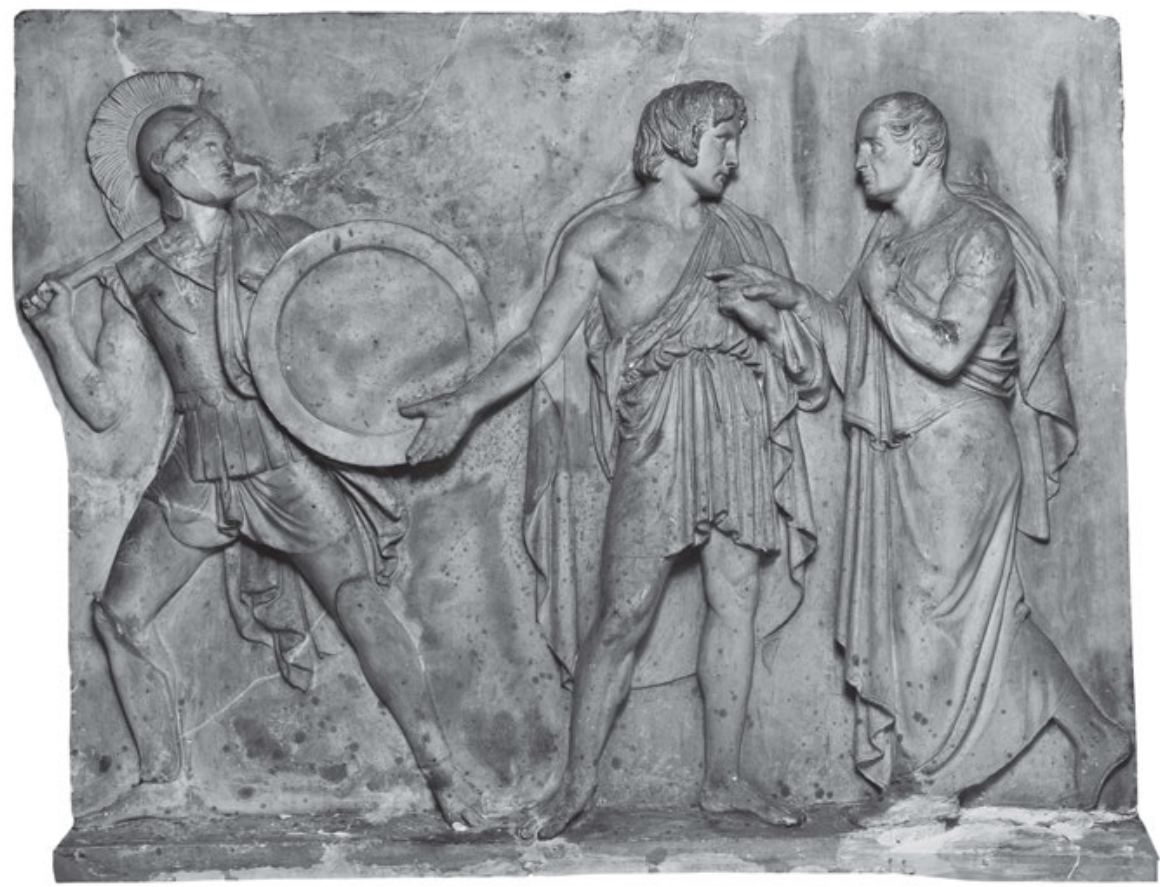

22 _Bertel Thorvaldsen, Einzug Alexanders des Großen in Babylon (Alexanderzug) für die Villa Carlotta in Tremezzo, 1818 - 1827, Gipsmodell, Detail, $103 \times 136 \mathrm{~cm}$, Kopenhagen, Thorvaldsens Museum (Inv.-Nr. A738)

ses. ${ }^{262}$ Generell können Thorvaldsens Selbstbildnisse in den verschiedenen Versionen des Alexanderzuges simultan auf zwei unterschiedlichen Wirklichkeitsebenen gelesen werden, einmal als externer Betrachter des dargestellten Triumphzuges und einmal als integraler Teil desselben.

Der Beamte Giovanni Corboli Bussi berichtet in seinen 1827 verfassten, jedoch nicht publizierten Memorie di Roma von seinem Besuch in Thorvaldsens Atelier, wo er jenes Teilstück des Alexanderzuges für Sommariva sah: „[...] und dieses stellt den Cav. Thorvaldsen in Gestalt eines schönen Jünglings dar, der sein Basrelief dem alten Grafen zeigt ${ }^{\text {"2. }}{ }^{63}$ Die Hervorhebung von Thorvaldsens Jugendlichkeit entspricht dem vom Künstler selbst ebenso wie von seinen Zeitgenossen bevorzugten Bild des damals 57-jährigen Dänen. Durch das damit kontrastierende fortgeschrittene Alter des Grafen wird diese

262 Bertel Thorvaldsen an Luigi Sommariva, 31. August 1826, TMA, Ref. gmVI, nr. 87.

263 Giovanni Corboli Bussi, Memorie di Roma, 1827 (Manuskript), zit. nach Randolfi 2010, 79: „[...] e questa rappresenta il cav. Thorvaldsen sotto le forme di un bel giovane, che accenna al vecchio Conte, il suo bassorilievo [...].“ 
Idealisierung Thorvaldsens sowohl in Corboli Bussis Bericht als auch im Relief selbst evident. Im Jahr 1832 publizierte die englische Zeitschrift The Foreign Quarterly Review eine Rezension des ein Jahr zuvor erschienenen ersten Bandes von Thieles Thorvaldsen-Biografie. Darin wird eine starke Ähnlichkeit des Selbstbildnisses im Alexanderzug für Sommariva zu Thorvaldsens realem Aussehen betont, die die anderen bei Thiele in Kupferstichen abgebildeten Selbstbildnisse des Dänen übertreffe. ${ }^{264}$ In diesem Zusammenhang ist ferner die Charakterisierung des Bildhauers durch die Künstlerin Lulu von Thürheim bemerkenswert, die im Dezember 1822 in ihr Tagebuch notierte:

Er gleicht selbst einer Statue, seine Muskeln und Formen besitzen die Starrheit und Festigkeit des Marmors. Seine Gesichtszüge, umwallt von langen, schweren Locken, sind die eines Jupiters, und sein blaßgrauer Augenstern gibt ihm den Blick einer Steinfigur. ${ }^{265}$

Ähnliche Vergleiche von Thorvaldsen mit einer Statue sind zudem von den Autoren Jacobsen und William Jerdan, vom Schiffskapitän Hans Birch Dahlerup, von den Gelehrten Heinrich Steffens und Salomon Ludwig Steinheim sowie von der Baronin Stampe bekannt. ${ }^{266}$ Diese Gleichsetzung des Bildhauers mit einem Kunstwerk ist in einer Überlieferung von Johannes Stein auf die Spitze getrieben, wonach ein Zeitgenosse zu Thorvaldsen gesagt haben soll: „Sie sehen so schön aus Herr Ritter, dass man glauben sollte[,] Sie haben Sie selbst gemacht “ ${ }^{267}$ Gerade vor dem Hintergrund des Genie- und celebrity-Kults um Thorvaldsen bringen solche Äußerungen die Konstruiertheit des öffentlichen Bildes des Künstlers klar zum Ausdruck und anerkennen zugleich dieses - und nicht etwa Thorvaldsens tatsächliche Identität oder Erscheinung - als Basis der zeitgenössischen Verehrung des Bildhauers.

Neben den verschiedenen Ausführungen des Alexanderzuges hat Thorvaldsen sein eigenes Bildnis auch in das 1836/1837 entstandene Relief Homer singt für das Volk integriert, diesmal zusammen mit jenem des Politikers Henry Labouchère, seines Zeichens Sohn des Auftraggebers des Werks, Peter Caesar Labouchère (Abb. 23). ${ }^{268}$ Schließlich be-

265 Von Thürheim 1914, 91. Siehe auch Sass 1963-1965, Bd. 1, 189.

266 Jacobsen 1820, 98: „Sein Gesicht gleicht dem Kopf einer Statue [...].“; Jerdan 1820, 94: „His head resembles that of a statue; [...].“; Heinrich Steffens an Christine Stampe, 1. Oktober 1840, KB, Ref. NKS 1732, $2^{\circ}$ : „Og han selv - er han ikke sin skiønne Statue?“; Salomon Ludwig Steinheim, Ende Oktober 1842, TMA, Ref. m30 II, nr. 78a: „Das Haupt des Künstlers gleicht selbst einer Antike, ist, wie sein übriger Körper, fast kolossal gebaut; allein in so edlen und harmonischen Verhältnissen [...].“; Dahlerup 1909, 223: „Hans hele Skikkelse [...] mindede En uvilkaarligt om de Marmorstatuer og Buster, som ere os levnede fra den græske og romerske Oldtid, forestillende Olympens Guder eller hine Tiders store Digtere, Philosopher og Talere.“; Baronesse Stampes Erindringer 1912, 252: „[...] thi han ragede frem som en Antik!“. Ein ähnlicher Vergleich mit einer antiken Statue ist auch für die Schauspielerin Sarah Siddons überliefert; McPherson 2008, 192.

267 Stein, J. 1918 - 1919, 112. Siehe auch Henschen 1989, 97.

268 Siehe auch Moltesen 1929, 260 und 486. 


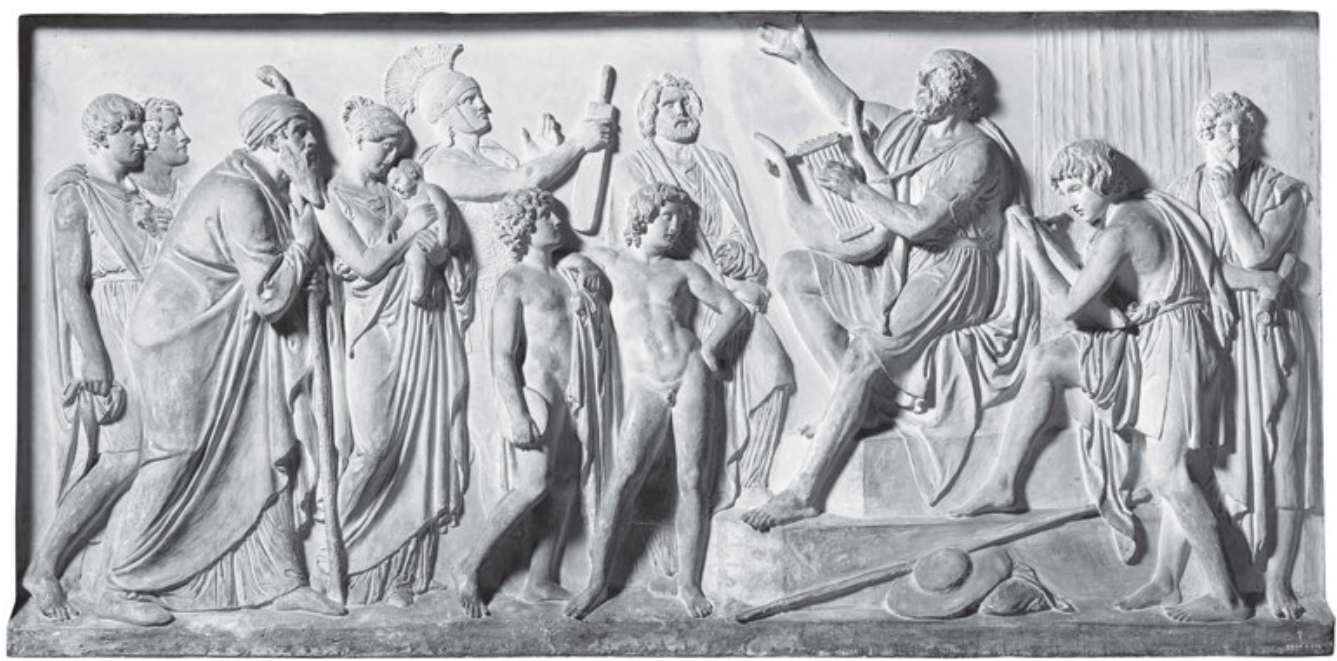

23_Bertel Thorvaldsen, Homer singt für das Volk, mit Thorvaldsens Selbstbildnis (2. v. 1.), 1836 - 1837, Gipsmodell, 97,7 × 198 cm, Kopenhagen, Thorvaldsens Museum (Inv.-Nr. A502)

richtet Andersen, dass Thorvaldsen in seinem Relief Tobias heilt seinen blinden Vater von 1828 dem jungen Tobias seine eigene Gestalt verliehen habe (Abb. 24). ${ }^{269}$ Allen genannten Assistenzselbstbildnissen ist gemein, dass sich Thorvaldsen deutlich jünger zeigte, als er es zu den jeweiligen Zeitpunkten war. Dabei handelt es sich um ein wichtiges Merkmal der celebrity-Kultur insgesamt. ${ }^{270}$ Diese Idealisierung des eigenen Bildes ist ebenso charakteristisch für Thorvaldsens eigenständige Selbstbildnisse, auf die im nächsten Kapitel eingegangen wird, wie für die gemalten Porträts des dänischen Bildhauers.

\section{Christoffer Wilhelm Eckersbergs Bild von Thorvaldsen}

In sämtlichen seiner Assistenzselbstbildnisse erscheint Thorvaldsen im Profil. Gerade vor dem Hintergrund der celebrity-Kultur und ihrer Reduzierung oder besser Stilisierung berühmter Personen auf wenige, sofort erkennbare Merkmale dürfte Thorvaldsen nicht zufällig auch in gemalten Porträts oft im Profil oder Halbprofil festgehalten worden sein. Dies ist etwa der Fall in dem oben vorgestellten Bildnis von Vogel sowie in dem sehr ähnlichen, kurz davor entstandenen Gemälde von Eckersberg, das sich als eines der bekann- 


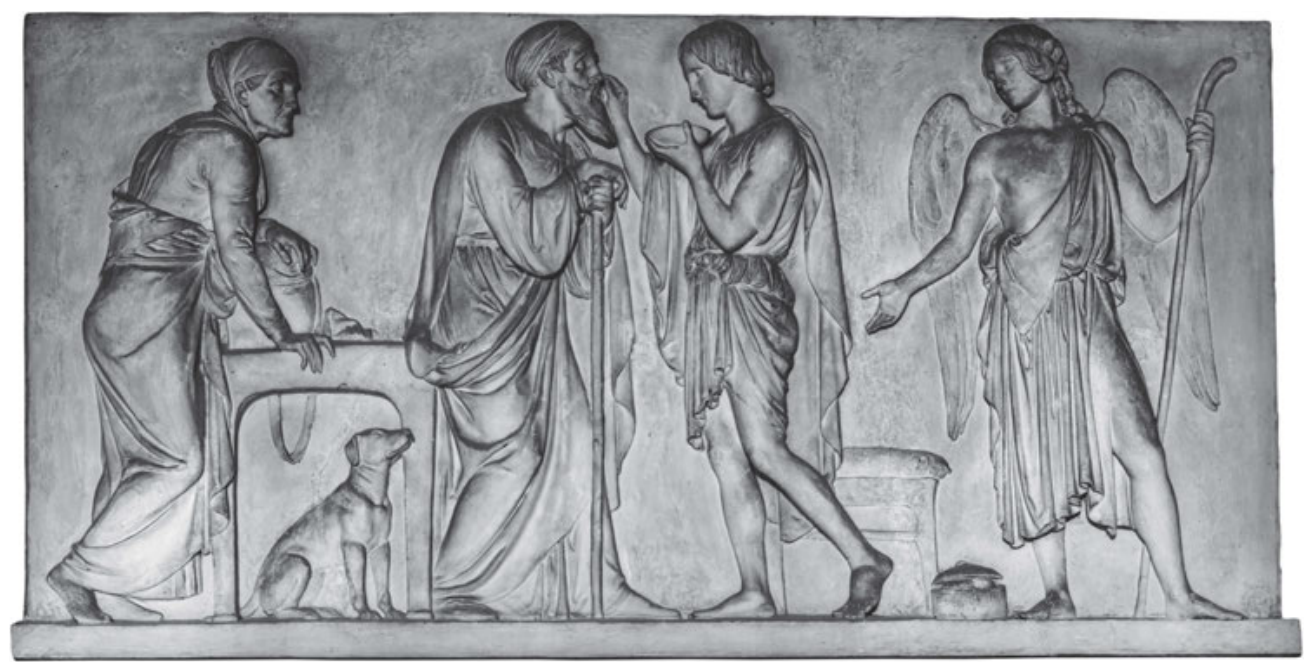

24_Bertel Thorvaldsen, Grabmal für Andrea Vaccà Berlinghieri mit dem Motiv, Tobias heilt seinen blinden Vater', mit Thorvaldsens Selbstbildnis (3. v. 1.), 1828, Gipsmodell, $103 \times 197$ cm, Kopenhagen, Thorvaldsens Museum (Inv.-Nr. A613)

testen Thorvaldsen-Porträts etablieren sollte (Taf. I und III). ${ }^{271}$ Der Bildhauer erscheint in beiden Gemälden in derselben Pose, ohne Bildhauerwerkzeuge, in die Uniform der Accademia di San Luca gekleidet und mit dem Kreuz des Dannebrog-Ordens geschmückt; bei Eckersberg wird Letzteres noch durch jenes des neapolitanischen Ritterordens ergänzt. ${ }^{272}$ Diese Aufmachung veranschaulicht Thorvaldsens bedeutende Rolle im römischen Kunstbetrieb und seine daraus erwachsene gesellschaftliche Stellung. ${ }^{273}$ Den Hintergrund bestimmt sowohl bei Vogel als auch bei Eckersberg das Schlüsselstück des Alexanderzuges. Generell kommen keine anderen Werke in zeitgenössischen Porträts von Thorvaldsen so häufig vor wie die Jason-Statue und der Alexanderzug, sei es in Kombination wie bei Vogel oder einzeln wie bei Eckersberg. Es handelt sich dabei um programmatische Bildnisse, indem Thorvaldsen mit denjenigen Werken dargestellt wurde, die seine Künstlerlaufbahn entscheidend geprägt hatten.

Bis heute ist unklar, ob Vogel sein Gemälde nach jenem von Eckersberg komponierte oder ob Thorvaldsen den beiden Malern gleichzeitig Modell saß. Für letztere Möglichkeit

271 Im Gegensatz zu Eckersbergs Gemälde wird Vogels Bildnis von Thorvaldsen in den Quellen nicht genannt; siehe dazu auch Müller, S. 1893, 119; Bramsen 1973, 11.

272 Siehe auch Christoffer Wilhelm Eckersberg an Johann Friedrich Clemens, 11. Februar 1815, zit. bei Bramsen/Ragn Jensen 1973, 76, und Kanzenbach 2007, 306.

273 Siehe auch Kanzenbach 2007, 306; Salling 2012, 166. 
spräche der leicht verschiedene Blickwinkel in den Bildnissen. ${ }^{274}$ Zudem unterscheiden sich die beiden Porträts in ihrer stimmungsmäßigen Erscheinung: Während Eckersbergs Gemälde durch die kühle Farbgebung, die Thorvaldsens klaren Blick und markante Konturen zusätzlich unterstreicht, klassizistischen Gestaltungsidealen verpflichtet ist, nähert sich Vogels Bildnis mit den dunkleren Farben, der diffusen Beleuchtung, den verwischten Konturen und dem verträumten Blick des Bildhauers der noch jungen romantischen Malerei an.

Schließlich weichen die beiden Gemälde in ihrer Hintergrundgestaltung voneinander ab: Im Gegensatz zu Vogel, der den Bildhauer vor dem auf dem Boden stehenden Mittelstück des Alexanderzuges porträtierte, platzierte Eckersberg dieses auf einem mit einem grünen Tuch bedeckten Sims. Dadurch räumte er dem Relief einen prominenteren Platz ein, machte mehr von der Figurengruppe um Alexander den Großen sichtbar und verknüpfte den triumphierenden Herrscher und die Siegesgöttin noch direkter mit Thorvaldsen. ${ }^{275}$ Von Eckersberg stammt denn auch die Betrachtung des im Relief wiedergegebenen Triumphzuges Alexanders des Großen als Thorvaldsens eigenem Triumph: Am 11. Februar 1815 berichtete der Maler in einem Brief an den Kupferstecher Johann Friedrich Clemens, er habe hinter Thorvaldsen „ein Stück seines schönen Basreliefs auf Monto [sic] Cavallo gezeigt, Alexanders Triumph, der auch Hr. Thorw. Triumph ist“.276 Diesen Vergleich wiederholte Thiele in seinen Biografien des Bildhauers, wonach „die ganze Welt sagte, dass der Künstler in diesem Werk selbst triumphiert hatte“.277

Eckersberg schenkte sein Thorvaldsen-Porträt - in einem vom Bildhauer bezahlten, vergoldeten Rahmen - kurz nach seiner Vollendung der Kopenhagener Kunstakademie. ${ }^{278}$ Dort wurde es ab August 1815 an dem zu Ehren der Krönung von Frederik VI. eröffneten Salon ausgestellt. ${ }^{279}$ Thiele berichtet, dass er als Ehrenmitglied der Kunstakademie diesen Salon zu Thorvaldsens „Verherrlichung“ benutzt habe, indem er bisherige, kaum beachtete Arbeiten von Thorvaldsen „aus dem akademischen Staube“ gezogen und erstmals zur

274 Siehe auch Müller, S. 1893, 119; Kanzenbach 2007, 306 - 307. Mildenberger 1991, 192, und Jørnæs 2011, 83 - 84, gehen hingegen von der ersten Möglichkeit aus.

275 Siehe auch Melander 1991, 297 - 298; Skjøthaug 2015b.

276 Christoffer Wilhelm Eckersberg an Johann Friedrich Clemens, 11. Februar 1815, zit. nach Bramsen/Ragn Jensen 1973, 76: „[...] bagved har jeg viist et Stykke af hans skjøne Basrelief paa Monto Cavallo, Alexanders Triumpf, som ogsaa er Hr. Thorw. Triumpf.“ Siehe auch Jørnæs 1991b, 39; Melander 1991, 297; Kanzenbach 2007, 306; Schulten 2008a, 33.

277 Thiele 1831-1850, Bd. 3, 8: „Thorvaldsen havde giort Alexanders Triumph, og hele Verden sagde, at Kunstneren i dette Værk selv havde triumpheret.“

278 Christoffer Wilhelm Eckersberg an Johann Friedrich Clemens, 11. Februar 1815, zit. bei Bramsen/Ragn Jensen 1973, 75.

279 Thiele 1852-1856, Bd. 1, 258 -259; Müller, S. 1893, 118-119; Trier 1903, 98; Bramsen 1973, 7; Bjarne Jørnæs, in: Helsted 1973, 10; Kanzenbach 2007, 245; Salling 2012, 166. Repliken dieses Gemäldes befinden sich im Nationalmuseum in Stockholm (1832; Inv.-Nr. NM 2491) und der Ny Carlsberg Glyptotek in Kopenhagen (1838; Inv.-Nr. 786). 
Ausstellung gebracht habe. ${ }^{280}$ Eine weitere Schlüsselrolle in der Bekanntmachung von Thorvaldsens Schaffen beim dänischen Publikum spielte Malling, der im selben Herbst Riepenhausens und Moris Umrissstiche nach Thorvaldsens Werken, einschließlich des Alexanderzuges, aus Rom mitbrachte. ${ }^{281}$ Schließlich bemühte sich Schubart im Hinblick auf die Charlottenborger Ausstellung 1815 um eine Präsentation des 1805-1807 modellierten Taufsteins für die Kirche Brahetrolleborg auf Fünen sowie der Zeichnungen, die Thorvaldsen ihm und seiner Frau jedes Jahr zum Geburtstag geschenkt hatte. ${ }^{282}$ Beim genannten Taufstein, der 1804 von Schubarts Schwester Charlotte Schimmelmann bei Thorvaldsen bestellt worden war, handelte es sich um einen der frühesten Aufträge aus Dänemark. Dieses Werk soll die Bewunderung des dänischen Königs erweckt haben, der nach Thiele ansonsten „kein besonderes Interesse an den Künsten“ gezeigt habe. ${ }^{283}$ Durch die Betonung des grundsätzlich geringen Interesses Frederiks VI. an der Kunst wird die Qualität von Thorvaldsens Werk zusätzlich hervorgehoben.

Eckersbergs Gemälde galt seit seiner Entstehung als eines der herausragendsten Thorvaldsen-Bildnisse. ${ }^{284}$ Bereits am 21. August 1815 schwärmte Brun in einem Brief an Caroline von Humboldt, dass sie jenem Porträt des Bildhauers „beinahe um den Hals gefallen“ wäre und dass es „das geistvoll-ähnlichste Bild ist, daß [sic] ich je gesehn!“285 Am 2. Dezember desselben Jahres lobte auch Brøndsted die Lebensnähe von Eckersbergs Gemälde in einem Brief an Thorvaldsen:

Mein Gott! Wie ist doch dein Porträt von Eckardsberg ganz vortrefflich. Die Wahrheit, womit Deine Persönlichkeit und Deine individuelle Manier in diesem Porträt gegeben sind, muss überraschen, muss in Erstaunen setzen jeden, der Dich kennt; mich rührte sie gehörig. ${ }^{286}$

Thiele 1852-1856, Bd. 1, 258-259.

281 Ebd., 259. Bei Thiele ist die Rede von einer neuen Auflage von Riepenhausens und Moris Stichwerk. Da dieses jedoch nachweislich frühestens 1817 neuaufgelegt und ergänzt wurde (Riepenhausen/Riepenhausen/Mori 1811b), dürfte Malling vielmehr die Erstausgabe jenes Stichwerks (Riepenhausen/Riepenhausen/Mori 181la) sowie einen separaten Kupferstich nach Thorvaldsens Alexanderzug mit sich nach Kopenhagen gebracht haben.

282 Thiele 1852-1856, Bd. 1, 259. Das originalgroße Gipsmodell des Taufsteins befindet sich in Thorvaldsens Museum in Kopenhagen (Inv.-Nr. A555). Ebd. Siehe auch Müller, S. 1893, 122.

284 Eugène Plon und Sigurd Müller sehen in Eckersbergs Gemälde eines der wirklichkeitsgetreusten aller Thorvaldsen-Porträts, und Sigurd Trier hält das Werk gar für das beste dänische Porträt überhaupt; Plon 1867, 50 - 51; Müller, S. 1893, 118; Trier 1903, 98.

285 Friederike Brun an Caroline von Humboldt, 21. August 1815, zit. nach Foerst-Crato 1975, 134.

286 Peter Oluf Brøndsted an Bertel Thorvaldsen, 2. Dezember 1815, TMA, Ref. m4 1815, nr. 18: „Min Gud! hvad er da dit Portrait af Eckardsberg ganske fortreffeligt. Den Sandhed hvormed Din Personlighed og individuelle Maneer er givet i dette Portrait maa overraske maa forbause enhver som kjender Dig; mig rørte den ordentlig." 


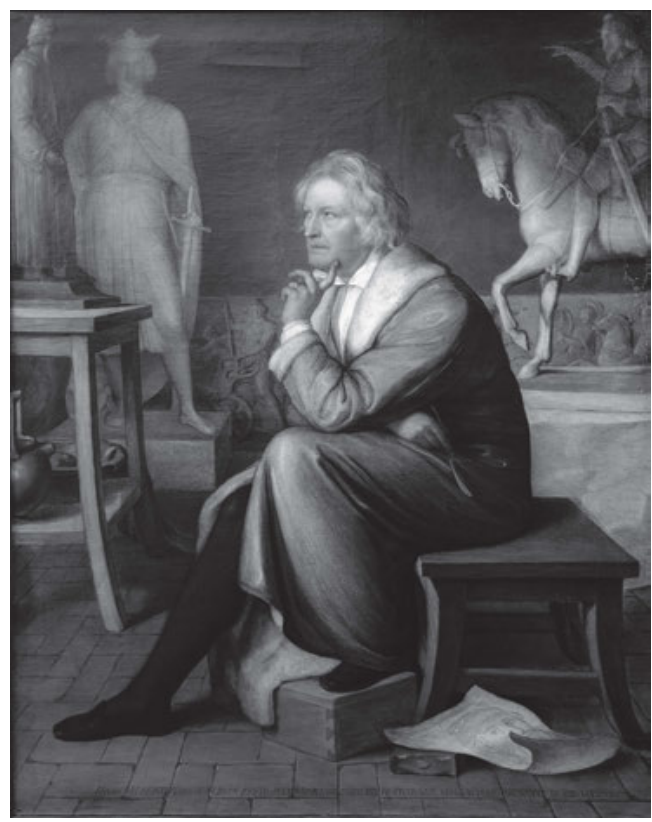

25_Eduard von Heuss, Bertel Thorvaldsen in seinem römischen Atelier, 1834, Öl auf Leinwand, $191 \times 152 \mathrm{~cm}$, Mainz, Landesmuseum (Inv.-Nr. 27)

Nur drei Tage später schrieb Schubart an den Bildhauer:

[...] und Ihr Porträt, so vortrefflich gemalt von Eckersberg, ist uns allen umso lieber gewesen, da es die frappanteste Ähnlichkeit mit dem vorzüglichsten Pinsel vereint. Ich gestehe aufrichtig, nie ein so vollkommenes Porträtgemälde gesehen zu haben $[\ldots]{ }^{287}$

Doch nicht nur wegen seiner malerischen Qualität und der von Zeitgenossen gepriesenen Ähnlichkeit zum Modell besitzt Eckersbergs Gemälde in der dänischen Kunstgeschichte einen wichtigen Stellenwert; vielmehr machte es zusammen mit der Ausstellung in der Kopenhagener Kunstakademie das breitere dänische Publikum erst auf Thorvaldsen und dessen Schaffen aufmerksam. ${ }^{288}$ „Alle Nationen kennen ihn“, hatte etwa Neergaard 1814 geschrieben, „alle wünschten, daß er zu ihnen gehörte, nur wir wissen zuweilen nicht, daß er unser Landsmann ist. ${ }^{\text {“289 }}$ Folglich scheint Eckersberg mit seinem Porträt wesentlich zur Konstruktion und Festigung von Thorvaldsens öffentlichem Bild und seinem Status als Berühmtheit beigetragen zu haben.

287 Herman Schubart an Bertel Thorvaldsen, 5. Dezember 1815, TMA, Ref. m4 1815, nr. 19: „[...] og Deres Portrait saa fortreffelig malet af Eckersberg har været os alle desto kiere, saasom det foreener den frapanteste Ligning med den fortrinligste Pensel. Jeg tilstaaer oprigtig, aldrig at have seet et saa fuldkomment Portrait Malerie, og jeg beder Dem indstændig min kiere Ven at meddeele den gode Eckersberg min Tanker [...] som ere saa fuldkommen eenstemige med Almeenmeeningen i vort kiere Fædreneland.“ Siehe bspw. Thiele 1852 - 1856, Bd. 1, 158; Müller, S. 1893, 121.

289 Neergaard 1814, 568. 


\section{Wem gehört Thorvaldsen?}

Im Zusammenhang mit der celebrity-Kultur ist außerdem Eduard von Heuss' 1834 gemaltes Porträt von Thorvaldsen sprechend, das an dieser Stelle genauer betrachtet werden soll. ${ }^{290}$ Heuss stellte den Bildhauer in seinem Atelier dar, wie er in Gedanken versunken seinen linken Zeigefinger ans Kinn legt (Abb. 25). Den Hintergrund des Gemäldes bestimmen Modelle von mehreren Werken Thorvaldsens: Neben dem der Rückwand des Raumes entlanglaufenden Alexanderzug sind das Tonmodell des Mainzer Gutenberg-Monuments (1833 - 1834) sowie die Gipsmodelle der Konradin-Statue (1833) und des Reiterstandbildes Maximilians I. von Bayern (1830-1835) zu sehen. Der Alexanderzug dürfte hier als das Hauptwerk des dänischen Bildhauers wiedergegeben sein, denn er hebt sich bezüglich der Datierung und des Motivs von den anderen drei Werken ab. Bei letzterer Gruppe handelt es sich nämlich um aktuelle Schöpfungen des Bildhauers, die allesamt deutschen Themen gewidmet sind. ${ }^{291}$

Zusätzlich zum Tonmodell der Gutenberg-Statue ist dieses Monument in Heuss' Gemälde auch auf der neben Thorvaldsen liegenden Zeichnung abgebildet. Es war Heuss, der während seines Romaufenthalts in den frühen 1830er Jahren im Auftrag des Großherzogs Ludwig I. von Hessen-Darmstadt bei Thorvaldsen jenes Denkmal für den wohl bekanntesten Sohn der Stadt Mainz bestellt hatte. ${ }^{292}$ Dadurch, dass die Zeichnung auf einem Hammer liegt, könnte sie zugleich auf die zentrale Rolle des disegno für alle bildenden Künste hindeuten. ${ }^{293}$ Drei Jahre nach der Entstehung des Thorvaldsen-Porträts konnte Heuss schließlich dem dänischen Bildhauer die Mainzer Ehrenbürgerschaft übersenden. ${ }^{294}$

In Heuss' Gemälde wird Thorvaldsen unmissverständlich als germanischer Künstler inszeniert, was er als Däne ja auch war. ${ }^{295}$ Die Beanspruchung und Bedeutung des Bildhauers spezifisch für das deutsche Selbstverständnis sowie seine Stilisierung zum deutschen Landsmann war ein verbreitetes Phänomen nach seinem künstlerischen Durchbruch mit der Jason-Statue 1803. Davon zeugen nebst Heuss' Porträt weitere Bild- sowie diverse Schriftquellen. Dieses Phänomen, das sich ferner in einer germanisierten Schreibweise von Thorvaldsens Namen (Thorwaldsen) manifestierte, lässt sich zum einen mit dem Status des Bildhauers als internationaler Berühmtheit erklären, von dem viele Zeitgenossen profitieren wollten. ${ }^{296}$ Zum anderen muss aber gerade mit Blick auf Deutschland beachtet werden, dass sich die Grenzen zu Dänemark bis 1920 mehrfach verschoben und die beiden Länder einen engen kulturellen und ökonomischen Austausch pfleg-

Bluncks und Hess' Gemälde werden in den Kapiteln II.1 bzw. III.1 nochmals erwähnt.

Siehe auch Kat. Nürnberg/Schleswig 1991, 534; Mildenberger 1991, 193.

Eduard von Heuss an Bertel Thorvaldsen, 20. August 1832, TMA, Ref. ml7 1832, nr. 76; Kat. Nürnberg/ Schleswig 1991, 534.

Siehe auch Kanzenbach 2007, 183.

TMA, Ref. m21 1837, nr. 37.

Siehe auch Kat. Nürnberg/Schleswig 1991, 534.

Siehe zu dieser Schreibweise auch Hartmann 1956, 76; „Alberto eller Bertel“ 2008. 
ten. ${ }^{297}$ Außerdem bestand Kopenhagen während Thorvaldsens Lebzeiten zu rund einem Drittel aus Deutschen, die sich in Form von eigenen Schulen, Kirchen und Medien wiederum stark untereinander organisierten. ${ }^{298}$

Bereits im Sommer 1805 erklärte der Philologe August Wilhelm Schlegel in einem Brief an Goethe, dass sich ihre deutschen Landsleute den jungen Thorvaldsen „gewissermaßen zueignen dürfen, da er, wiewohl eine Däne von Geburt, wie ein Deutscher unsere Sprache redet, und ganz deutsche Bildung besitzt“.299 Letztere Annahme vertritt fälschlicherweise auch die Schriftstellerin de Staël in ihrem erstmals 1813 erschienenen Buch De l'Allemagne. ${ }^{300}$ Die starke Verehrung von Thorvaldsen in Deutschland spiegelt sich auch in den Festlichkeiten wider, die zu Ehren des Bildhauers während dessen Reise von Rom nach Kopenhagen im Sommer 1819 in jeder größeren deutschen Stadt veranstaltet wurden. ${ }^{301}$ Wenige Jahre später wies der Landschaftsmaler Ferdinand Olivier in seiner Lithografie Stammbaum der neudeutschen Kunst von 1823 Thorvaldsen explizit Vorbildcharakter für die deutschen Künstler zu (Abb. 26). ${ }^{302}$

Einen besonderen Stellenwert verlieh schließlich Athanasius von Raczynski dem dänischen Bildhauer in seiner 1836-1841 in drei Bänden erschienenen Geschichte der neueren deutschen Kunst. Das 1836 von Wilhelm von Kaulbach gezeichnete und zwei Jahre später von Heinrich Lödel in Kupfer gestochene Frontispiz des zweiten Bandes zeigt Thorvaldsen zusammen mit drei deutschen Künstlern (Abb. 27). Er verkörpert dabei die Bildhauerei, während Peter Cornelius für die Fresko- und Wilhelm Schirmer für die Ölmalerei sowie Karl Friedrich Schinkel für die Architektur stehen. ${ }^{303}$ Neben Letzterem ist Thorvaldsen dargestellt, die rechte Hand auf dem Modell seiner Jason-Statue ruhend. Diese Darstellung nahm Kaulbach in seinem Freskenzyklus von 1850 - 1854 nochmals auf, der

Siehe bspw. Winge 2001, bes. 58 (Landkarte) und 63; Kofoed 2009b. Infolge einer Volksabstimmung fiel 1920 ein Teil von Nordschleswig an Dänemark; seither sind die Grenzen zwischen den beiden Ländern gleichgeblieben.

298 Kofoed 2009b.

299 August Wilhelm Schlegel an Johann Wolfgang von Goethe, Sommer 1805, TMA, Ref. Småtryk 1805, A. W. Schlegel (dieser Brief wurde erstmals im Intelligenzblatt der Jenaischen Allgemeinen Literatur-Zeitung, 23. - 28. Oktober 1805, publiziert; daraus zit. auch bei Wittstock 1975, 343).

300 De Staël 1844, 410; siehe auch „ART. IX“ 1832, 210; Wittstock 1975, 79.

301 Die am 14. Juli 1819 angetretene Reise von Rom nach Kopenhagen führte auf dem Landweg über Siena, Florenz, Bologna, Parma, Mailand, Luzern, Zürich, Schaffhausen, Stuttgart, Heidelberg, Darmstadt, Frankfurt a. M., Mainz, Bonn, Köln, Hamburg/Altona und Schleswig nach Kopenhagen, wo Thorvaldsen am 3. Oktober 1819 eintraf. Siehe dazu ausführlich Thiele 1852 -1856, Bd. 1, 4-11.

302 Siehe dazu auch Kat. Nürnberg/Schleswig 1991, 429. Im selben Jahr zeichnete Hieronymus Hess die Deutsche Künstlergesellschaft in Rom (München, Stadtmuseum, Inv.-Nr. VII a/407) in einem Innenraum, dessen Wand Bildnisse von bewunderten Künstlern aus Vergangenheit und Gegenwart schmücken, darunter auch eines von Thorvaldsen; siehe dazu bspw. Kat. Nürnberg/Schleswig 1991, $422-423$.

303 Siehe auch ebd., 537; Kanzenbach 2007, 28, Anm. 51. Kaulbachs Originalzeichnung von 1836 befindet sich im Nationalmuseum Posen. 


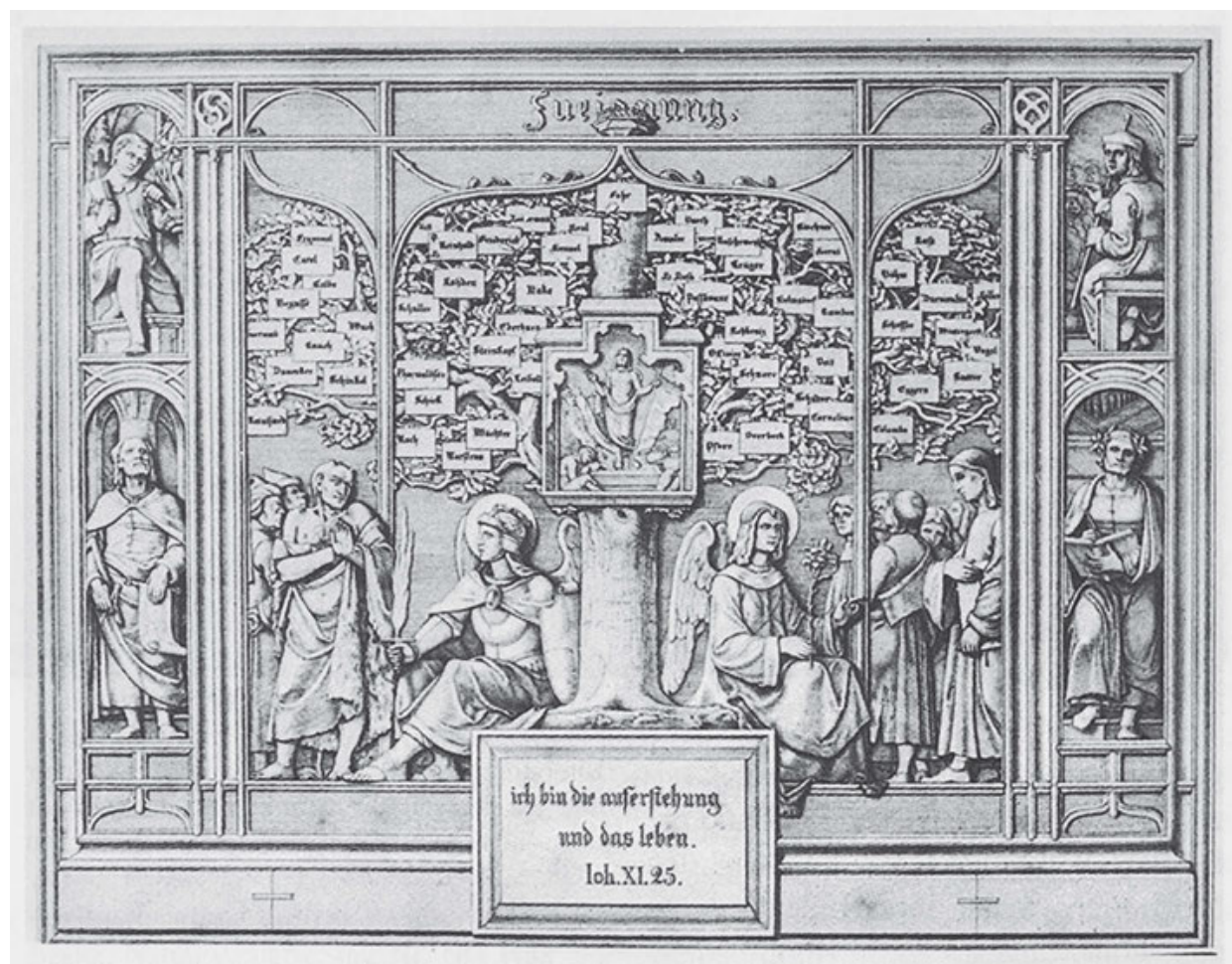

26_Ferdinand Olivier, Stammbaum der neudeutschen Kunst, 1823, Lithografie, $278 \times 355 \mathrm{~mm}$, München, Staatliche Graphische Sammlung (Inv.-Nr. 66926)

die im Zweiten Weltkrieg zerstörte Außenfassade der Neuen Pinakothek in München schmückte. ${ }^{304}$ Thorvaldsen erschien hier ebenfalls auf ein kleines Modell des Jason gestützt, jedoch neben dem Architekten Leo von Klenze statt neben Schinkel stehend. In einem anderen Bildfeld im selben Fries war Thorvaldsen als einer der für Ludwig I. von Bayern arbeitenden Bildhauer dargestellt. Thorvaldsens Bedeutung für die deutsche Kunst und Kunstgeschichte wurde folglich noch in der zweiten Hälfte des 19. Jahrhunderts untermalt. ${ }^{305}$

304 Die Gemälde, die diesem Freskenzyklus zugrunde lagen, befinden sich in der Neuen Pinakothek in München (Inv.-Nr. WAF 406 - WAF 424, Thorvaldsen ist auf den Gemälden WAF 412 und WAF 420 abgebildet). Der ursprüngliche Fassadenschmuck der Neuen Pinakothek mit Kaulbachs Fries erinnert stark an den kurz zuvor von Jørgen Sonne ausgeführten Fries an Thorvaldsens Museum in Kopenhagen, der im Kap. IV.2 besprochen wird.

305 So bspw. bei Eckart 1868, 17; Händler 1876, IX; Lücke 1883, 47; von Binzer 1894, 353; Grimm, H. 1897, Sp. $8827-828$. 


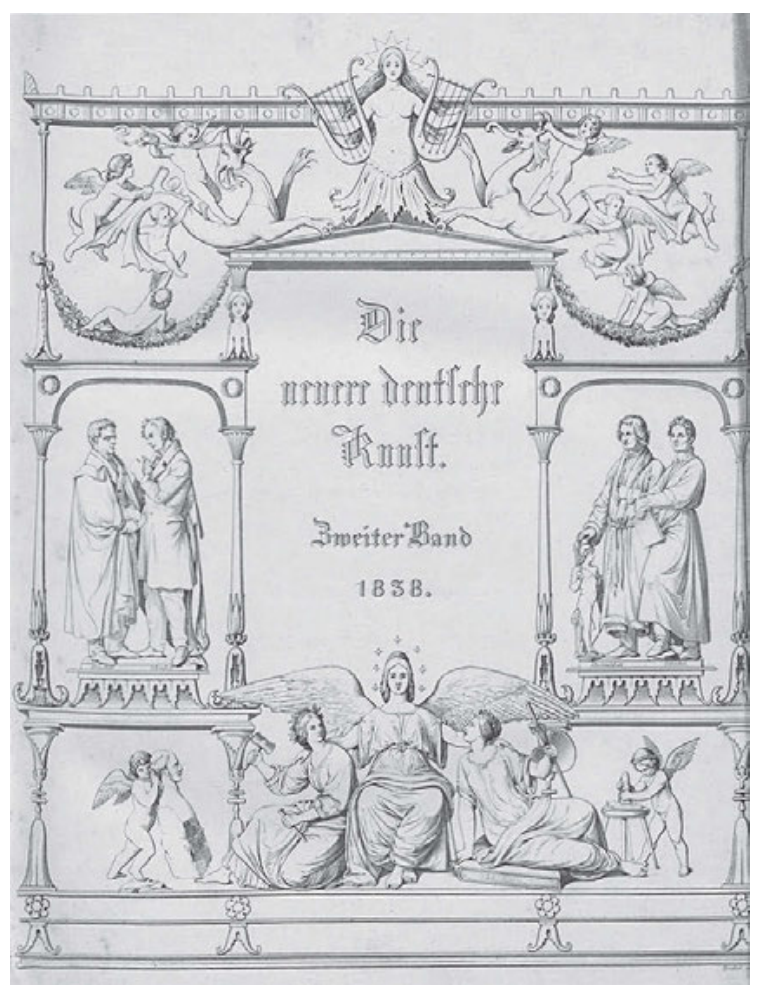

27 Wilhelm von Kaulbach, Die neuere deutsche Kunst, 1836, Zeichnung, Kupferstich von Heinrich Lödel 1838, in: von Raczynski 1836 - 1841, Bd. 2, Frontispiz

Mit der Wiedergabe von Thorvaldsen auf dem Titelblatt seines Buches machte Raczynski den Dänen zu einem Aushängeschild der deutschen Kunst. Dies begründet der Autor im dritten Band in einem ausführlichen Kapitel über Thorvaldsen damit, dass der „Genius [...] größer [ist], als das Land, das ihn gebar“ und sein Name „in der Geschichte unsrer Kunst [...] unauslöschlich prangen“ werde. ${ }^{306}$ Die Betrachtung von Thorvaldsen als nicht einer Nation, sondern der ganzen Welt angehörend und für die ganze Welt lebend, äußerten auch andere Zeitgenossen. ${ }^{307}$ Sie kann als eine Fortführung der von Carstens 1796 thematisierten Problematik der Besitzergreifung von Künstlern durch Institutionen verstanden werden, wonach er selbst „nicht der Berliner Akademie, sondern der Menschheit angehöre“. ${ }^{308}$ In diesem Zusammenhang ist schließlich ein von Felix von Schiller ver-

306 Von Raczynski 1836 - 1841, Bd. 3, 270.

307 Siehe bspw. Bruun, R. E. 1817, 543; Jacobsen 1820, 97; „Thorwaldsen“, Allgemeine Zeitung, 68/69, 7. Februar $1838,31$.

308 Asmus Jacob Carstens an die Königliche Akademie der bildenden Künste und mechanischen Wissenschaften zu Berlin, 20. Februar 1796, zit. nach Bencard 2009. Siehe bspw. auch Conti 1998, 214; Maaz $2008,17$. 
fasstes Theaterstück zu Ehren Thorvaldsens beachtenswert, das anlässlich von dessen Besuch in München im Sommer 1841 aufgeführt wurde. Es ging dabei um die Frage, welcher Stadt beziehungsweise welchem Land der berühmte Bildhauer angehöre:

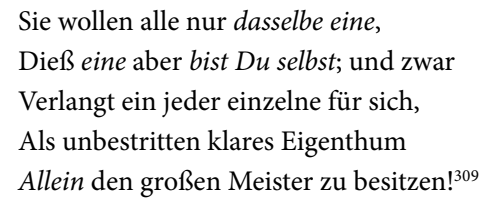

Mit diesem Anspruch traten in Schillers Theaterstück Mainz, Stuttgart, Kopenhagen, die Vereinigten Staaten von Amerika, München und Rom als „Kläger“ vor die „Richter“ Zeus und Juno, während Merkur die Debatte leitete. Gemäß Juno sei Thorvaldsen des „Olympus unsterblicher Sohn“, denn

\footnotetext{
Wissen sie nicht, daß Du all' meine Söhne

Mit der Wahrheit durchdringenden Macht

Nachgebildet in strahlender Schöne,

Wie's noch kein Sterblicher jemals vollbracht? ${ }^{310}$
}

Das letzte Urteil des Zeus, der sich als Thorvaldsens Vater betrachtete und dadurch den Bildhauer ähnlich vergöttlichte wie Juno, ist gerade im größeren Kontext der celebrity-Kultur bezeichnend: Nicht nur betont es den auch im celebrity-Kult verbreiteten Topos der ewigen Jugend („Ein Jüngling noch im vollen Silberhaar“), sondern schließt mit dem Vers:

\footnotetext{
Nein, dieser Mann gehört nicht einem Lande,

Nicht einer Stadt allein gehört er an.

Denn er umfaßt mit seines Geistes Bande

Die ganze Welt, nur ihr, der Welt, gehört er an! ${ }^{311}$
}

Die hier verarbeiteten nationalen Besitzansprüche gegenüber Thorvaldsen einerseits und die Anerkennung des Bildhauers als der ganzen Welt zugehörig andererseits veranschaulichen nicht nur den Kult um den dänischen Künstler, sondern besonders den die celebrityKultur des frühen 19. Jahrhunderts durchdringenden Widerspruch zwischen Nationalität und Internationalität. ${ }^{312}$

Felix von Schiller, „Schiedsrichterliches Urtheil des alten Vater Zeus in Sachen Stuttgart, Mainz \& Consorten wider Ritter Thorwaldsen“, Theaterstück, aufgeführt in München am 19. Juli 1841, TMA, Ref. M18,15 (Thorvaldsens Museums Småtryk-Samling 1841) (Hervorhebungen im Original).

310 Ebd. (Hervorhebungen im Original).

311 Ebd. (Hervorhebungen im Original). Auf Schillers Theaterstück wird auch bei Thiele 1831-1850, Bd. 4, 152, und Thiele $1852-1856$, Bd. 3, 122, verwiesen.

312 Siehe dazu bspw. Mole 2009, 7. 


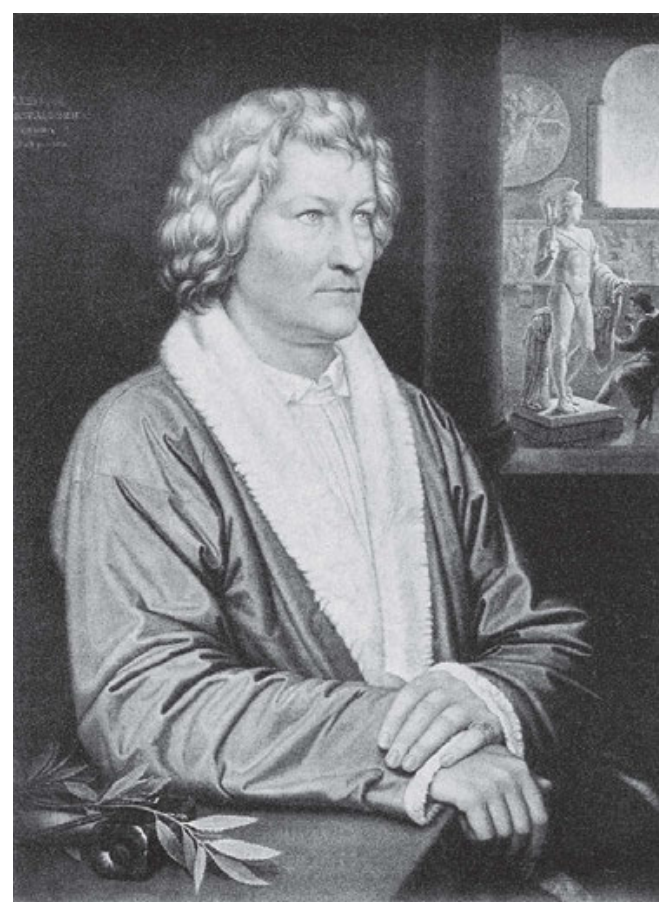

28__Heinrich Maria von Hess, Bertel Thorwaldsen, 1834, Öl auf Holz, $85 \times 68 \mathrm{~cm}$, zerstört (ehem. München, Schackgalerie)

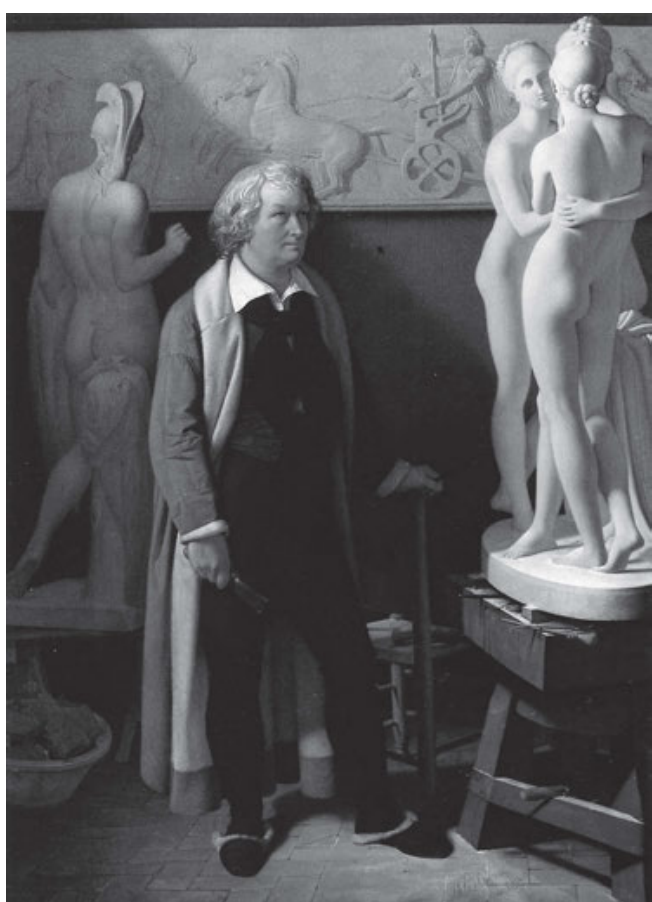

29__Ditlev Conrad Blunck, Bertel Thorvaldsen in seinem römischen Atelier, 1834, Öl auf Leinwand, $139 \times 102$ cm, Kiel, Kunsthalle zu Kiel (Inv.-Nr. 734)

\section{Thorvaldsen, Jason und der Alexanderzug}

Aus den beiden bisherigen Kapiteln wurde die Bedeutung der Jason-Statue und des Alexanderzuges für Thorvaldsens Künstlerbiografie und seinen stetig wachsenden Status als internationale Berühmtheit deutlich. Dazu trugen nicht nur die Erfolge mit diesen beiden Werken bei, sondern in entscheidender Weise auch deren fast massenweise Verbreitung mittels plastischer und druckgrafischer Reproduktionen. Es sind auch jene beiden Schöpfungen, mit denen der Bildhauer am häufigsten porträtiert wurde. Da Thorvaldsen gerne selbst bestimmte, mit welchen Werken er malerisch verewigt wurde, könnte die mannigfache Präsenz der Jason-Statue und des Alexanderzuges darauf hindeuten, dass er seine künstlerische und soziale Stellung vor allem über den Erfolg dieser beiden Werke definierte und sich insofern selbst als ,neuer Phidias' sah. ${ }^{313}$ Folglich hatten entsprechende Porträts durchaus programmatischen Charakter und prägten Thorvaldsens öffentliches 
30_Emilius Ditlev Bærentzen, Bertel Thorvaldsen, 1839, Öl auf Leinwand, $68 \times 57,5 \mathrm{~cm}$, Schleswig, Schleswig-Holsteinisches Landesmuseum, Schloss Gottorf (Inv.-Nr. SHLM 1986/1033)

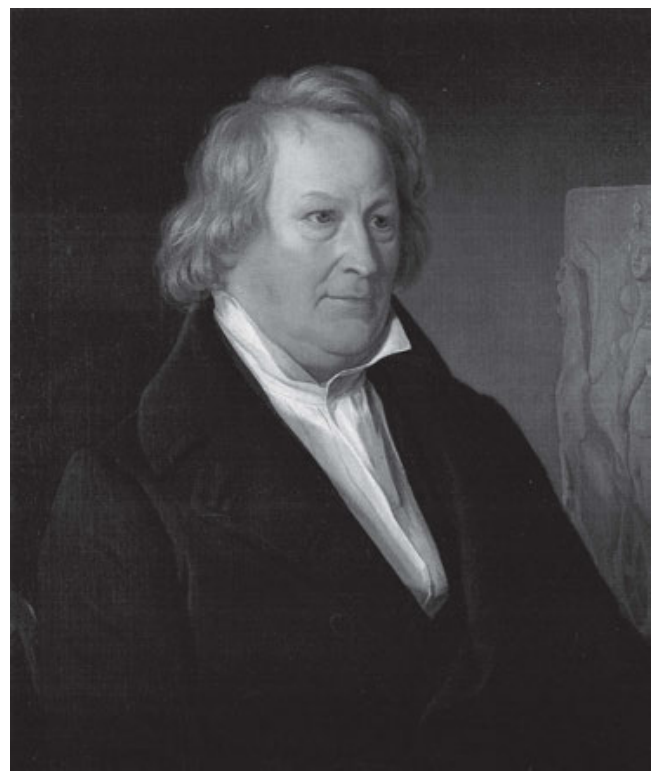

Bild zu einem wesentlichen Teil, was wiederum durch Kopien und druckgrafische Reproduktionen jener Gemälde veranschaulicht wird.

Dabei ist bezeichnend, dass Jason und der Alexanderzug nicht nur als neue Schöpfungen mit Aktualitätswert in zeitgleich oder kurz danach entstandenen Porträts erscheinen, sondern auch in deutlich späteren Bildnissen. So sind mit den Gemälden von Heuss, Heinrich Maria von Hess und Ditlev Conrad Blunck allein im Jahr 1834 wenigstens drei Porträts entstanden, die den Bildhauer neben zumindest einer dieser beiden Plastiken zeigen (Abb. 25, 28 und 29). Noch 1839 malte Emilius Ditlev Bærentzen seinen bewunderten Landsmann im Halbprofil vor dem scheinbar eine Säule zierenden Mittelstück des Alexanderzuges (Abb. 30). Trotz des fortgeschrittenen Alters und des fülligeren Gesichts sind die in den meisten Bildnissen betonten äußeren Merkmale Thorvaldsens - die blauen Augen, der klare Blick in die Ferne, die weißen Locken und die markanten Gesichtszüge deutlich erkennbar, die verschiedene Zeitgenossen veranlasst hatten, Thorvaldsens Aussehen mit dem einer Statue zu vergleichen. Wenn Thorvaldsen mit dem Alexanderzug porträtiert wurde, dann handelt es sich in allen Fällen um das Schlüsselstück mit dem Makedonierkönig auf dem Streitwagen. Vor dem Hintergrund der zeitgenössischen Rezeption dieses Relieffrieses sowie Thorvaldsens eigener Einschätzung seines Werks dürfte es bei der Wahl dieses Teilstücks nicht nur um den Wiedererkennungswert gegangen sein, sondern vor allem auch um einen direkten Vergleich des siegreichen antiken Herrschers mit dem für seine triumphale Künstlerlaufbahn gefeierten dänischen Bildhauer. 


\section{Thorvaldsens Selbstbildnisstatue, oder: Ein klassizistischer Bildhauer nordischer Herkunft}

Verschiedene Quellen überliefern, dass Thorvaldsen sich lange Zeit dagegen gesträubt habe, eine ganzfigurige Statue von sich selbst zu fertigen. Ohnehin hat er im Verhältnis zu seinem Gesamtwerk nur wenige Selbstporträts hinterlassen. Neben den im vorangegangenen Kapitel vorgestellten Assistenzselbstbildnissen handelt es sich nach aktuellem Wissensstand um sieben mehr oder weniger formelle und vier genrehafte Selbstdarstellungen (darunter Abb. 19-21 und 31). ${ }^{314}$ Dieses Kapitel konzentriert sich auf das lebensgroße Selbstbildnis mit der Statue der Hoffnung und ferner das Relief Selbstbildnis mit der Familie Stampe aus Thorvaldsens Spätwerk, da sich in ihnen die jahrzehntelang betriebene Stilisierung des Bildhauers auf verschiedenen Ebenen verdichtet (Abb. 32 und 33). Mehr als

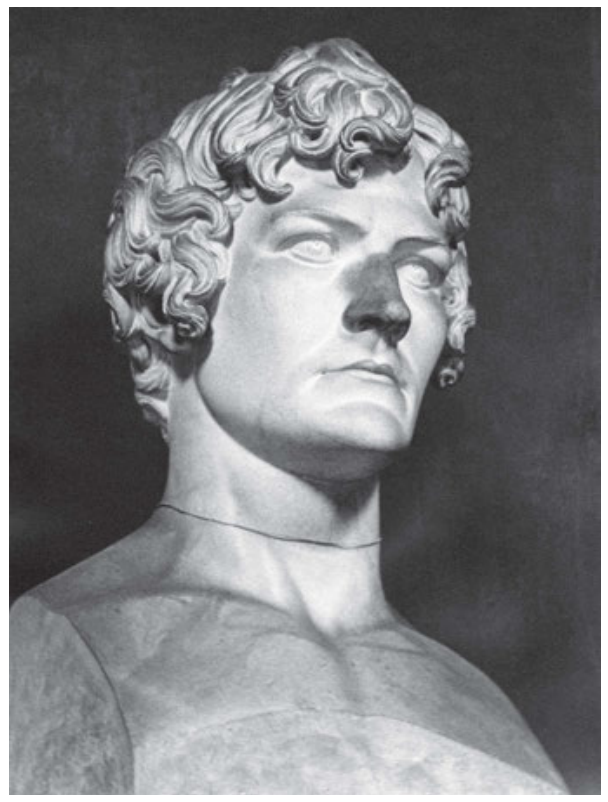

31_Bertel Thorvaldsen, Selbstbildnis, 1810, Gipsmodell, Höhe: 73,5 cm, Kopenhagen, Thorvaldsens Museum (Inv.-Nr. A223)

314 Neben den hier vorgestellten Darstellungen umfassen die mehr oder weniger formellen Selbstbildnisse ein Aquarell des 24-jährigen Künstlers beim Stopfen seiner Pfeife (Kopenhagen, Thorvaldsens Museum, Inv.-Nr. C885) und eine Kreidezeichnung von 1810 (Kopenhagen, Ny Carlsberg Glyptotek, Inv.-Nr. 1025), während zu den genrehaften Selbstbildnissen außerdem das Aquarell einer privaten Abschiedsfeier vor Thorvaldsens Abreise nach Rom 1796 (zugeschrieben; Kopenhagen, Thorvaldsens Museum, Inv.-Nr. C757) und zwei Zeichnungen der Reise des Bildhauers mit der Baronenfamilie Stampe von Kopenhagen nach Rom im Sommer 1841 (Kopenhagen, Thorvaldsens Museum, Inv.-Nr. C1069; Nysø, Thorvaldsen-Samlingen, Inv.-Nr. NysøC) zählen. 


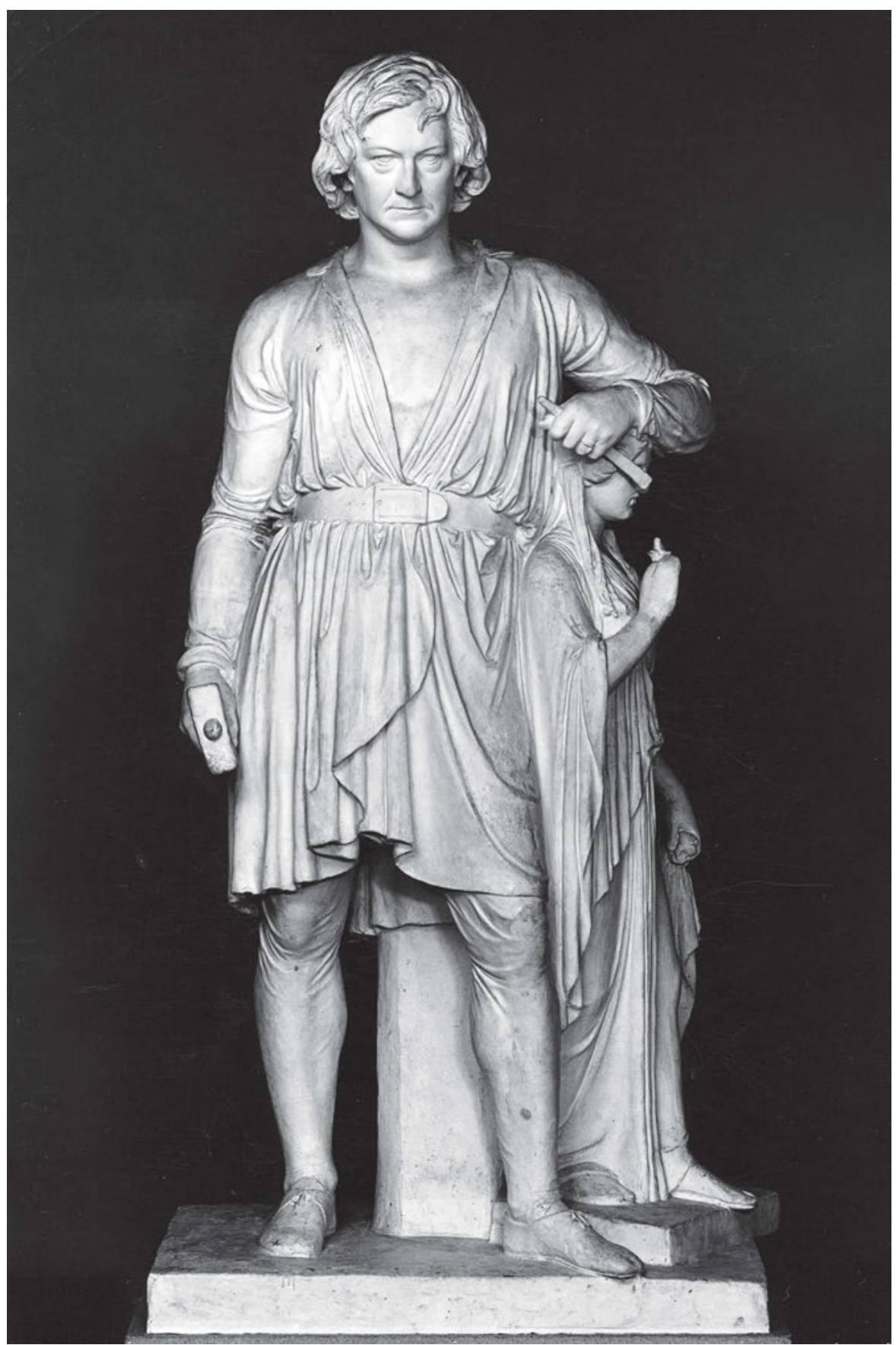

32_Bertel Thorvaldsen, Selbstbildnis mit der Statue der Hoffnung, 1839, Gipsmodell, Höhe: 198,5 cm, Nysø, Thorvaldsen-Samlingen (Inv.-Nr. Nysø1) 


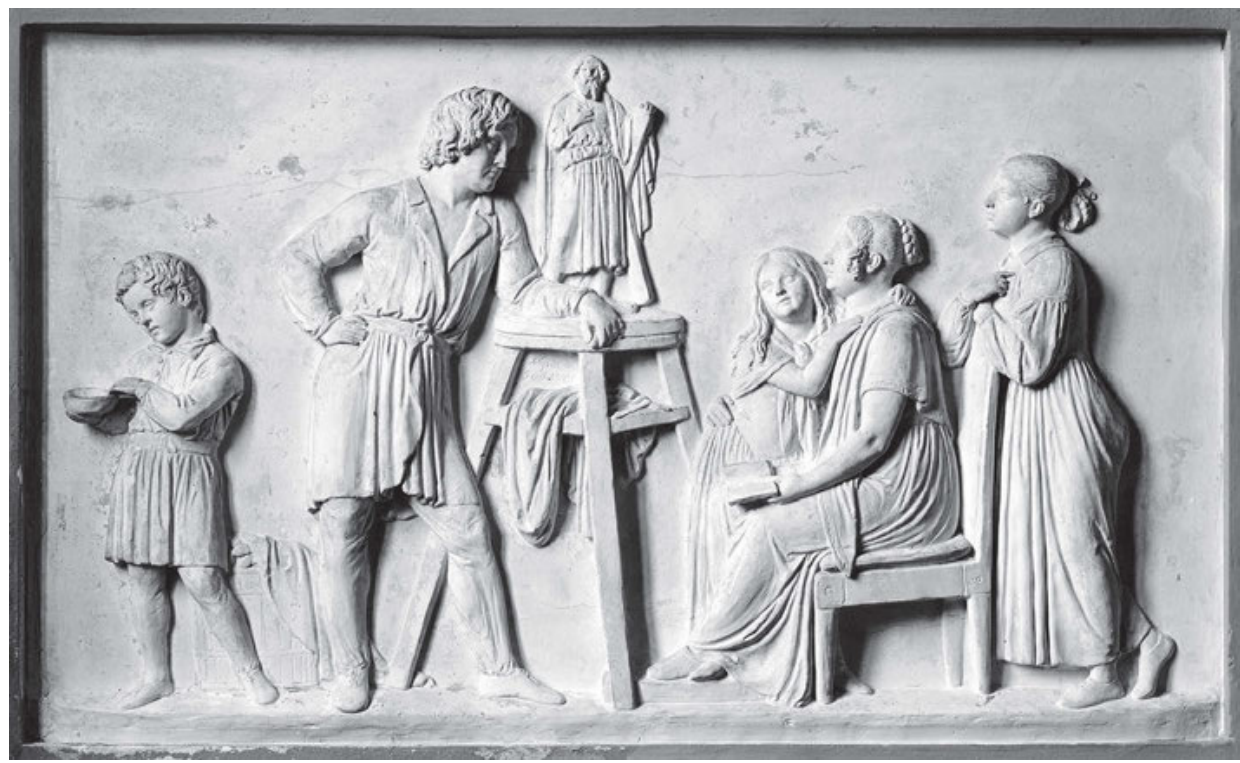

33_Bertel Thorvaldsen, Selbstbildnis mit der Familie Stampe, 1840, Gipsmodell, $60 \times 101 \mathrm{~cm}$, Nysø, Thorvaldsen-Samlingen (Inv.-Nr. Nysø38)

alle anderen Werke des Dänen geben sie Einblick in dessen künstlerisches Selbstverständnis sowie den damaligen Personen- und celebrity-Kult um ihn.

Thorvaldsens Selbstbildnis mit der Statue der Hoffnung von 1839 besteht im Wesentlichen aus drei Komponenten: dem ganzfigurigen Selbstporträt des Bildhauers, der in Ausführung begriffenen Statue der Göttin der Hoffnung und einem Steinquader. ${ }^{315}$ In seinem lebensgroßen Selbstporträt zeigt sich der damals 69-Jährige in frontaler Ansicht als selbstbewusster, jung gebliebener Bildhauer. In seinen Händen hält er Hammer und Meißel. Der rechte Arm liegt locker an seinem Oberkörper, während der Ellbogen leicht gebeugt ist. Mit dem linken Unterarm stützt er sich auf das noch unvollendete kleine Modell der Göttin der Hoffnung, die er bereits 1817 geschaffen hatte (Abb. 34). Trotz Hammer, Meißel und der unvollendeten Statue ist Thorvaldsens Selbstporträt keine Momentaufnahme des Arbeitsprozesses; mit seinem in die Ferne gerichteten Blick zeigt sich der Bildhauer vielmehr in einem Augenblick der Kontemplation. Diese Darstellungsweise teilt das Selbstbildnis mit zahlreichen gemalten Porträts, die ihn zwar oft in seinem Atelier oder zumindest neben seinen Werken präsentieren, jedoch nie bei der physischen Arbeit. Entsprechend dem romantischen Geniekult wird damit der geistigen Schöpfungskraft Ausdruck verliehen.

In ähnlicher Weise sollte Thorvaldsen in den Jahren 1843 und 1844 den Genius der Skulptur in zwei Reliefs und einer Zeichnung darstellen. Damit ist auch sein letzter Ent- 


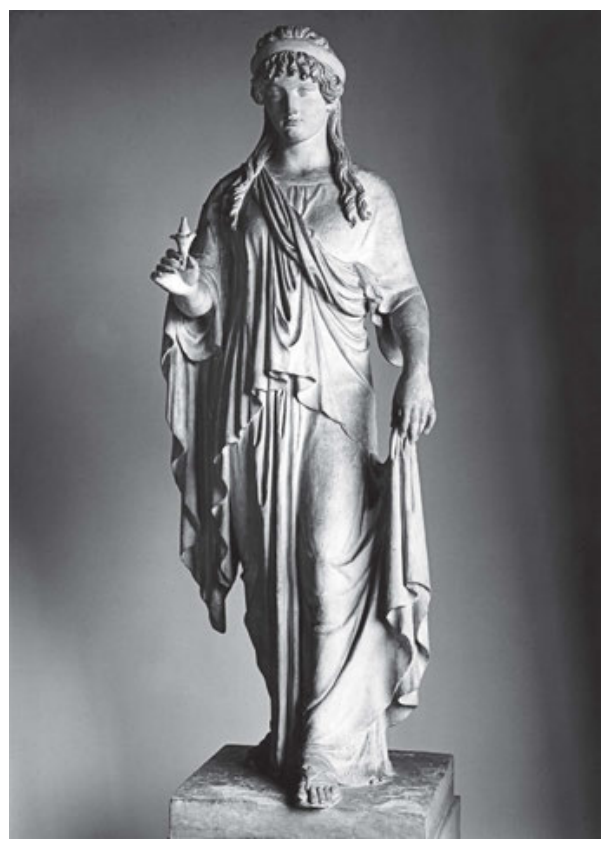

34_Bertel Thorvaldsen, Göttin der Hoffnung, 1817, Gipsmodell, Höhe: 160,8 cm, Kopenhagen, Thorvaldsens Museum (Inv.-Nr. A47)

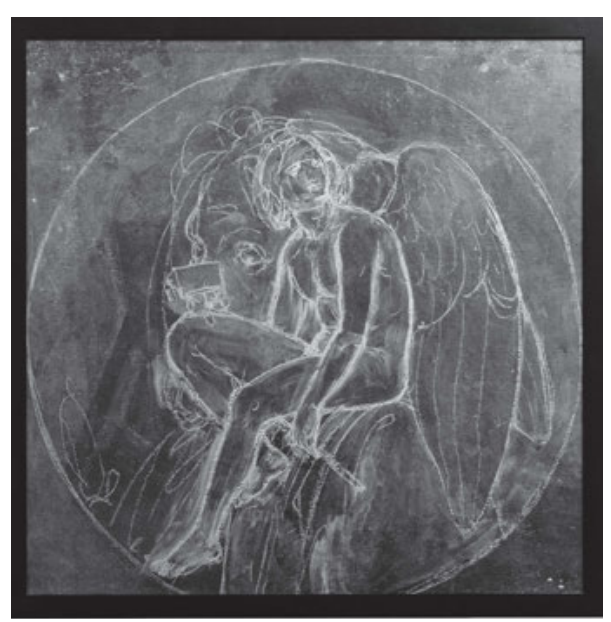

35_Bertel Thorvaldsen, Der Genius der Skulptur, 1844 , Kreide auf Schiefer, $109 \times 109 \mathrm{~cm}$, Kopenhagen, Thorvaldsens Museum (Inv.-Nr. A524)

wurf vor seinem Tod diesem Motiv gewidmet: In der Kreidezeichnung auf einer Schieferplatte sitzt der geflügelte Genius auf der linken Schulter einer kolossalen Zeus-Statue, während er die Bildhauerwerkzeuge in den Händen hält und den Blick in die Ferne schweifen lässt (Abb. 35). ${ }^{316}$ Zeus' Kopf ist dabei an die römische Büste des Zeus von Otricoli im Museo Pio-Clementino angelehnt, von der sich ein Gipsabguss in Thorvaldsens eigener Sammlung befand.

\section{Die Göttin der Hoffnung und die Ägineten}

Die in Thorvaldsens Selbstbildnis zitierte Göttin der Hoffnung zeigt eine junge Frau in frontaler Ansicht, die mit dem linken Fuß einen Schritt auf die Betrachterin oder den Betrachter zuzugehen scheint. Ein Teil ihrer Locken ist von hinten in die Stirn des strengen Gesichts gekämmt und wird durch ein Haarband zusammengehalten. Mit der linken

316 Siehe dazu auch Kat. Nürnberg/Schleswig 1991, 574; Melcher 1999, 275. Thorvaldsen legte seine Reliefs oft auf einer Schiefertafel über mit Kreide gezeichneten Umrissen an. Die genannten Zeichnungen befinden sich ebenfalls in Thorvaldsens Museum (Inv.-Nr. A522 und A523). 
Hand hebt sie ihr langes, in aufwendiger Draperie modelliertes Kleid, während sie in ihrer Rechten die Knospe einer Granatapfelblüte hält. Diese Statue war das Ergebnis von Thorvaldsens intensiver Beschäftigung mit den sogenannten Ägineten, den insgesamt 17 archaischen Giebelfiguren des Aphaia-Tempels auf der griechischen Insel Ägina. Die Fragmente der Frontons dieser Tempelruine waren 1811 von einer Gruppe von Archäologen und Architekten um Charles Robert Cockerell und Carl Haller von Hallerstein entdeckt und 1812 vom bayerischen Kronprinzen Ludwig ersteigert worden. ${ }^{317}$ Bei den seit 1830 in der damals neu eröffneten Münchner Glyptothek aufbewahrten Ägineten handelt es sich um zwei Figurengruppen, die den Kampf um Troja darstellen. ${ }^{318}$

Nach ihrer Auffindung wurden die Ägineten 1815 nach Rom gebracht, und im folgenden Jahr beauftragte Ludwig, der schon lange zu Thorvaldsens größten Bewunderern zählte, den Bildhauer mit der Restaurierung dieser Figuren. ${ }^{319}$ Der Grund für Thorvaldsens anfängliches Zögern lag einerseits sicherlich in seinem Respekt vor dieser Aufgabe; andererseits hielt er das Restaurieren antiker Skulpturen laut Thiele für eine „undankbare Arbeit“, denn „[h] at man es nicht gut gemacht, dann wäre es besser ungethan, und macht man es gut, dann ist es, als wenn Nichts geschehen sei“. ${ }^{320}$ Gemäß Thieles zweifellos verherrlichender Darstellung nahm er den Auftrag für die Restaurierung schließlich an, „damit sie nicht in weniger tüchtige Hände fallen solle“. ${ }^{221}$ Insgesamt war Thorvaldsens Wahl durchaus naheliegend, hatte er sich doch in Rom sowohl als Antikenkenner und -sammler wie auch als Berater für Antikenkäufe einen Namen gemacht. ${ }^{322}$

Ludwigs Kunstagent in Rom, der Bildhauer Wagner, mietete eigens für die rund ein Jahr dauernde Arbeit an den Ägineten ein zusätzliches Atelier für Thorvaldsen nahe der Via del Corso und der Piazza del Popolo an. ${ }^{323}$ Wie von der Hagen in einem Brief vom

Thiele 1852 - 1856, Bd. 1, 267; auch Trier 1903, 104; Larsson 1969, 25; Grunwald 1977, 243; Wünsche 1991, 313; Diebold 1995, 60; Jørnæs 2011, 91; Wünsche 2011, 4 und 37 - 48; Bindman 2014, 139 - 140; Grandesso 2015, 144. Zu den Ägineten allg. siehe ausführlich Ohly 1976 - 2001. Aus Dänemark gehörte unter anderem der Archäologe und Philologe Peter Oluf Brøndsted zur Reisegesellschaft, der Thorvaldsen während seines Romaufenthalts in den Jahren 1809/1810 kennen gelernt hatte und anschließend mit ihm in Briefkontakt stand. Zur Bekanntschaft zwischen Cockerell und Haller von Hallerstein, deren Reise nach Ägina und der Ausgrabung der Ägineten siehe Wünsche 2011, 7 - 35 und 76 - 78. Dass der Kronprinz Ludwig bereit war, fast jeden Preis für die Ägineten zu zahlen, zeigt ein Brief an Johann Martin von Wagner, in dem er schrieb: „Mir liegt der Erwerb sehr am Herzen und sollte er auch den ganzen Kreditbrief betragen u. mehr noch, sehr theuer sein, ersteigern sie mir die Sammlung dennoch, selbst übertrieben darf der Preis, nur nicht lächerlich übertrieben lauten.“; zit. nach Wünsche 2011, 40.

318 Zur Deutung der Figurengruppen siehe Wünsche 2011, 205-221.

319 Zu diesem Auftrag siehe Thiele 1852 - 1856, Bd. 1, 267 - 268; Hannover 1907, 27; Larsson 1969, 25-26; Grunwald 1977, 243; Melander 1991, 299; Wünsche 1991, 313; Jørnæs 2011, 91; Wünsche 2011, 81 - 88. Thiele 1852-1856, Bd. 1, 267.

321 Ebd.

322 Siehe bspw. Oppermann 1930, 113 -129; Melander 1991, 296- 299.

323 Thiele 1852-1856, Bd. 1, 268; Atkinson 1873, 61; Moltesen 1929, 299; Wittstock 1975, 116; Wünsche 2011, 82; Grandesso 2015, 144. Wagner publizierte 1817 mit seinem Bericht über die aeginetischen Bildwerke im 
25. April 1817 berichtete, war „diese Werkstätte [...] eine der besuchtesten“.324 Der Arbeitsablauf glich Thorvaldsens üblichem Vorgehen, das im Kapitel III.1 genauer besprochen wird: Nachdem er die Ergänzungen der Skulpturen in seiner Wohnung mithilfe von Abgüssen der äginetischen Figuren modelliert hatte, wurden sie in der erwähnten Werkstatt von drei Gehilfen in Marmor übertragen und mit den Originalfragmenten zusammengesetzt. ${ }^{325}$ Thorvaldsen war schließlich für den letzten Schliff der Figuren zuständig. ${ }^{326}$ Teil des äginetischen Fundes waren auch zwei Koren, die das Akroterion des Westgiebels des Aphaia-Tempels flankierten und als Sinnbilder für die Hoffnung oder die Jahreszeiten gedeutet wurden (Abb. 36). ${ }^{327}$ Diese Frauenfiguren, deren Gipsabgüsse sich ebenfalls in Thorvaldsens eigener Sammlung befanden, dienten dem Bildhauer als direkte Vorbilder für seine Statue der Göttin der Hoffnung. ${ }^{328}$ In der Tat verwendete er für diese Statue noch einmal das von ihm geschaffene Modell des Kopfes zur Ergänzung der äginetischen Akroterfiguren. $^{329}$

Besitz seiner Königl. Hoheit des Kronprinzen von Baiern außerdem die erste und eine der detailliertesten Untersuchungen zu den Ägineten; Wagner 1817; siehe auch Larsson 1969, 36. Auch Cockerell, der an den Ausgrabungen in Ägina teilgenommen hatte, veröffentlichte in seiner reich illustrierten Schrift The Temples of Jupiter Panhellenius at Ægina, and of Apollo Epicurius at Basse near Phigaleia in Arcadia eine einflussreiche Studie zu den Ägineten; Cockerell 1860.

324 Von der Hagen 1818 - 1821, Bd. 4, 28. Siehe auch Wittstock 1975, 289.

325 Von Urlichs 1887, 7; Rosenberg 1901, 50; Wünsche 1991, 314 - 315; Wünsche 2011, 88; Bindman 2014, 141; Grandesso 2015, 144. Raimund Wünsche betont, dass Thorvaldsens Anteil an der Restaurierung der Ägineten lange Zeit überschätzt wurde und dass ihm weder die Leitung dieses Auftrags (diese lag bei Wagner) noch die Zusammensetzung der Fragmente mit den von ihm modellierten Ergänzungen zukam (dafür war ein Bildhauer namens Antonio zuständig); Wünsche 1991, 313 - 315; Wünsche 2011, 82 und 88.

Grandesso 2015, 144.

327 Nach Thiele 1852 - 1856, Bd. 1, 296 - 297, Müller, S. 1893, 133, und Moltesen 1929, 302, symbolisierten die Akroterfiguren die Hoffnung, nach Rosenstand 1905, 71, und Hannover 1907, 27, hingegen die Jahreszeiten. Siehe zu den beiden Figuren auch Kat. Nürnberg/Schleswig 1991, 657.

328 Siehe auch Thiele 1852 - 1856, Bd. 1, 296 - 298; Müller, S. 1893, 133; Lange, J. 1894, 118; Rosenberg 1901, 50; Hannover 1907, 27; Oppermann 1927, 131; Moltesen 1929, 302; Grunwald 1977, 244; Hartmann 1979, 65; Bogh 2001, 22; Jørnæs 2011, 91; Bindman 2014, 143; Friborg 2014; Grandesso 2015, 145. Eine vergleichbare Ikonografie wie jene der Göttin der Hoffnung findet sich außerdem auf drei antiken Schmucksteinen mit Spes-Darstellungen aus Thorvaldsens Besitz; Kopenhagen, Thorvaldsens Museum (Inv.-Nr. I69, I607 und I608). Als weitere mögliche Vorbilder für die Göttin der Hoffnung werden in der Forschung die Peploskore im Walters Art Museum und eine Statue der Hoffnung in der Lady Lever Art Gallery bei Liverpool genannt, die beide aus dem Nachlass von Thorvaldsens frühem Gönner Thomas Hope stammen; Kat. Köln 1977, 186; Hartmann 1979, 66. Schließlich lässt sich die Göttin der Hoffnung mit dem Statuentypus der Hera mit dem Granatapfel sowie mit einer archaischen Kore aus der Villa Albani in Rom in Verbindung bringen, die nach Johann Joachim Winckelmann und Georg Zoëga die Spes darstellte; Kat. Köln 1977, 186; Hartmann 1979, 66. 


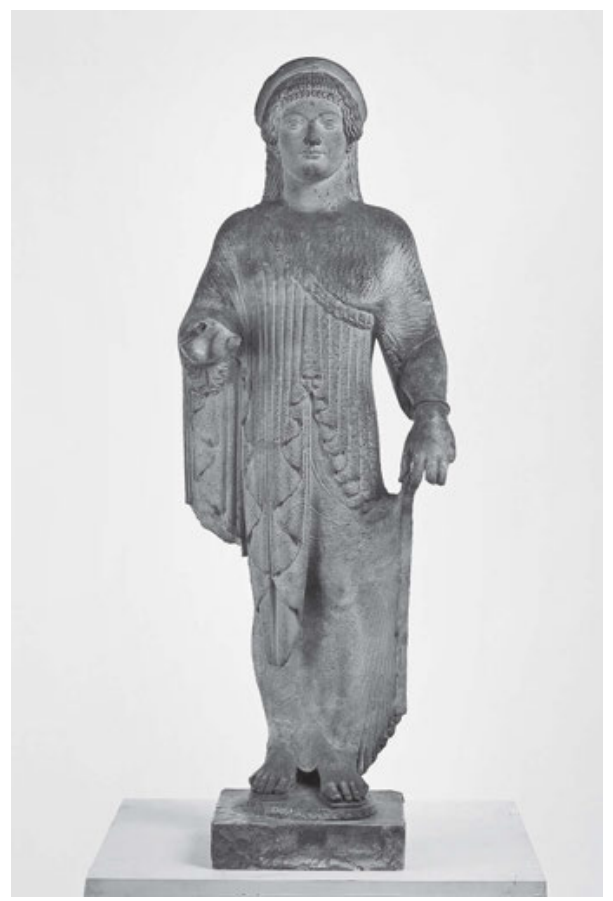

36_Kore vom Akroterion des Aphaia-Tempels auf Ägina, 500 - 480 v. Chr., Gipsabguss, Höhe: 90,5 cm, Kopenhagen, Thorvaldsens Museum (Inv.-Nr. L7)

Insgesamt zog die Restaurierung der Ägineten schon während des Arbeitsprozesses die Bewunderung der Zeitgenossen auf sich. ${ }^{330}$ Thiele berichtet etwa, der Bildhauer habe sich den archaischen Stil der Ägineten derart angeeignet und das verwitterte Material der Originale so täuschend echt nachgeahmt, dass „selbst das geübteste Auge“ die restaurierten Stellen kaum erkennen könne. ${ }^{331}$ Dies unterstreicht er mit einer Anekdote, die gemäß Thiele typisch für die „geniale Schelmerei unseres Künstlers“ war, aber aus heutiger Sicht vor allem Aufschluss über die allgemeine Bewunderung für den Bildhauer sowie über dessen Selbstinszenierung gibt. ${ }^{332}$ So habe Thorvaldsen, wenn er die ergänzten Teile an den Ägineten zeigen sollte, geantwortet: „,G]emerkt habe ich mir sie nicht und herausfinden kann ich sie nicht. “333

Nach der anfänglichen Begeisterung begann sich besonders in der zweiten Hälfte des 19. Jahrhunderts negative Kritik an Thorvaldsens Ergänzungen zu häufen. So seien diese

330 Siehe auch Larsson 1969, 29; Wünsche 2011, 153.

331 Thiele 1852-1856, Bd. 1, 268. Siehe auch Eaton 1852, 313; Larsson 1969, 28. Die verwitterte Erscheinung erreichte Thorvaldsen, indem er die Oberfläche seiner Ergänzungen mit einem Spitzmeißel bearbeitete; Wünsche 2011, 136. Zur Praxis der Antikenrestaurierung im späten 18. und frühen 19. Jahrhundert siehe bspw. ebd., $61-72$.

332 Zitat: Thiele $1852-1856$, Bd. 1, 268.

333 Ebd. Siehe auch Larsson 1969, 30. 
gemäß Plon sofort erkennbar, da sich die Farbe des neuen Marmors an der Luft noch veränderte, während das originale Material diesen Prozess bereits lange hinter sich hatte und folglich gleich blieb. ${ }^{334}$ Einer der frühen Kritiker von Thorvaldsens Ergänzungen war zudem Cockerell, der die Restaurierungsarbeit zu Beginn noch gelobt hatte. ${ }^{335}$ Die kritischen Stimmen gegenüber Thorvaldsens Ergänzung der Ägineten sind im Kontext eines damals neuen Ansatzes in der Antikenrestaurierung zu sehen. Dieses Umdenken war wesentlich durch die Bewahrung der Parthenonskulpturen als Fragmente ausgelöst und durch das Auffinden zahlreicher Skulpturen in Athen und Olympia in den 1870er und 1880er Jahren gefestigt worden. Der neue Blick auf das Fragmentarische antiker Skulpturen weniger als Mangel denn als Qualität führte beispielsweise in der Dresdner Skulpturensammlung bereits kurz vor der Wende zum 20. Jahrhundert dazu, dass ergänzte Teile entfernt wurden. ${ }^{336}$ Bei den Ägineten geschah dies in den 1960er Jahren: Nicht nur wurden zwischen 1962 und 1966 Thorvaldsens Ergänzungen abgenommen, sondern die Giebelfiguren wurden 1972 für die Wiedereröffnung der 1944 durch einen Bombenangriff stark beschädigten Glyptothek auf der Grundlage von jüngeren Erkenntnissen über ihre ursprüngliche Anordnung neu arrangiert. ${ }^{337}$ Im ersten Jahrzehnt des 21. Jahrhunderts wurden Thorvaldsens Ergänzungen schließlich an Kunstmarmorabgüssen der Figuren erneut angefügt und im klassizistischen Sinn aufgestellt. ${ }^{338}$ Darüber hinaus wurde an Rekonstruktionen der Ägineten versucht, deren originale Farbigkeit zu präsentieren. ${ }^{339}$

Mit einer Datierung um 500 bis 480 v. Chr. waren die Ägineten bei ihrer Auffindung die ältesten bekannten Statuen aus dem antiken Griechenland. ${ }^{340}$ Ihre nie zuvor gesehene Formensprache übte eine besondere Faszination auf Thorvaldsen und dessen Zeitgenossen aus und prägte ein neues Verständnis der antiken Kunst. ${ }^{341}$ Gelobt wurde in den Quellen vor allem die Modellierung von Körpern, Gewändern und Rüstungen, während man

35 Cockerell 1860, 34. Siehe auch Larsson 1969, 30 - 31; Grunwald 1977, 244; Diebold 1995, 60; Wünsche 2011, 153 und 155.

336 Wünsche 2011, 156 - 157; auch Larsson 1969, 31 und 35 - 36.

337 Grunwald 1977, 244; Wünsche 1991, 313; Jørnæs 2011, 91; Wünsche 2011, 5, 158, 174 und 191; Grandesso 2015, 144-145. Diebold 1995 bringt die Entfernung von Thorvaldsens Ägineten-Ergänzungen mit einem Bedürfnis nach Abgrenzung vom Nationalsozialismus in Verbindung. Die Neuaufstellung der Ägineten basiert wesentlich auf Rekonstruktionen von Adolf Furtwängler und Eduard Schmidt; siehe dazu Larsson 1969, 23; Diebold 1995, 60. Zur Neuaufstellung der Ägineten und deren Rezeption siehe außerdem Wünsche 2011, $172-178$.

338 Wünsche 2011, 5 und $187-191$.

339 Ebd., 5. Zur Farbigkeit der Ägineten siehe ausführlich Wagner 1817, 209 - 226; Wünsche 2011, 223 - 228, 238 - 246 und 256 - 261; auch Kat. München 2003; Bindman 2014, 139.

340 Die Figurengruppe des Westgiebels wird um 500/490 v. Chr., jene des Ostgiebels um 490/480 v. Chr. datiert; siehe dazu Wünsche 2011, 73; auch Larsson 1969, 27; Grunwald 1977, 243.

341 Trier 1903, 104; Sass 1950, 307; Larsson 1969, 49; Friborg 2014. 
über die starren, ausdruckslosen Gesichter staunte. ${ }^{342}$ Thorvaldsens Orientierung an der archaischen Plastik und speziell an den beiden Akroterfiguren zeigt sich in der ausgesprochenen Frontalität der Göttin der Hoffnung, in der Abweichung vom Kontrapost zugunsten einer stärkeren Symmetrie, besonders von Gesicht, Schultern und Hüftstellung, im maskenhaften Antlitz mit der flachen Stirn, der spitzen Nase und dem kräftigen Kinn sowie im regelmäßigen Faltenwurf des Gewandes. ${ }^{343}$

Entsprechend der einschneidenden Bedeutung des Äginetenfundes zog auch Thorvaldsens Göttin der Hoffnung bereits während ihrer Entstehung große Aufmerksamkeit unter den kunstinteressierten Zeitgenossen auf sich, wie aus zahlreichen Quellen hervorgeht. $^{344}$ Die eifrigste Bewunderin dieser Statue war Caroline von Humboldt, die in einem Brief vom 23. Dezember 1817 an ihren Ehemann schwärmte:

Schrieb ich schon von einer jugendlichen weiblichen Figur, die Thorvaldsen eben jetzt, und zwar in wenig Tagen, gemacht hat? Die Restauration der letzten aeginetischen Statuen gab ihm die Idee dazu. Von modernen Bildhauern hat man nie so etwas gesehen. Es ist ganz etwas Neues. Die Figur stellt eine Hoffnung vor, in der rechten Hand hält sie eine Granatblume, der Blick ruht darauf, als hoffe er still auf die Frucht, mit der linken hebt sie das schönste Gewand. Die Bekleidung ist ungemein schön. Die ganze Statue hat etwas Lichtes, Hohes, Stillbewegtes, als träte sie einem vom Fußgestell entgegen. Es ist etwas durchaus Neues, nie Gesehenes, sie macht sich in allen Linien, und wie man sie auch wendet, gleich schön. Ich möchte sie wohl in Marmor besitzen. ${ }^{345}$

Bereits am 15. Januar 1818 antwortete Wilhelm von Humboldt seiner Ehefrau: „Die kleine weibliche Figur von Thorvaldsen solltest Du wohl [...] in Marmor haben. "346 Am 17. Februar berichtete Caroline von Humboldt ihrem Gatten schließlich, dass sie mit Thorvaldsen über den Auftrag gesprochen habe und dass die Marmorversion „nah an 1.000 scudi kosten“ würde, was ein guter Preis sei. ${ }^{347}$ Weiter versicherte sie ihrem Ehemann, dass auch er „die größte Freude daran haben [werde], es ist wirklich eine himmlische Figur, etwas noch nie Gekanntes und im edelsten Stil“; und in einem Brief vom 16. April wiederholte

342 Siehe bspw. den Bericht im Morgenblatt der gebildeten Stände vom 15. Januar 1812 oder Johann Martin von Wagners Brief an den bayerischen Kronprinzen Ludwig vom 13. März 1813, beides zit. bei Wünsche 2011, 37 - 38 bzw. 45.

343 Siehe bspw. Pfundheller 1886, 232; Müller, S. 1893, 133; Moltesen 1929, 300; Bogh 2001, 22.

344 Siehe bspw. Frances von Bunsen an ihre Mutter, 19. Februar 1818, zit. bei Hare 1879, 130; Eaton 1852, $306-307$.

345 Caroline von Humboldt an Wilhelm von Humboldt, 23. Dezember 1817, zit. nach Wittstock 1975, 303. Am Tag darauf berichtete Caroline von Humboldt an Friederike Brun in einer sehr ähnlichen Formulierung von Thorvaldsens Göttin der Hoffnung; zit. bei Foerst-Crato 1975, 161, die den Brief jedoch auf den 29. Dezember 1817 datiert. Zu Caroline von Humboldts Bewunderung für die Göttin der Hoffnung siehe auch Jørnæs 2011, 91-92.

346 Wilhelm von Humboldt an Caroline von Humboldt, 15. Januar 1818, zit. nach Wittstock 1975, 311.

347 Caroline von Humboldt an Wilhelm von Humboldt, 17. Februar 1818, zit. nach Wittstock 1975, 305. 
sie: „Mit meinen Ankäufen sollst Du, hoffe ich, zufrieden sein. Die Thorvaldsensche Statue ist schön wie eine Antike." 348 Ihre Vorfreude auf die Marmorfassung der Göttin der Hoffnung teilte sie auch weiteren Zeitgenossen mit. ${ }^{349}$ Wie es bei Thorvaldsen jedoch oft vorkam, ließ er sich mit der Ausführung dieses Auftrags Zeit. In der Tat erreichte die Marmorversion der Göttin der Hoffnung Berlin erst 1829 nach Caroline von Humboldts Tod. ${ }^{350}$ Ihr von Schinkel entworfenes Grabmal in Berlin-Tegel wurde schließlich mit einer verkleinerten, vom Bildhauer Christian Friedrich Tieck angefertigten Marmorkopie nach Thorvaldsens Statue geschmückt. ${ }^{351}$ Das Original der Göttin der Hoffnung befindet sich nachdem es im Anschluss an den Zweiten Weltkrieg während gut vier Jahrzehnten in der damaligen Nationalgalerie in Ostberlin ausgestellt war - heute wieder im Schloss Tegel. ${ }^{352}$

\section{Vorbilder und skulpturgeschichtliche Bedeutung}

Das Selbstbildnis mit der Statue der Hoffnung besitzt nicht nur in Thorvaldsens Euvre einen wichtigen Stellenwert, sondern in der Geschichte der Bildhauerei generell: Es handelt sich bei diesem Werk um eine der seltenen eigenständigen, ganzfigurigen und vollplastischen Selbstporträtstatuen. ${ }^{353}$ In den meisten Fällen haben Selbstbildnisplastiken die Form von Büsten oder Assistenzbildnissen in Skulpturengruppen und Reliefs und sind als solche bis in die ägyptische und griechische Kunst des Altertums zurückzuführen. ${ }^{354} \mathrm{Hin}$ gegen berichtet Plinius der Ältere in seiner Naturkunde von einer Selbstporträtstatue des Theodoros von Samos:

\footnotetext{
Theodoros, der das Labyrinth von Samos geschaffen hat, goß von sich selbst eine Bronzestatue; außer durch den besonderen Ruf der Porträtähnlichkeit (seines Werks) wird er wegen der großen Feinheit (seiner Kunst) gepriesen: in der Rechten hält er eine Feile, in der Linken hielt er mit drei Fingern ein kleines Viergespann; es wurde als ein Wunder an Kleinheit später nach Präneste gebracht: Wenn man (diese Quadriga) aufzeichnete, würde eine (von Theodoros) gleichzeitig verfertigte Fliege sie - den Wagen samt dem Lenker - mit ihren Flügeln bedecken. ${ }^{355}$
}

Mit seinem Selbstbildnis und der Göttin der Hoffnung kombinierte auch Thorvaldsen zwei Figuren, die durch unterschiedliche Realitätsebenen gekennzeichnet sind. ${ }^{356}$ Die mate-

348 Caroline von Humboldt an Wilhelm von Humboldt, 16. April 1818, zit. nach Wittstock 1975, 305 - 306.

349 So bspw. dem Archäologen Friedrich Gottlieb Welcker in einem Brief vom 8. Mai 1818; siehe dazu Wittstock 1975, 306-307.

350 Thiele 1852 - 1856, Bd. 1, 298; Rosenberg 1901, 46; Jørnæs 2011, 92; Grandesso 2015, 145.

351 Thiele 1831-1850, Bd. 3, 33; Thiele 1852-1856, Bd. 1, 298; Thiele 1852-1856, Bd. 2, 210; Jørnæs $2011,92$. Grandesso 2015, 145, spricht hingegen fälschlicherweise von einer Kopie in Bronze.

352 Jørnæs 2011, $92-95$.

353 Siehe auch Bogh 2001, 18. Zur historischen Einordnung des Selbstbildnisses mit der Statue der Hoffnung siehe außerdem Bogh 1997, 58.

354 Goldscheider 1936, 8-11 und 17. Siehe auch Kap. I.2.

355 Plinius 1989, 63:83. Auf diese Textstelle verweisen bspw. auch Goldscheider 1936, 11, und Holsten $1978,9$.

356 Siehe auch Oppermann 1930, 156; Henschen 1989, 102; Bogh 2001, 22; Reichardt 2009, 133. 
rielle Unterscheidung zwischen der ,lebenden' Figur und jener aus Stein erfolgt sowohl durch den strengen, archaischen Stil der Göttin der Hoffnung als auch durch deren Unfertigkeit und Art der Oberflächenbehandlung. Während die Selbstporträtstatue bis in die Details fein ausgearbeitet ist, weisen die grobe Modellierung der Hände, Füße und Gesichtszüge sowie die raue Oberflächenbeschaffenheit die Göttin der Hoffnung klar als eine in Entstehung begriffene Skulptur aus. ${ }^{357}$ Damit wird hier auf den bildhauerischen Arbeitsprozess verwiesen, der im Selbstbildnis mit der Statue der Hoffnung zwar nicht gezeigt, aber impliziert ist. Diese materiellen Unterschiede in der Darstellung von Leben und Stein hat Thorvaldsens Schüler Bissen in der 15 Jahre nach Thorvaldsens Tod ausgeführten Marmorversion des Selbstbildnisses mit der Statue der Hoffnung noch gesteigert, indem an der Göttin der Hoffnung deutliche Spuren der bildhauerischen Arbeitsgeräte zu sehen sind (Abb. 37).

Die Wahl der Göttin der Hoffnung für Thorvaldsens Selbstbildnisstatue spricht dafür, dass die Beschäftigung mit den Ägineten für den Bildhauer von einschneidender Bedeutung war. Denn da jene Frauenfigur bereits 1817 entstanden war, kann ihre Integrierung in das 1839 entstandene Selbstporträt nicht mit einem Neuheits- oder Aktualitätswert begründet werden. Wie zu den meisten seiner Werke existieren auch zum Selbstbildnis mit der Statue der Hoffnung kaum Äußerungen von Thorvaldsen selbst. In der Ausgabe vom 28. Juli 1839 erwähnt jedoch die Tageszeitung Kjøbenhavnsposten Thorvaldsens Skulptur und zitiert den Bildhauer mit Bezug auf die Wahl der Göttin der Hoffnung:

Ich habe die Hoffnung gewählt und nicht, wie manche vielleicht passender gefunden haben mögen, die Erinnerung - weil ich mich noch fest an die Hoffnung lehne, Werke in meiner Kunst zu vollenden, die all jene übertreffen werden, die ich bis jetzt geliefert habe. ${ }^{358}$

Thiele bezweifelt später in seinen biografischen Schriften über Thorvaldsen, dass dieses Zitat tatsächlich vom Bildhauer stammte, da „diese Aeußerung wenig mit der gewöhnlichen Art und Weise übereinstimmte, in welcher Thorvaldsen sich auszusprechen pflegte, und auch nicht mit seinem eigenen Blick auf die zurückgelegte künstlerische Thätigkeit“ " Mit dieser Bemerkung deutet Thiele die topisch gewordene Bescheidenheit des Bildhauers sowie dessen Zurückhaltung an, seine eigenen Werke zu kommentieren. Auf seine Nachfrage hin habe Thorvaldsen allerdings bestätigt, ,etwas dergleichen gesagt“ zu haben. ${ }^{360}$ Ausschlaggebender für die Wahl der Göttin der Hoffnung sei jedoch „der strengere aegine-

Siehe auch Bogh 2001, 21-22; Friborg 2014.

Kjøbenhavnsposten, 13:205, 28. Juli 1839, 822: „,Jeg har valgt Haabet' - saa fortælles Konstneren at have yttret sig - ,og ikke, som Mange maaskee vilde have fundet mere passende, Erindringen - fordi jeg endnu fast støtter mig til det Haab, at fuldende Værker i min Konst, som skulle overgaae alle dem, jeg hidtil har leveret.“' Siehe auch Thiele 1831-1850, Bd. 4, 76.

Thiele $1852-1856$, Bd. 3, 52.

Ebd. 
37_Bertel Thorvaldsen, Selbstbildnis mit der Statue der Hoffnung, 1859, Marmor, ausgeführt durch Herman Wilhelm Bissen nach Thorvaldsens Originalmodell in Gips von 1839, Höhe: 198 cm, Detail, Kopenhagen, Thorvaldsens Museum (Inv.-Nr. A771)

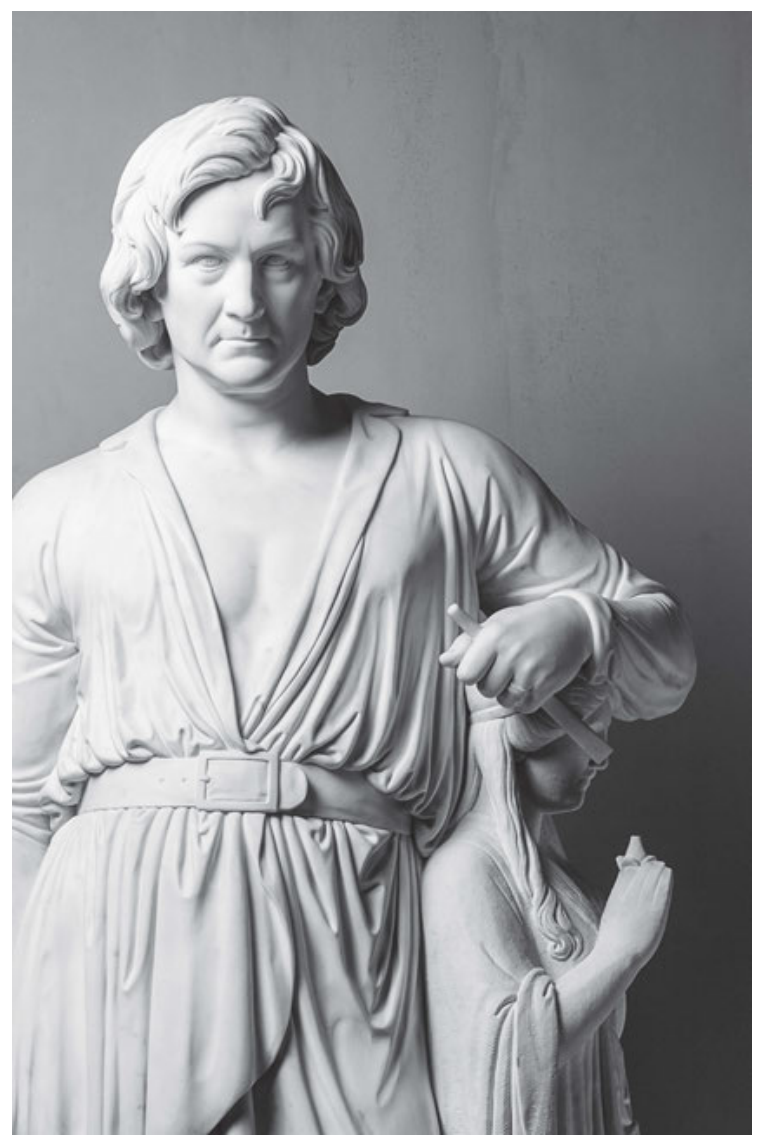

tische Styl derselben“ gewesen, der „einen bessern Contrast zu seiner eigenen Statue darbiete, welche ja das Lebende vorstellen solle“. ${ }^{361}$ Ob diese Begründung tatsächlich auf den Bildhauer zurückgeht oder aber auf dessen Biografen, lässt sich nicht nachweisen. Doch machen die beiden Erklärungen deutlich, dass das Werk bereits unmittelbar nach Vollendung in seiner Vielschichtigkeit erkannt und auf verschiedenen diskursiven Ebenen besprochen wurde. Die angeführten Gründe für die Wahl der Göttin der Hoffnung - fokussierend auf die geistige Komponente der Kunst einerseits und die materielle andererseits - verdeutlichen die zeitgenössische Stilisierung von Thorvaldsen zum Künstlergenie und Handwerker gleichermaßen. ${ }^{362}$ 


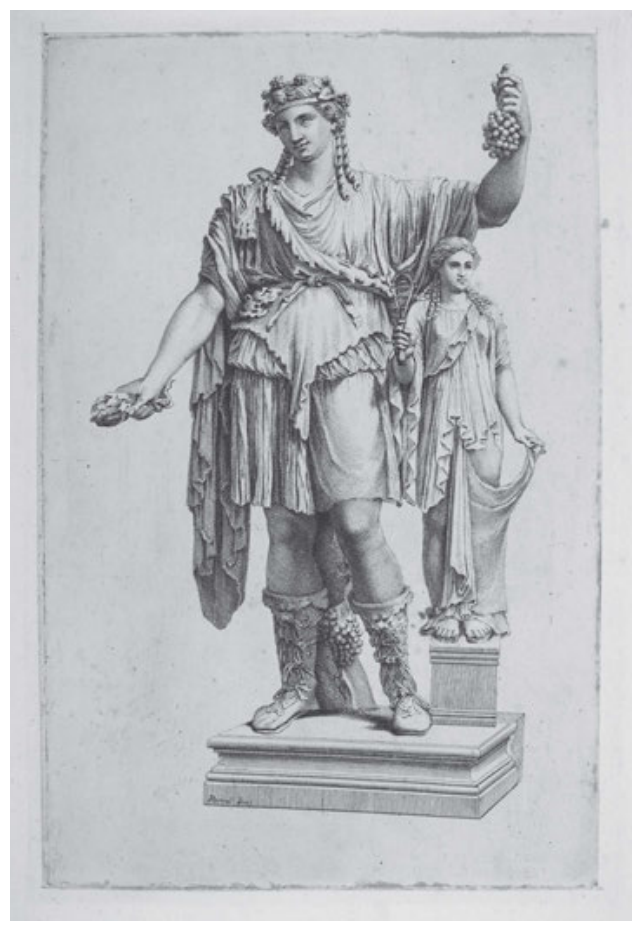

38_Giuseppe Sforza Perini, Bacchus mit der Göttin der Hoffnung oder Spes (nach der antiken Dionysos-Statue in der Eremitage in St. Petersburg), Radierung, $291 \times 188 \mathrm{~mm}$, Kopenhagen, Thorvaldsens Museum (Inv.-Nr. E1457)

Wie auch Plinius' Verweis auf Theodoros von Samos veranschaulicht, lässt sich die Kombination einer ,lebenden' Figur und einer Statue auf vereinzelte antike Vorbilder zurückführen, während sie in der späteren Bildhauerei bis zu Thorvaldsen kaum mehr vorkommt. Am wahrscheinlichsten erscheint die Orientierung Thorvaldsens an einer antiken Dionysos-Statue, die sich damals im Besitz seines ersten Gönners Hope befand und 1836 als Kupferstich verbreitet wurde. ${ }^{363}$ Der sogenannte Dionysos Hope besteht - wie Thorvaldsens Werk - aus zwei Figuren: dem Weingott und einer Spes-Statue, deren Kopf Bacchus' linken Arm stützt. Eng mit dieser Skulptur in Verbindung steht Giuseppe Sforza Perinis Radierung Bacchus mit der Göttin der Hoffnung oder Spes, von der Thorvaldsen selbst einen Abzug besaß (Abb. 38).

Was Thorvaldsens Selbstbildnis mit der Statue der Hoffnung indessen von möglichen Vorbildern unterscheidet, ist die rechtwinklige Platzierung der Selbstporträtfigur und der

363 Hartmann 1979, 66 und 73; auch Mildenberger 1991, 191; Kanzenbach 2007, 30, Anm. 58; Reichardt 2009, 133; Friborg 2014. Der Dionysos Hope befindet sich heute im Metropolitan Museum in New York (Inv.-Nr. 1990.247). Else Kai Sass verweist zudem auf die späthellenistische Statue von Aphrodite im Museo Archeologico in Venedig, deren linker Arm auf einer mit einer archaischen Frauenfigur geschmückten Plinthe ruht; Sass 1958, 79. 
Göttin der Hoffnung zueinander. Nach Mikkel Bogh entspricht die Selbstporträtfigur für sich genommen in ihrer Frontalität den klassizistischen Gestaltungsprinzipien, indem der „Rundskulptur ein ausgesprochener Reliefcharakter“ verliehen und der Betrachterblick damit auf eine bestimmte Ansicht des Werks gelenkt wird. ${ }^{364}$ Als Ganzes zeichnet sich Thorvaldsens Selbstbildnis mit der Statue der Hoffnung hingegen gerade durch die Aufhebung der für die klassizistische Plastik charakteristischen Frontalität aus: Dadurch, dass das Modell der Göttin der Hoffnung im rechten Winkel zum Selbstporträt platziert ist, wird die Betrachterin oder der Betrachter aufgefordert, um das Werk herumzugehen und es sich von mehreren Seiten anzusehen. ${ }^{365}$ Darin kommt wiederum das in den beiden vorangegangenen Kapiteln angesprochene neue Verständnis der Kunstbetrachtung zum Ausdruck, wonach ein Werk nicht mehr einzig in seiner Hauptansicht, sondern von allen Seiten studiert werden sollte. In demselben Kontext sind auch die zitierten Lobpreisungen der Mehransichtigkeit der Jason-Statue und der Göttin der Hoffnung zu verstehen. ${ }^{366}$

\section{Drei Schritte im bildhauerischen Arbeitsprozess}

Zur Umrundung von Thorvaldsens Skulptur durch das Publikum trägt neben der rechtwinkligen Platzierung des Selbstporträts und der Göttin der Hoffnung zueinander das unscheinbarste Element in diesem Werk bei: der Marmorblock hinter den beiden Figuren. Bogh deutet ihn als „neutrale Komponente“ im Werk, die dessen Statik diene. ${ }^{367}$ Die scheinbar untergeordnete Bedeutung des Steinblocks wird durch die Aufstellung der Marmorversion der Skulptur in Thorvaldsens Museum in Kopenhagen unterstrichen: Im Gegensatz zur freieren Aufstellung des Originalmodells in der Thorvaldsen-Sammlung auf Nysø steht die Marmorskulptur mit ihrer Rückseite so dicht an der Wand, dass man sie nicht vollständig umrunden kann. Doch wäre gerade dies notwendig für die Entfaltung nicht nur ihrer plastischen und räumlichen Wirkung, sondern auch ihrer inhaltlichen Aussage. Denn betrachtet man die verschiedenen Elemente des Selbstbildnisses mit der Statue der Hoffnung in ihrem inneren Zusammenhang, so scheint der Marmorblock keineswegs eine neutrale oder gar nebensächliche Werkkomponente zu sein. Vielmehr dürfte er wie die unvollendete Göttin der Hoffnung einen Schritt im bildhauerischen Arbeitsprozess verkörpern. Dadurch, dass der Marmorblock schon behauen ist, jedoch noch

365 Ebd., 29-30. Bogh sieht die rechtwinklige Platzierung der beiden Figuren zueinander indessen eher als einen Widerspruch innerhalb des Werks: Auf der einen Seite habe man das klassizistische Gestaltungsprinzip der Frontalität, die nach Bogh dieses Werk insgesamt beherrsche; auf der anderen Seite breche die räumliche Ausrichtung der Göttin der Hoffnung mit diesem Prinzip.

366 Zu Jason siehe Fernow 1806, 198 -199, Anm.: „gefällige Ansicht [...] von allen Seiten“; zur Göttin der Hoffnung siehe Caroline von Humboldt an Wilhelm von Humboldt, 23. Dezember 1817, zit. nach Wittstock 1975, 303: „[...] sie macht sich in allen Linien, und wie man sie auch wendet, gleich schön [...]“.

367 Bogh 2001, 19-20. In seiner früheren Thorvaldsen-Monografie räumt Bogh jedoch ein, dass der Marmorblock für die Statik des Werks nicht notwendig ist; Bogh 1997, 59. 
keine konkrete Gestalt erkennen lässt, kann er gewissermaßen am Übergang zwischen dem reinen Material und der daraus zu schaffenden Form gesehen werden. ${ }^{368}$ Folglich stellt Thorvaldsens Werk mit dem Steinquader, der unfertigen Göttin der Hoffnung und schließlich der Selbstporträtfigur drei sich steigernde Grade von Bildhaftigkeit dar.

Bogh betrachtet den Marmorblock zudem als primitiven Ausgangspunkt einer zeitlichen Entwicklung in der Geschichte der Bildhauerei, die über die archaische Plastik bis hin zu jener von Thorvaldsens eigener Epoche führt. ${ }^{369}$ Dabei symbolisiert Thorvaldsens Selbstbildnis nach Bogh den Höhepunkt der Skulpturgeschichte. ${ }^{370}$ Flemming Friborg geht in seiner Interpretation noch einen Schritt weiter, indem er Thorvaldsens Selbstbildnis mit der Statue der Hoffnung im Sinn einer Selbstinszenierung des Bildhauers als Erschaffer des archaischen Ideals versteht. ${ }^{371} \mathrm{Zu}$ dieser Selbstinszenierung trägt sicherlich auch bei, dass sich Thorvaldsen als Schöpfer einer göttlichen Figur und dadurch gewissermaßen als sculptor deus darstellte. ${ }^{372}$ Schon 1820 hatte der Autor Bernhard Severin Ingemann in seinen lyrischen Reiseerinnerungen den dänischen Bildhauer als „Schöpfer“ der „alten Götter der Welt“ bezeichnet. ${ }^{373}$

Diese Vergötterung Thorvaldsens lässt den Wortlaut in Vasaris Raffael-Vita nachklingen, die den Urbinaten den „sterblichen Göttern“ (Dei mortali) zurechnet, und muss erneut im größeren Kontext des romantischen Künstlerkults gelesen werden: Der Künstler wird nicht mehr nur als fähiger Handwerker betrachtet, sondern als gottgleiches Genie verehrt. ${ }^{374}$ Dementsprechend ist sogar von Canova überliefert, dass er Thorvaldsen nach dessen Modellierung der Adonis-Statue 1808 gegenüber der Dichterin Brun einen „göttlichen Mann“ genannt habe. ${ }^{375}$ Auf Oehlenschlägers Bezeichnung des Bildhauers als „wahres, göttliches Genie“ im Jahr 1809 wurde bereits in der Einleitung hingewiesen. ${ }^{376}$ Wenige Jahre später bemühten sich die Dänen vergeblich, Thorvaldsen zu einem längeren Aufenthalt in seiner Heimat zu bewegen. Dieses Vorhaben wurde besonders durch den Baron Schubart vorangetrieben, der den Bildhauer in einem Brief vom 28. Februar 1812 mit den

368 Siehe auch Bogh 2001, 20 und 25 - 26; Friborg 2014.

369 Bogh 1997, 60; Bogh 2001, 21-22; auch Miss 2016, 74.

370 Bogh 2001, 24-25.

371 Friborg 2014.

372 Siehe auch Bogh 2001, 19.

373 Bernhard Severin Ingemann, Rejselyren, Bd. 2, Kopenhagen: Boas Brünnich, 1820, 75, zit. nach Wittstock 1975, 311: „[...] Seer Verdens gamle Guder - og deres Skabermand.“

374 Siehe dazu auch Friborg 2014. Zu Vasaris Raffael-Vita siehe bspw. Thimann 2015, 11.

375 Zit. nach Brun 1815, 26: „Questo davvero e un uomo divino!“ (Hervorhebungen im Original). Dieser Ausruf wurde in den meisten späteren Quellen und in der Sekundärliteratur ebenfalls zitiert oder paraphrasiert.

376 Adam Oehlenschläger an Christiane Heger, im April 1809, zit. nach Paludan/Preisz/Borup 1945 - 1950, 260: „Thorwaldsen har glædet mig usigelig. Det er et sandt guddommeligt Genie [...]. “ Siehe auch Wittstock 1975, 322. 
Worten „Sie werden von Allen wie ein Halbgott empfangen werden“ zu locken suchte. ${ }^{377}$ Dieses Verständnis von Thorvaldsen als Künstlergott kommt auch in einem Brief zum Ausdruck, in dem Caroline von Humboldt am 20. Juni 1817 an den Archäologen Welcker schrieb: „Thorvaldsen ist als Künstler ein Gott geworden. “378 Am 14. August desselben Jahres formulierte sie ihre Verehrung für den Bildhauer als gottgleichen Schöpfer in einem Brief an ihren Gatten Wilhelm von Humboldt schließlich in den folgenden Worten:

Thorvaldsen ist zu einer schwindlichen Höhe als Künstler gestiegen, und es gelingt ihm jetzt, die Gestalten seines Künstlersinnes gleichsam wie durch einen Zauberschlag hinzustellen, die Mühe ist überwunden und nichts erinnert mehr beim Anschauen des Werks, dass es gemacht ist. ${ }^{379}$

Ähnlich klingen die Briefe, die Caroline von Humboldt von Brun empfing. Diese schrieb am 3. Dezember 1819 anlässlich von Thorvaldsens langersehntem Besuch in Kopenhagen: „Man vergöttert ihn u trägt ihn liebevoll auf Händen“, und am 27. Juni des folgenden Jahres subjektiver: „[...] ich vergöttere ihn als Künstler!“380 Diese fast grenzenlose Verehrung des Bildhauers beobachtete 1834 auch ein finnischer Reisender, wonach die „Dänen [...] an den Lippen von Thorvaldsen wie an jenen eines Gottes“ hingen. ${ }^{381}$ Schließlich bezeichnete Johanna Steinheim Thorvaldsen in einem vom 29. Oktober 1842 datierenden Brief an den Gelehrten Hanno als „wahre Göttergestalt, [...] wie ich noch nie ein menschliches Antlitz gesehen habe“. ${ }^{382}$ All diesen Huldigungen an Thorvaldsen als Künstlergott zum Trotz ging es den Zeitgenossen zu weit, als die Improvisatorin Rosa Taddei in einer Darbietung in Rom zum Thema „I progressi della scultura“ am 21. März 1826 den dänischen Bildhauer als „un figlio di Dio“ bezeichnete. ${ }^{383}$

\section{Die Rolle der Baronin Christine Stampe}

Eine der wichtigsten Triebfedern im Entstehungsprozess von Thorvaldsens Selbstbildnis mit der Statue der Hoffnung war die Baronin Stampe, die Thorvaldsen nach seiner Rückkehr nach Dänemark 1838 regelmäßig auf ihrem Landsitz Nysø bei Præstø beherbergte. Sie schreibt in ihren Memoiren: „Thorvaldsen hatte mehrere Bedenken gehabt, und ich

377 Herman Schubart an Bertel Thorvaldsen, 28. Februar 1812, TMA, Ref. m3 1812, nr. 11: „De vil af alle blive modtaget som en Halv Gud.“ Siehe auch Thiele 1852-1856, Bd. 1, 216.

378 Caroline von Humboldt an Friedrich Welcker, 20. Juni 1817, zit. nach Wittstock 1975, 300, auch 122. Siehe auch Jørnæs 2011, 204.

379 Caroline von Humboldt an Wilhelm von Humboldt, 14. August 1817, zit. nach Wittstock 1975, 302, auch 122.

380 Friederike Brun an Caroline von Humboldt, 3. Dezember 1819 bzw. 27. Juni 1820, zit. nach Foerst-Crato 1975,187 und 210.

381 Zit. nach Hartmann 1966, 4: „I danesi pendevano dalle labbra del Thorvaldsen come da quelle di un dio."

382 Johanna Steinheim an Raphael Hanno, 29. Oktober 1842, TMA, Ref. m30 II, nr. 78.

383 Thiele 1852-1856, Bd. 2, 166. Siehe auch Andersen 1845, 48. 
musste [sie] wesentlich beseitigen, bevor ich ihn zu dieser Arbeit [der Selbstbildnisstatue] überredet bekam. “" ${ }^{384}$ Unter anderem war sein Arbeitszimmer in ihrem Wohnhaus auf Nysø nicht geräumig und hell genug, damit der Künstler eine Selbstbildnisstatue in Lebensgröße hätte ausführen können. Dies veranlasste die Baronin, ihm ein separates Atelier im Garten ihres Guts errichten zu lassen, das im Kapitel III.3 eingehend besprochen wird (Abb. 89). ${ }^{385}$ Unmittelbar nach der Fertigstellung von Vølunds Voerksted (Vølunds Werkstatt), wie dieses kleine Atelier in Anlehnung an den Meisterschmied aus der nordischen Mythologie benannt wurde, motivierte Stampe den Bildhauer zur Ausführung des lebensgroßen Modells seines Selbstbildnisses. Stampes Rolle beschränkte sich dabei nicht auf mündlichen Zuspruch: Sie fasste tatkräftig mit an, indem sie fehlendes Material wie Eisen für das innere Gerüst des Modells herbeischaffte und für dieses unter Thorvaldsens Anleitung Hunderte kleine Holzkreuze herstellte sowie den Ton vorbereitete. ${ }^{386}$ „Kurz“, schreibt Stampe, „wir begannen zu arbeiten - ich sage wir, denn ich arbeitete mit nach vollen Kräften -, denkend, dass man schmieden muss, während das Eisen warm ist. “" ${ }^{387}$ Diese Aussage ist ein eindeutiger Verweis auf die Bezeichnung von Thorvaldsens Atelier als Werkstatt des nordischen Meisterschmieds Vølund. Nach einigen Tagen war das großformatige Modell fertig, woraufhin es in Gips gegossen wurde. ${ }^{388}$

Nicht nur ist die Entstehung des Selbstbildnisses mit der Statue der Hoffnung zu einem wesentlichen Teil der Baronin zu verdanken; auch die spezifische Darstellung des Bildhauers von sich selbst offenbart dessen enge Verbindung zu seiner Gönnerin. Beispielsweise scheint er sich in demjenigen Hemd zu präsentieren, das Stampe für ihn nach sei-

384 Baronesse Stampes Erindringer 1912, 38: „Thorvaldsen havde haft adskillige Betænkeligheder, og jeg havde haft adskilligt at rydde af Veien, før jeg fik ham overtalt til dette Arbeide. “ Zu Christine Stampes Rolle im Entstehungsprozess von Thorvaldsens Selbstbildnis mit der Statue der Hoffnung siehe auch Repholtz 1911, 24; Repholtz 1921, 92 - 93; Helsted 1973, 52 - 53; Gelius/Henschen/Miss 2001, 21; Helsted 2001b, 11; Bech 2009a. Das Selbstbildnis mit der Statue der Hoffnung war gemäß Stampes eigener Überlieferung ihr gewidmet; Baronesse Stampes Erindringer 1912, 41; siehe auch Henschen 1982, 56; Berner 2005, 78. In der Tat schenkte Thorvaldsen seiner Gönnerin das Originalmodell seines Selbstbildnisses mit der Statue der Hoffnung; siehe dazu Gelius/Henschen/Miss 2001, 22.

385 Baronesse Stampes Erindringer 1912, 26; auch Repholtz 1911, 23 - 24; Henschen 1989, 100 - 101; Jørnæs 2011, 222.

386 Baronesse Stampes Erindringer 1912, 37. Zu Thorvaldsens Arbeitsmethode siehe Kap. III.1. Jene aktive Mitarbeit der Baronin Stampe scheint sich nicht auf den Entstehungsprozess von Thorvaldsens Selbstbildnis mit der Statue der Hoffnung beschränkt zu haben; Bech 2009a.

387 Baronesse Stampes Erindringer 1912, 37: „Kort vi begyndte at arbeide - jeg siger vi, thi jeg arbeidede med af alle Kræfter -, tænkende, man maa smede, mens Jærnet er varmt.“

388 Üblicherweise wurde das Tonmodell nach dem Gießen zerstört, doch Stampe gelang es, das tönerne Gesicht des Bildhauers aufzuheben, weshalb es bis heute in der Thorvaldsen-Sammlung auf Nysø zu sehen ist (Inv.-Nr. Nysø72); siehe dazu auch Schultz 1938, 90; Helsted 1977, 11; Henschen 1982, 57; Helsted/Henschen/Jørnæs 1990, 108; Kat. Nürnberg/Schleswig 1991, 523; Gelius/Henschen/Miss 2001, 36; Helsted 2001a, 12. Neben diesem Tonfragment werden bis heute zwei Studien, die kleinformatige Skizze sowie das Originalmodell auf Nysø aufbewahrt. 
nem eigenen Entwurf während der Arbeit an der Selbstporträtstatue nähte. ${ }^{389}$ Es ist bezeichnend, dass Thorvaldsen dasselbe Hemd auch in seinem zweiten Selbstporträt aus jenen Jahren trägt: Das 1840 geschaffene Relief Selbstbildnis mit der Familie Stampe zeigt den Bildhauer, wie er seine rechte Hand in die Hüfte stützt und sich mit seinem linken Unterarm auf das Kavalett lehnt (Abb. 33). ${ }^{390}$ Darauf steht der Bozzetto des Apostels Andreas für die Kopenhagener Frauenkirche, den er ebenfalls ab 1840 modellierte. ${ }^{391}$ Thorvaldsen ist umgeben von Christine Stampe und ihren Kindern Christian, Jeanina und Elisa (v. 1.). ${ }^{392}$ Die Baronin scheint dem Bildhauer eben aus einem Buch vorgelesen zu haben, wie sie es oft zu tun pflegte. Während die beiden Töchter der Unterhaltung zwischen ihrer Mutter und Thorvaldsen lauschen, hält Christian Stampe die Wasserschale zum Benetzen des Tuches über dem Ton in den Händen.

Beim Selbstbildnis mit der Familie Stampe handelt es sich um eine der seltenen Reliefdarstellungen eines Bildhauers an seinem Arbeitsplatz. ${ }^{393} \mathrm{Zu}$ diesem Werk schuf Thorvaldsen im selben Jahr ein Pendant, das den Baron Henrik Stampe beim Baden sowie seine Söhne Holger zu Pferd und Henrik bei der Rückkehr von der Jagd zeigt (Abb. 39). ${ }^{394}$ Diese beiden Reliefs bilden die einzigen Alltagsdarstellungen in Thorvaldsens plastischem Oeuvre. ${ }^{395}$ Christine Stampes Bezeichnung dieser Reliefpendants als „Familienstücke“ (Familiestykker) untermalt ebenjenen genrehaften Charakter. ${ }^{396}$

Thorvaldsens Darstellung von sich selbst im Zentrum des Reliefs mit der Familie Stampe ist ähnlich selbstbewusst und idealisierend wie jene im Selbstbildnis mit der Statue der Hoffnung. Die Bewunderung für Thorvaldsen wird durch den zu ihm empor gerichteten Blick von Christine Stampe und ihren Töchtern unterstrichen. Eine weitere Parallele zwischen dem Relief und der Selbstbildnisstatue ist schließlich die Gegenüberstellung von

389 Baronesse Stampes Erindringer 1912, 41; siehe auch Repholtz 1911, 29; Bach 2001, 37; Berner 2005, 78 - 79.

390 Siehe zu diesem Relief auch Thiele 1831-1850, Bd. 4, 104; Thiele 1852-1856, Bd. 3, 78 - 79.

3911820 hatte Thorvaldsen den Auftrag zur skulpturalen Gesamtausstattung der Kopenhagener Frauenkirche erhalten; siehe dazu auch Kap. III.1.

392 Siehe auch Bjarne Jørnæs, in: Wilckens 1973, 152; Helsted/Henschen/Jørnæs 1990, 110; Gelius/Henschen/Miss 2001, 43.

393 Kanzenbach 2007, 191. Ein weiteres Beispiel ist Nanni di Bancos Relief einer Bildhauerwerkstatt am Fuß des Tabernakels der Vier Heiligen von 1410-1412 an der Fassade von Orsanmichele in Florenz; siehe dazu Goldscheider 1936, 13.

394 Siehe zu diesem Relief auch Thiele 1831-1850, Bd. 4, 105; Thiele 1852 - 1856, Bd. 3, 79; Repholtz 1911, 54; Baronesse Stampes Erindringer 1912, 73 - 74; Bjarne Jørnæs, in: Wilckens 1973, 153; Gelius/Henschen/ Miss 2001, 44; Miss 2016, 76.

395 Siehe auch Baronesse Stampes Erindringer 1912, 76 - 77; Repholtz 1921, 93; Helsted 1973, 32; Kat. Reykjavik 1982, 127; Helsted/Henschen/Jørnæs 1990, 110; Jørnæs 2011, 228; Miss 2016, 76. Die anderen genrehaften Darstellungen in Thorvaldsens plastischem Oeuvre entstammen einem mythologischen oder poetischen Kontext.

396 Baronesse Stampes Erindringer 1912, $73-74$. 


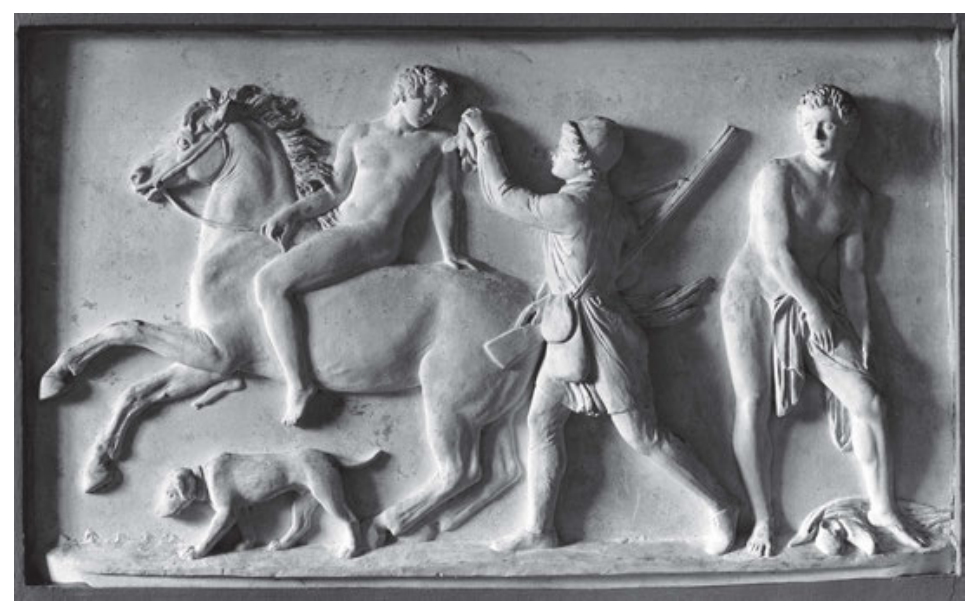

39_Bertel Thorvaldsen, Henrik Stampe mit zwei Söhnen, 1840, Gipsmodell, $60 \times 101 \mathrm{~cm}$, Nysø, Thorvaldsen-Samlingen (Inv.-Nr. Nysø39)

menschlichen Figuren und Skulptur, deren Unterscheidung im Familienstück vor allem durch die bewegte beziehungsweise statische Körperhaltung erfolgt. ${ }^{397}$

Dass sich Thorvaldsen in den beiden Selbstporträts in seinem Arbeitsgewand darstellte, hat sich Erik Moltesen mit der bescheidenen Natur des Bildhauers erklärt. ${ }^{398}$ Dass es sich bei diesem oft betonten Charakterzug jedoch in erster Linie um einen Topos handelt, veranschaulicht Thorvaldsens äußerst selbstbewusste Erscheinung sowohl in zeitgenössischen Porträts, an deren Resultat der Bildhauer nicht selten aktiv beteiligt war, als auch in seinen Selbstbildnissen. ${ }^{399}$ Dies untermalt gerade auch Thorvaldsens Kleidung in seinen beiden späten Selbstporträts: Das von der Baronin genähte Hemd mit dem Gürtel mit großer Schnalle ist nicht bloß ein zeitgenössisches Arbeitsgewand, sondern erinnert besonders in Kombination mit dem Hammer in der Selbstbildnisstatue - an die Ikonografie des nordischen Donnergottes Thor. ${ }^{400}$ Gemäß Stampe sah auch Thorvaldsen selbst einen Zusammenhang zwischen seinem Selbstporträt und der Thor-Ikonografie. So soll er beim Anlegen des Hemdes und beim Schließen der Gürtelschnalle scherzhaft zur Baronin gesagt haben: „So werde ich stark, das tat Thor, wenn er Kräfte brauchte; man hat mich Thor genannt, der eine Thor zerschlägt, der andere schafft." ${ }^{401}$ Diese Bemerkung spielt sowohl auf Thors Machtgürtel Megingiard als auch auf den Kosenamen „Thor“ an, den

397 Siehe auch Helsted 1973, 32.

398 Moltesen 1929, 487, mit Bezug auf das Selbstbildnis mit der Statue der Hoffnung.

399 Für Ausführungen zu den Porträts von Thorvaldsen siehe Kap. II.

400 Siehe auch Jørgensen 1972a, 48; Jørgensen 1972b, 30; Bjarne Jørnæs, in: Helsted 1973, 54; Eldjárn 1982, 29; Krause 2010, 157; Jørnæs 2011, 222.

401 Zit. nach Baronesse Stampes Erindringer 1912, 41: „Saa bliver jeg stærk, det giorde Thor, naar han brugte Kræfter; man har kaldt mig Thor, den eene Thor knuser, den Anden skaber.“ 
Stampe dem Bildhauer gab. Dabei dürfte es sich um weit mehr als eine Abkürzung von Thorvaldsens Namen handeln. Bezeichnenderweise hatte der Geistliche und Dichter Nikolai Frederik Severin Grundtvig in Thorvaldsen bereits bei dessen Heimkehr nach Kopenhagen 1838 den ,wiedererwachten Vingthor' gesehen. ${ }^{402}$

\section{Thorvaldsen und die nordische Mythologie}

Weil sich in Thorvaldsens plastischem CEuvre - ganz im Gegensatz zu jenem seines Schülers Hermann Ernst Freund - keine Motive aus der nordischen Mythologie finden, ist ihm in Quellen und Sekundärliteratur eine Auseinandersetzung mit dem skandinavischen Erbe weitgehend abgesprochen worden. ${ }^{403}$ Im ersten Jahrzehnt des 19. Jahrhunderts hatte sich Thorvaldsen im Zusammenhang mit der skulpturalen Dekoration für das wiederaufgebaute Schloss Christiansborg zumindest indirekt von einer Darstellung nordischer Themen distanziert. Nachdem Schubart ihn am 28. Dezember 1804 zur Schaffung von Skulpturen mit Motiven aus der nordischen Sagenwelt anregen wollte, begründete Thorvaldsen in einem Schreiben vom 16. Februar 1807 an den für den Neubau des Schlosses verantwortlichen Architekten Christian Frederik Hansen seinen Entscheid für Themen aus der griechischen Mythologie in folgenden Worten:

Es schmeichelt mir sehr, dass die Wahl der Themen mir selbst überlassen wird - um die Forderung der Hohen Kommission nach allegorischen Themen in den Medaillons für das Schloss zu erfüllen, gedenke ich von der griechischen Mythologie Gebrauch zu machen, da dieselbe die kultivierteste und folglich die würdigste für die Kunst ist [...].404

Das Fehlen von unmittelbaren Äußerungen Thorvaldsens zur Behandlung von Motiven aus der nordischen Mythologie dürfte - zusätzlich zu seiner klassizistischen Gesinnung auf einen öffentlichen Streit zurückgehen, der in den 1810er und frühen 1820er Jahren in Dänemark die Gemüter erhitzte. Dabei ging es um die Frage nach der Brauchbarkeit und

Nikolai Frederik Severin Grundtvig, „Til Thorvaldsen“, 7. Oktober 1838, TMA, Ref. m33, nr. 26: „Vingthor er vaagnet paany!“ (letzte Zeile eines anlässlich von Thorvaldsens Rückkehr nach Dänemark gesungenen Liedes). Vingthor ist ein anderer Name für Thor.

403 Siehe bspw. Atkinson 1873, 57; Lücke 1883, 42; Stein, J. 1918 - 1919, 117; Jørnæs 2011, 131. Zu Freunds Beschäftigung mit der nordischen Mythologie siehe bspw. Ljøgodt 2012, $150-151$.

404 Bertel Thorvaldsen an Christian Frederik Hansen, 16. Februar 1807, TMA, Ref. m28, nr. 5: „Det er mig saare smigrende at Valget af Sysetterne overlades til mig selv - for at opfylde den Høye Commissions Forlangende med Allegoriske Sysetter i Medaillionerne til Slottes mener jeg at gjøre Brug af den Græske Mytologie, saa som samme er den mest cultiverde og følgelig den værdigste for Konsten [...]“. Siehe auch Thiele 1852-1856, Bd. 1, 156. Zum erwähnten Brief von Schubart: Herman Schubart an Bertel Thorvaldsen, 28. Dezember 1804, TMA, Ref. ml 1804, nr. 24. Siehe auch Thiele 1852-1856, Bd.1, 116 - 117. Auf diesen Brief ist keine Antwort des Bildhauers erhalten geblieben, doch in seinem darauffolgenden Brief scheint sich Schubart auf Thorvaldsens Wunsch zu beziehen, sich weiterhin Motiven aus der antiken Mythologie zu widmen; Herman Schubart an Bertel Thorvaldsen, 4. März 1805, TMA, Ref. ml 1805, nr. 2; auch Kofoed 2014a. 
Legitimität von Themen aus der erst in den 1770er Jahren wiederentdeckten und dementsprechend noch relativ unbekannten skandinavischen Sagenwelt. ${ }^{405}$ Die Gegner sahen darin eine Quelle der Barbarei und waren überzeugt, dass große Kunst nur am Vorbild von antiken und christlichen Motiven geschaffen werden könne. Die Befürworter, darunter der später die Errichtung von Thorvaldsens Museum wesentlich vorantreibende Kunsthistoriker Niels Lauritz Høyen, betrachteten die nordische Mythologie hingegen als wertvolles Erbe ihres Volkes, das gerade im Formationsprozess eines neuen dänischen Nationalbewusstseins in den Jahren nach 1800 eine zentrale Rolle spielte und allein schon deshalb der Darstellung in den bildenden Künsten würdig sei. Zentral für diese neue Gesinnung war das Bewusstsein, nicht Erbe der Griechen und Römer zu sein, sondern eine eigene Geschichte zu besitzen. ${ }^{406}$

Kira Kofoed hat in ihrem Aufsatz zu jenem Streit die interessante Beobachtung gemacht, dass beide Seiten angebliche Aussagen von Thorvaldsen zur Stärkung ihrer Argumente benutzten. ${ }^{407}$ Die Tatsache, dass Thorvaldsens Name zur Rechtfertigung der unterschiedlichsten Anliegen beigezogen wurde, veranschaulicht dessen celebrity-Status, der dem Bildhauer eine außerordentliche Präsenz im kollektiven Bewusstsein der Dänen gesichert hatte. Der genannte Streit ging so weit, dass Kronprinz Christian Frederik den Bildhauer am 12. August 1821 in einem erfolglos gebliebenen Brief gar um einige Zeichnungen mit nordisch-mythologischen Motiven bat. ${ }^{408}$ Dahinter steckte die am Ende nicht erfüllte Absicht, die Kritik von nordischen Themen in der Skulptur verstummen zu lassen.

Im selben Kontext der Wiederentdeckung des nordischen Erbes bemühte sich Thorvaldsens Umfeld über die Jahre hinweg, den Bildhauer mit der altnordischen Götter- und Sagenwelt vertraut zu machen. Besonders deutlich manifestierte sich diese Absicht in der Eröffnungsfeier von Thorvaldsens Atelier auf Nysø, Vølunds Vorksted, die sich altnordische Legenden zum Motto nahm. ${ }^{409}$ Ferner las Christine Stampe - zusätzlich zu ihrer Funktion als Thorvaldsens „Handlangerin“ (Haandlanger), wie sie ihre eigene Rolle bezeichnete - dem Bildhauer während dessen Arbeit am Selbstbildnis mit der Statue der

405 Siehe zu diesem Streit ausführlich Kofoed 2014a; auch Ljøgodt 2012, 146 - 147; Skjøthaug 2017. Die Wiederentdeckung der nordischen Mythologie muss im Dunstkreis von James Macphersons in den 1760er Jahren erschienenem, der keltischen Mythologie zuzurechnendem Ossian-Epos betrachtet werden. Die enorme Popularität dieses Epos reichte weit über die schottischen und britischen Grenzen hinaus, erfuhr eine rege literarische und bildkünstlerische Rezeption und weckte in verschiedenen nordeuropäischen Ländern das Bedürfnis, die eigene, von den Griechen und Römern unabhängige Geschichte wiederzuentdecken. Siehe dazu bspw. Krause 2010, bes. 194; Ljøgodt 2012, 142.

406 Siehe auch Ljøgodt 2012, 146; Skjøthaug 2017, 92 - 93.

407 Kofoed 2014a.

408 Christian Frederik von Dänemark (später Christian VIII.) an Bertel Thorvaldsen, 12. August 1821, TMA, Ref. m7 1821, nr. 58. Siehe auch Thiele 1852 - 1856, Bd. 2, 61; Oppermann 1930, 14; Kofoed 2014a; Skjøthaug 2017, $93-94$.

409 Siehe dazu Kap. III.3. 
Hoffnung laut vor. ${ }^{410}$ Dabei stand neben Martin Luthers und Franklins Briefen vor allem die neuere dänische Literatur im Zentrum, namentlich Oehlenschlägers episches Gedicht Nordens Guder (dt. Titel: Die Götter Nordens) von 1819. ${ }^{411}$ Damit befolgte die Baronin ein Anliegen des Dichters, der Thorvaldsen bereits in jenem Jahr aufgefordert hatte, sich in seiner Kunst der nordischen Mythologie anzunehmen. ${ }^{412}$ Ähnliche Bestrebungen sind ferner von Seiten Freunds und des dänischen Juristen Jonas Collin überliefert. ${ }^{413}$

Obwohl sich in Thorvaldsens Euvre kein vollendetes Werk findet, das sich explizit mit nordischen Themen befasst, belegen vier eigenhändige Zeichnungen sowie sein Besitz von mindestens sechs Büchern über die nordische Mythologie, dass er dem kulturellen Erbe Skandinaviens gegenüber weniger gleichgültig war, als in Quellen und Sekundärliteratur oft angenommen wird. Die am meisten ausgereifte Zeichnung ist ein Entwurf für sein eigenes Wappen, das er anlässlich der Verleihung des Großkreuzes des DannebrogOrdens am 18. November 1839 zusammen mit einem offiziellen Bildnis für die Porträtgalerie auf Schloss Frederiksborg in Hillerød einreichen sollte (Abb. 40). ${ }^{414}$ Letzteres führte Christian Albrecht Jensen aus, worauf noch zurückgekommen wird. ${ }^{415} \mathrm{Da}$ Thorvaldsen bis zu seiner Ernennung zum Großkreuz-Ritter kein Wappen führte, zeichnete er nun verschiedene Entwürfe für ein solches. ${ }^{416} \mathrm{Zu}$ sehen ist auf der genannten Zeichnung Thor mit Bärenfell und Hammer. ${ }^{417}$ Bereits um 1827 hatte der Bildhauer ein Siegel mit einer Darstellung des Donnergottes entworfen. ${ }^{418}$ In demselben Jahr scheint er zudem schon mit der Konzipierung eines eigenen Wappens beschäftigt gewesen zu sein, wie aus zwei verschiedenen Zeichnungen ersichtlich wird, die vermutlich ebenfalls Thor darstellen. ${ }^{419}$ Sein Wappen von 1839 ergänzte Thorvaldsen mit dem Wahlspruch „Freiheit und Liebe zum Vaterland“" (Frihed og Kjorlighed til Foedrelandet). Die Nennung der Freiheit scheint auf einen Rat von Oehlenschläger zurückzugehen: „Du bist ja ein Mann der Freiheit [...], darum sollst du diese Worte brauchen: ,Freiheit und Liebe zum Vaterlande.““420 Damit

Zitat: Baronesse Stampes Erindringer 1912, 38. Neben Stampe besuchte auch Andersen den Bildhauer in seinem Atelier auf Nysø und las ihm vor; siehe dazu Repholtz 1911, 30 - 31; Baronesse Stampes Erindringer 1912, 39.

411 Baronesse Stampes Erindringer 1912, 38; auch Repholtz 1911, 30; Helsted 1973, 53.

412 Oehlenschläger 1819, 43. Siehe auch Thiele 1852 - 1856, Bd. 2, 113; Jørnæs 1982a, 41; Henschen 1989, 100; Jørnæs 2011, 131; Kofoed 2014a.

413 Siehe dazu Kofoed 2014a.

414 Thiele 1852 - 1856, Bd. 3, 68; auch Kanzenbach 2007, 307, inkl. Anm. 1169.

415 Siehe dazu Kap. II.3.

416 Mehrere dieser Entwürfe sind auf Briefe gezeichnet; siehe dazu Thiele 1831-1850, Bd. 4, 92; Thiele 1852 -1856, Bd. 3, bes. 69; Wilckens 1875, 70; Müller, S. 1893, 280.

417 Siehe auch Thiele 1831-1850, Bd. 4, 92; Thiele 1852-1856, Bd. 3, 69; Wilckens 1875, 70; Müller, S. 1893, 280; Kofoed 2014a.

418 Kopenhagen, Thorvaldsens Museum (Inv.-Nr. C386v).

419 Kopenhagen, Thorvaldsens Museum (Inv.-Nr. C559a und C560r). Siehe dazu Kofoed 2014a.

420 Zit. nach Wilckens 1875, 70 - 71. Siehe auch Müller, S. 1893, 280 - 281. 


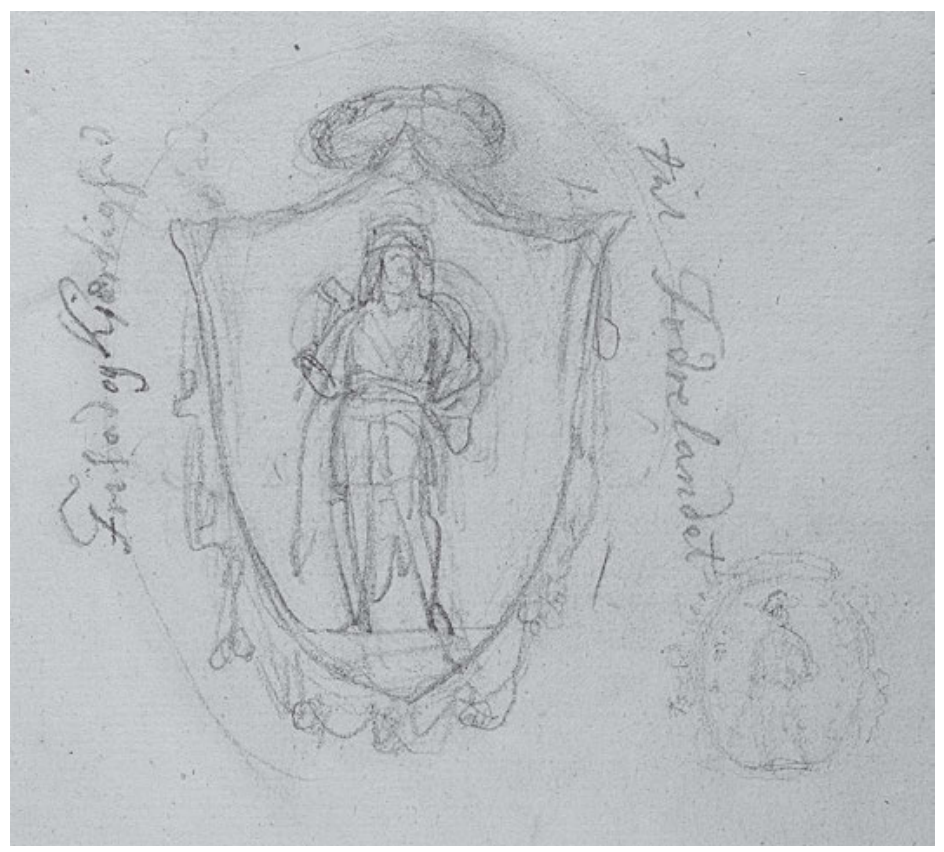

40_Bertel Thorvaldsen, Thorvaldsens Wappen und Wahlspruch, um 1839, Bleistift auf Papier, $227 \times$ 195/187 mm, Detail, Kopenhagen, Thorvaldsens Museum (Inv.-Nr. C559b)

dürfte Oehlenschläger Thorvaldsens Ablehnung der Ehe, sein Festhalten an der Eigenständigkeit als Künstler sowie die aktuelle politische Situation nach den napoleonischen Kriegen gleichermaßen angedeutet haben ${ }^{421}$ Nach Thorvaldsens Tod vollendete Ole Larsen den Entwurf für das Wappen, damit es schließlich auf Schloss Frederiksborg aufgehängt werden konnte. 422

Dass sich Thorvaldsen nur aufgrund seines Nachnamens und seines Kosenamens für eine Thor-Darstellung entschied, wie Rikard Magnussen behauptet hat, ist unwahrscheinlich. ${ }^{423}$ Vielmehr dürfte er mit seinem Wappen ganz bewusst das Bild erfüllt haben, das seine dänischen Zeitgenossen seit Langem von ihm konstruierten. Denn bereits kurz nach seinem künstlerischen Durchbruch mit seiner Jason-Statue hatten sie begonnen, seine nordische Herkunft zu betonen. Dabei ging es nicht nur um seine dänische Abstammung; vor allem wurden auch seine isländischen Wurzeln väterlicherseits stilisiert und mythisiert, indem er genealogisch mit altnordischen Figuren wie König Harald Hildetand,

421 Siehe auch Kofoed 2014a.

422 Kopenhagen, Thorvaldsens Museum (Inv.-Nr. N152). Siehe dazu Thiele 1831-1850, Bd. 4, 92; Thiele 1852 - 1856, Bd. 3, 69; Wilckens 1875, 71; Müller, S. 1893, 281; Kofoed 2014a.

423 Magnussen 1939, 58. 
dem Häuptling Oluf Paa und dem Entdecker Erik, dem Roten 'Thorvaldsson sowie ideologisch mit dem nordischen Meisterschmied Vølund in Verbindung gebracht wurde. ${ }^{424}$ Mit solchen Assoziationen bezweckte man, den Bildhauer in die skandinavische Geschichte einzuschreiben. Damit diente Thorvaldsen in der vorrevolutionären Zeit voller politischer Unsicherheiten und Unruhen als Referenzpunkt für ein neues dänisches Selbstverständnis.

Jenem durch seine Landsleute stilisierten Bild scheint Thorvaldsen keineswegs abgeneigt gewesen zu sein, sondern scheint es gelegentlich aktiv genährt zu haben. Gerade vor diesem Hintergrund ist signifikant, dass er sich für ein nordisches Motiv als Wappen entschied. Darüber hinaus dürfte es auch kein Zufall sein, dass seine Selbstbildnisstatue an die Thor-Ikonografie erinnert. Dass dies jedoch nicht ausdrücklich geschieht, ist naheliegend, da eine ernsthafte Behandlung nordischer Themen von Thorvaldsen neue Kenntnisse hinsichtlich Kleidung, Waffen und Symbolik sowie andere technische Fertigkeiten zu deren Darstellung gefordert hätte, als dies Motive aus der antiken Mythologie taten. ${ }^{425}$ Zudem war die nordische Sagenwelt im frühen 19. Jahrhundert erst einem kleinen Kreis von Intellektuellen geläufig, was Thorvaldsens Publikum merklich eingeschränkt hätte. Folglich dürfte hinter Thorvaldsens weitgehender Ausklammerung nordischer Themen aus seinem künstlerischen Schaffen - obschon er sich zweifellos mit ihnen befasste ebenfalls eine vermarktungsstrategische Überlegung gestanden haben.

\section{Zwischen griechischer Antike, römischer Mythologie und nordischer Sagenwelt} Neben der Thor-Ikonografie lassen sich beide späten Selbstbildnisse von Thorvaldsen mit dessen Darstellungen von Vulkan in Verbindung bringen, der als traditionelle Personifikation der Kunstfertigkeit gerade im Zusammenhang mit künstlerischen Selbstdarstellungen sinnstiftend ist. So erscheint das Selbstbildnis mit der Statue der Hoffnung von 1839 wie eine spiegelverkehrte Version der ein Jahr zuvor in Rom entstandenen Vulkan-Statue (Abb. 41). ${ }^{426}$ Der mythologische Feuer- und Schmiedegott stützt sich mit der rechten Hand auf Hammer und Amboss, während er in der linken Hand eine Zange hält. Seine Tunika ist über der rechten Schulter geöffnet und gibt den Blick auf seinen muskulösen Oberkörper frei. Der leicht nach unten geneigte Kopf, die selbstbewusste Haltung des starken Körpers mit dem Stützmotiv und dem vorgesetzten Bein, das mit einem Gürtel zusammengehaltene Gewand sowie das konzentrierte Innehalten im Schaffensprozess kehren in Thorvaldsens Selbstbildnis mit der Statue der Hoffnung wieder. Während bei Thorvaldsen das Modell der Göttin der Hoffnung sowie Hammer, Meißel und Marmorblock auf die Arbeit des Bildhauers verweisen, dienen in der Statue des Vulkan die ge- 


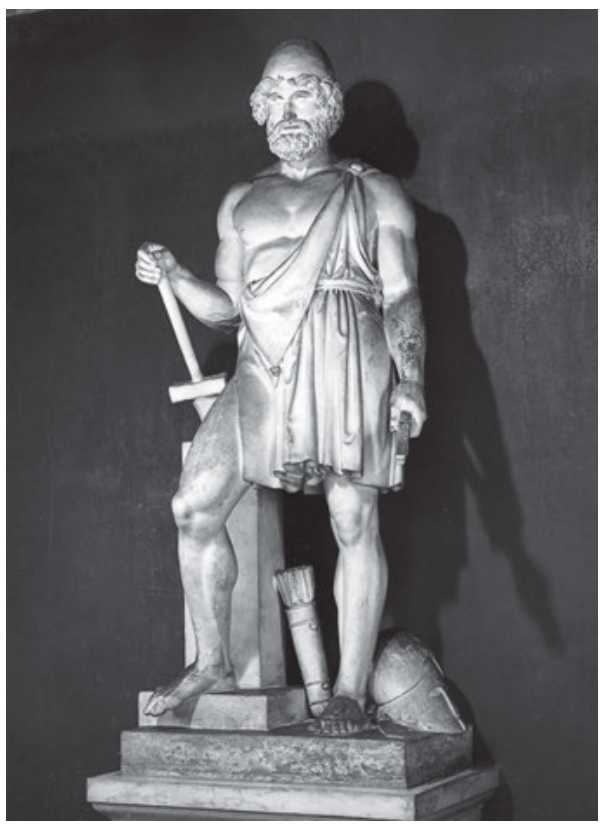

41_Bertel Thorvaldsen, Vulkan, 1838, Gipsmodell, Höhe: $241 \mathrm{~cm}$, Kopenhagen, Thorvaldsens Museum (Inv.-Nr. A9)

nannten Werkzeuge sowie der bereits geschmiedete Helm für Mars und die Pfeile für Amor als Attribute des mythologischen Feuergottes.

Derweil erinnert die Komposition des Selbstbildnisses mit der Familie Stampe an jene des um 1810 modellierten Reliefs Venus, Mars und Amor in Vulkans Schmiede (Abb. 42). Im Gegensatz zur Vulkan-Statue ist der Feuergott hier bei der Arbeit, genauer beim Schmieden von Amors Pfeilen, dargestellt. ${ }^{427}$ Besonders ähnlich ist in diesen Reliefs die Gruppe um den Künstler-Handwerker und die sitzende Frau. Formal gesehen handelt es sich beim Selbstbildnis mit der Statue der Hoffnung und dem Selbstbildnis mit der Familie Stampe folglich um keine gänzlich neuen Schöpfungen. Doch unterscheiden sie sich durch die innerskulpturale Kombination von menschlichen Figuren und lebloser Plastik von den anderen Werken in Thorvaldsens CEuvre. ${ }^{428}$

Während die beiden besprochenen Selbstporträts mit der Verknüpfung von Thorvaldsen und Vulkan einen Topos aus der antiken Mythologie aufnehmen, verkörpert die in der Selbstbildnisstatue wiedergegebene Göttin der Hoffnung den klassizistischen Rückbezug auf die Kunst und Ideale des griechischen Altertums. Dem gegenüber steht die Anlehnung an die Thor-Ikonografie in der Selbstporträtfigur Thorvaldsens, die auf dessen nordische Wurzeln verweist. Der Bildhauer scheint sich hier zwischen griechischer und 


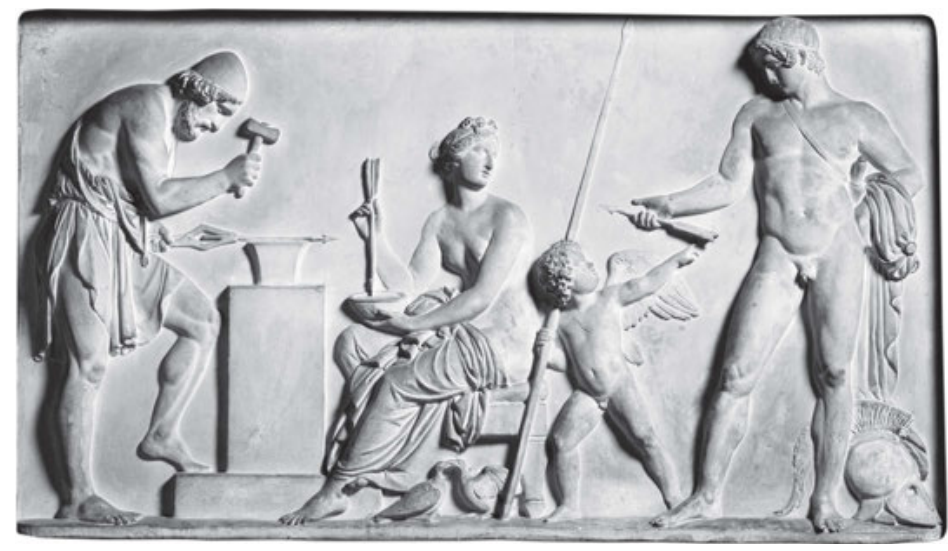

42_Bertel Thorvaldsen, Venus, Mars und Amor in Vulkans Schmiede, um 1810, Gipsmodell, $74,5 \times 130,3$ cm, Kopenhagen, Thorvaldsens Museum (Inv.-Nr. A419)

römischer Antike einerseits und nordischer Mythologie andererseits - oder genauer: als klassizistischer Bildhauer nordischer Abstammung - zu positionieren.

Diese Vereinigung zweier unterschiedlicher, man könnte fast sagen: gegensätzlicher kultureller Traditionen in Thorvaldsens Schaffen und Selbstverständnis wurde schon von Zeitgenossen beobachtet. Bereits 1812 baute Brun diesen Kontrast in ihre Kurzbiografie des Bildhauers ein: „Allein, mitten unter allen freundlichen und Hoffnung verheißenden Gestirnen am römischen Kunsthimmel, stieg plötzlich ein Stern erster Größe am Horizont empor! - Aus nördlichen Fernen glänzte Thorwaldson, der Däne! “429 Von der Hagen verstärkte jenen geografischen Gegensatz in einem Brief vom 5. November 1816 noch, indem er Thorvaldsen als Isländer bezeichnet, der „alle Italischen Bildhauer seiner Zeit“ übertreffe. ${ }^{430}$ Der Kunstkritiker und Geograf Malthe Conrad Bruun bemerkte 1826, dass „die Götter Roms oder eher Griechenlands durch den Meißel eines Kindes von Odin [gemeint ist Thor] wiederauferstanden sind“, dass also ein Skandinavier die griechische Antike wiederbelebt habe. ${ }^{431}$ Weitere vergleichbare Zitate stammen beispielsweise von der Schriftstellerin Eaton (1817), dem Archäologen Kephalides (1818), dem Dichter Oehlenschläger (1819), dem Mediziner Friedländer (1820) und dem Autor Johan Ludvig Heiberg (1841). ${ }^{432}$

431 Malthe Conrad Bruun an Bertel Thorvaldsen, zwischen Februar und Dezember 1826, KB, Abrahamske autografsamling 4º (Transkript im TMA): „[...] que les Dieux de Rome ou plutot de la Grece sont ressuscités par le ciseau d'un enfant d'Odin." Siehe auch Kofoed 2014a.

432 Kephalides 1818, 156: „Der ferne Norden sendet jetzt, wie es scheint, die talentvollsten Männer nach Rom, um die Künste pflegen zu lassen, welche unter den Händen der jetzigen Italiäner kümmerlich verkommen zu wollen scheinen.“; Friedländer 1820, 305: „Was ihm [Canova] die Muse versagte, ge- 


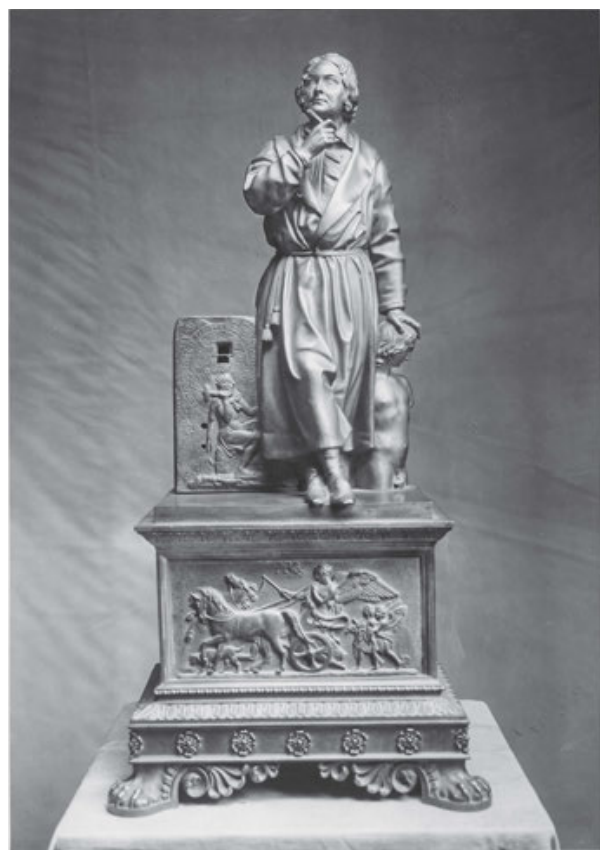

43_Alessandro Puttinati, Porträtstatuette von Bertel Thorvaldsen, 1830er Jahre, Bronze, Höhe: $61 \mathrm{~cm}$, Verbleib unbekannt

Auch in der bildenden Kunst schlug sich die Vereinigung von nordischem und südlichem Erbe in Thorvaldsens Persona und Schaffen nieder. So schuf Alessandro Puttinati in den 1830er Jahren eine bronzene Porträtstatuette von Thorvaldsen, den er zwischen einem Relief mit dem von einer Runeninschrift gerahmten, hämmernden Thor einerseits und einem antikisierenden Jungentorso andererseits platzierte (Abb. 43). ${ }^{433}$ Schließlich sei auch die 1844 entstandene Thor-Statue von Bengt Erland Fogelberg genannt (Abb. 44). Skizzen zu dieser Statue gehen bis ins Jahr 1818 zurück und befinden sich im Stockholmer

währte sie einem Jüngling im äußersten Norden, welchem sie bei der Geburt eine reiche Fülle wahrhaft griechischen Geistes einblies. In dem fernen Island erweckte sie Thorwaldsen und ließ ihn unter italischem Himmel bald zum Manne reifen, der die Bildhauerkunst auf den höchsten Gipfel der Vollendung hob.“; Eaton 1852, 307: „[...] this truly great genius, who has come from the frozen shores of Iceland to the land of arts, [...].“; Adam Oehlenschläger, 1819, zit. nach Thiele 1852-1856, Bd. 2, 13: „Habe der Gothe auch gefrevelt [...] dann hat der Gothe jetzt wieder seinen Frevel gut gemacht! Haben unsere Vorväter in Rom die Bildsäulen und Statuen niedergehauen, so erheben sie sich jetzt wieder, Griechenland würdig, durch die Kunst des Normannen.“; Johann Ludvig Heiberg, „En Sjæl efter Døden“, 1841, zit. nach Helsted 1973, 30: „Er du fra hiin Stad i Nord, / Hvor Antikens cedle Stamme, / Pleiet ved Geniets Flamme, / I barbarisk Jordbund groer, / Og hvor stolte Værker bramme, / Med et Navn, som kom fra Thor?" Siehe außerdem Eggers 1867, 37.

433 Siehe auch Kofoed 2014a. Von dieser Statuette befindet sich eine Gipsversion mit einem reduzierten Thor-Relief in der Fondation Custodia in Paris. 
44__Bengt Erland Fogelberg, Thor, 1844, Marmor, Höhe: $280 \mathrm{~cm}$, Solna (nahe Stockholm), Schloss Ulriksdal, Orangerie Museum

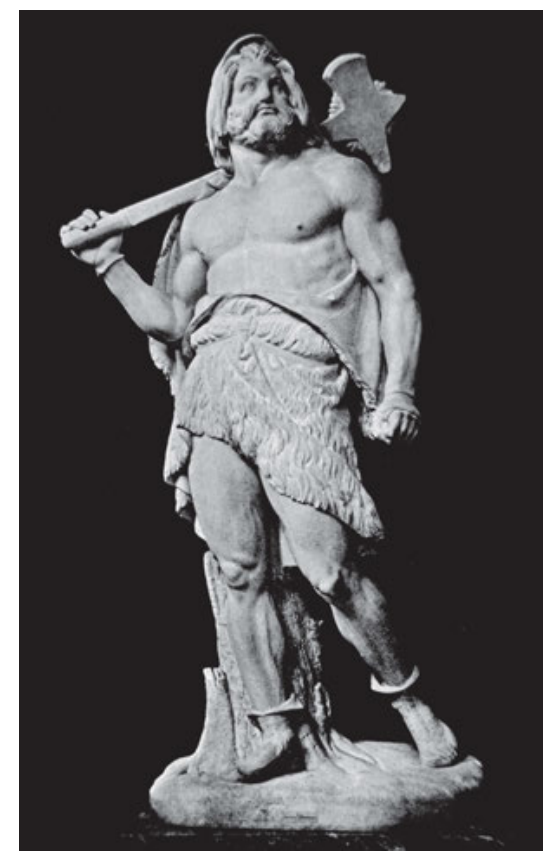

Nationalmuseum. Als Fogelberg jene Entwürfe Thorvaldsen zeigte, soll dieser gemeint haben: „Na, so sieht er [Thor] aus!“434 In der Tat lässt sich in Thorvaldsens oben erwähntem Siegel von 1827 eine Orientierung an Fogelbergs Skizzen erkennen. In Fogelbergs schließlich ausgeführter Thor-Skulptur hat sich die Rezeptionsrichtung hingegen gewendet, indem das Werk eine deutliche Orientierung an Thorvaldsens Jason und dessen Selbstbildnis mit der Statue der Hoffnung zeigt. ${ }^{435}$ Geschaffen in Thorvaldsens Todesjahr, scheint es mit Jason den Durchbruch und mit dem Selbstporträt den Zenit von Thorvaldsens Künstlerlaufbahn visuell zu vereinen.

Bei den Referenzen im Selbstbildnis mit der Statue der Hoffnung auf die griechische und römische Antike einerseits und die nordische Kultur andererseits handelt es sich um die beiden Grundfesten in Thorvaldsens Schaffen, Selbstverständnis, Selbstinszenierung und Persona. Sie verdeutlichen, dass sich verschiedene kulturelle Einflüsse keineswegs ausschließen, sondern die Selbstbildnisstatue gerade in ihrer Kombination zu einem hochprogrammatischen Werk machen - vielleicht dem programmatischsten in Thorvaldaußerdem Ljøgodt 2012, 149-150. 
sens ganzem CEuvre. ${ }^{436}$ Die zentrale Bedeutung, die diese Statue sowohl für Thorvaldsens künstlerisches Selbstverständnis als auch für sein öffentliches Bild einnahm, veranschaulicht schließlich ihre Rolle bei der Begräbniszeremonie für den Bildhauer: Thorvaldsens Sarg wurde mit einem Gipsabguss des halbgroßen Modells dieses Werks begraben (Abb. 121-122). ${ }^{437}$ Mit der archaisierenden Göttin der Hoffnung wählte Thorvaldsen für sein Selbstbildnis diejenige Schöpfung aus seinem Schaffen, die am weitesten in die Vergangenheit weist. ${ }^{438}$ Gemäß Sigurd Müller ist sie gar dasjenige Werk in Thorvaldsens Euvre, das die zeitgenössische Bezeichnung des Bildhauers als eines „spät geborenen Hellenen“ am besten veranschauliche. ${ }^{439}$ Jenen Blick zurück auf das antike Erbe seiner Kunst vereinte Thorvaldsen im Selbstbildnis mit der Statue der Hoffnung durch die Orientierung an der Thor-Ikonografie mit seinem nordischen Erbe sowie durch die Selbstdarstellung mit seiner Gegenwart. ${ }^{440}$ Die mit diesen Elementen veranschaulichten Zeitlichkeiten werden durch die Granatapfelblüte als Sinnbild sowohl der Vergänglichkeit als auch der Unsterblichkeit untermauert und durch den Aspekt der Ewigkeit ergänzt. ${ }^{441}$ Somit scheint kein anderes Werk Thorvaldsens geeigneter gewesen zu sein, den Sarg des Künstlers zu begleiten und dessen Bild und Werk zu verewigen.

In derselben Weise kann Karl Joseph Begas' 1823 gemaltes Porträt des Bildhauers verstanden werden (Abb. 45). ${ }^{442}$ Thorvaldsen ist hier in seinem gefütterten Morgenrock zwischen seinen Werkzeugen und dem kleinen Gipsmodell der Göttin der Hoffnung dargestellt und hält in seiner linken Hand einen Lorbeerzweig. Letzterer sowie die Granatapfelblüte in der Hand der Göttin der Hoffnung stehen für die prophezeite Unsterblichkeit des Bildhauers, während die Wandöffnung im Hintergrund den Blick auf antike Ruinen als Thorvaldsens Wirkungsort Rom freigibt. ${ }^{443} 1840$ porträtierte Johan Vilhelm Gertner

436 Kofoed 2014a bezweifelt hingegen eine bewusste Anlehnung an die Thor-Ikonografie und argumentiert mit der archaisierenden Figur der Göttin der Hoffnung und mit Thorvaldsens oben zitierter Aussage im Brief an Hansen über die künstlerische Darstellungswürdigkeit der antiken Mythologie; siehe dazu Bertel Thorvaldsen an Christian Frederik Hansen, 16. Februar 1807, TMA, Ref. m28, nr. 5. Bereits Thorvaldsens Lehrer, der Maler Nicolai Abildgaard, hatte sich jedoch dem Studium der Antike und jenem der nordischen Mythologie gleichermaßen gewidmet; siehe dazu bspw. Sutton 1972, 4.

437 Siehe bspw. Thiele 1831 - 1850, Bd. 4, 76; Thiele 1852 - 1856, Bd. 3, 53; Hannover 1907, 36; Bjarne Jørnæs, in: Helsted 1973, 54. Für Ausführungen zur Begräbniszeremonie siehe Kap. IV.3.

438 Siehe auch Hannover 1907, 35.

439 Müller, S. 1893, 134: „den sildig fødte Hellener“.

440 Siehe z. T. auch Sass 1950, 324; Bogh 1997, 60; Bogh 2001, 26; Friborg 2014.

441 Zur Symbolik der Granatapfelblüte siehe Henschen 1989, 101; Friborg 2014.

442 Begas wohnte in Rom wie Thorvaldsen in der Casa Buti. Siehe zu diesem Porträt auch Kat. Köln 1977, 342; Kat. Nürnberg/Schleswig 1991, 515; Kanzenbach 2007, 323 - 324.

443 Eine reduzierte Replik dieses Gemäldes befindet sich in der St. Petersburger Eremitage (Inv.-Nr. ГЭ5761). Begas' Gemälde weist außerdem starke Ähnlichkeit mit einem ebenfalls 1823 entstandenen Thorvaldsen-Porträt von Heinrich Maria von Hess auf (München, Neue Pinakothek, Inv.-Nr. WAF 348). Siehe auch Kat. Nürnberg/Schleswig 1991, 515; Mildenberger 1991, 192; Kanzenbach 2007, 323. 


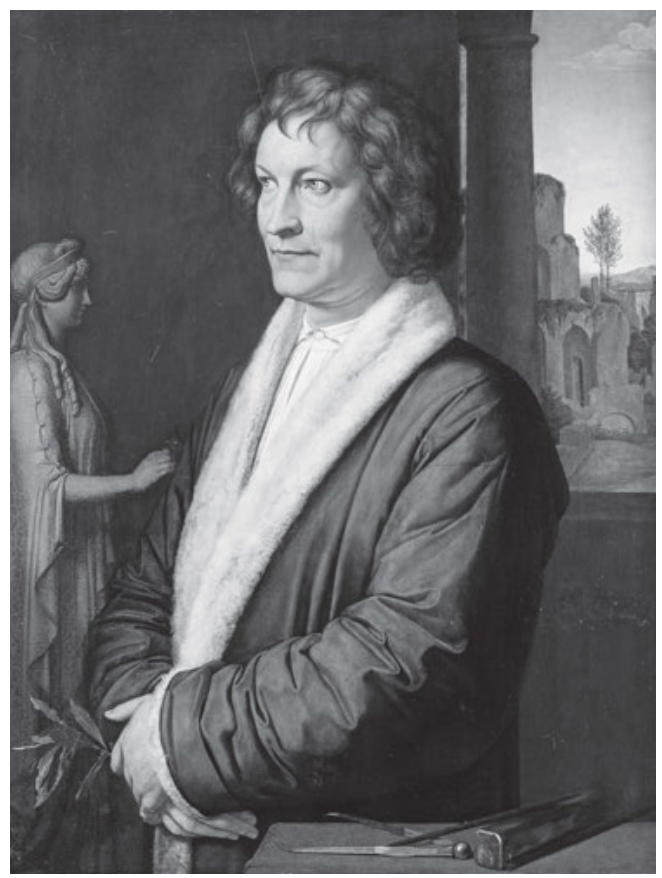

45_Carl Joseph Begas d. Ä., Bertel Thorvaldsen, 1823, Öl auf Holz, $93 \times 71,5 \mathrm{~cm}$, Berlin, Staatliche Museen zu Berlin, Alte Nationalgalerie (Inv.-Nr. A I 16)

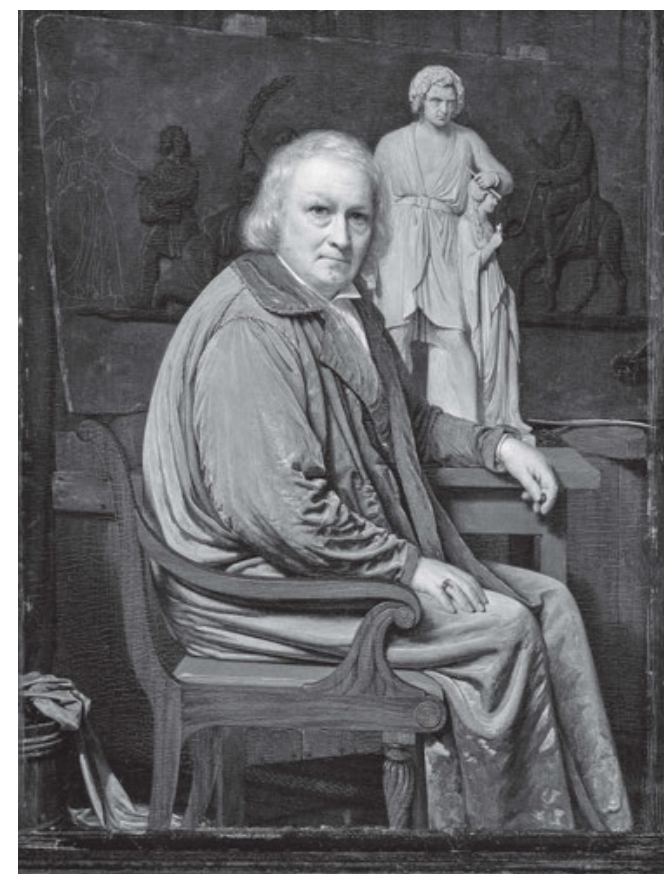

46_Johan Vilhelm Gertner, Bertel Thorvaldsen, 1840, Öl auf Holz, 26,1 × 19,5 cm, Hamburg, Hamburger Kunsthalle (Inv.-Nr. HK-1356)

den Bildhauer schließlich mit dem Selbstbildnis mit der Statue der Hoffnung und dem Relief Einzug in Jerusalem von 1839-1840 (Abb. 46). Der ähnlich wie bei Begas gekleidete Thorvaldsen sitzt in seinem Atelier, ist ebenfalls umgeben von Arbeitsutensilien und hält eine Tonkugel in der linken Hand. Nur ein Jahr nach der Selbstbildnisstatue entstanden, wird der idealisierende Charakter von Thorvaldsens Selbstdarstellung im Kontrast mit der von Gertner festgehaltenen Erscheinung des alternden Künstlers evident. Der im Relief dargestellte Christus hat die Hand zu einem Segnungsgestus gehoben, der nicht nur der gezeigten Menschenmenge zu gelten scheint, sondern auch der davorstehenden Selbstbildnisstatue von Thorvaldsen und damit diesem selbst. Das Relief Einzug in Jerusalem war Teil des erwähnten Auftrags zur skulpturalen Ausstattung der Kopenhagener Frauenkirche und damit gerade in Dänemark von zentraler Bedeutung für Thorvaldsens Ruhm.

\section{Das Nachleben des Selbstbildnisses mit der Statue der Hoffnung}

Der wichtige Stellenwert, den das Selbstbildnis mit der Statue der Hoffnung auch nach Thorvaldsens Tod für dessen öffentliches Bild und den noch einige Zeit fortdauernden Kult um ihn einnahm, manifestiert sich insbesondere im Nachleben der Skulptur in Form 


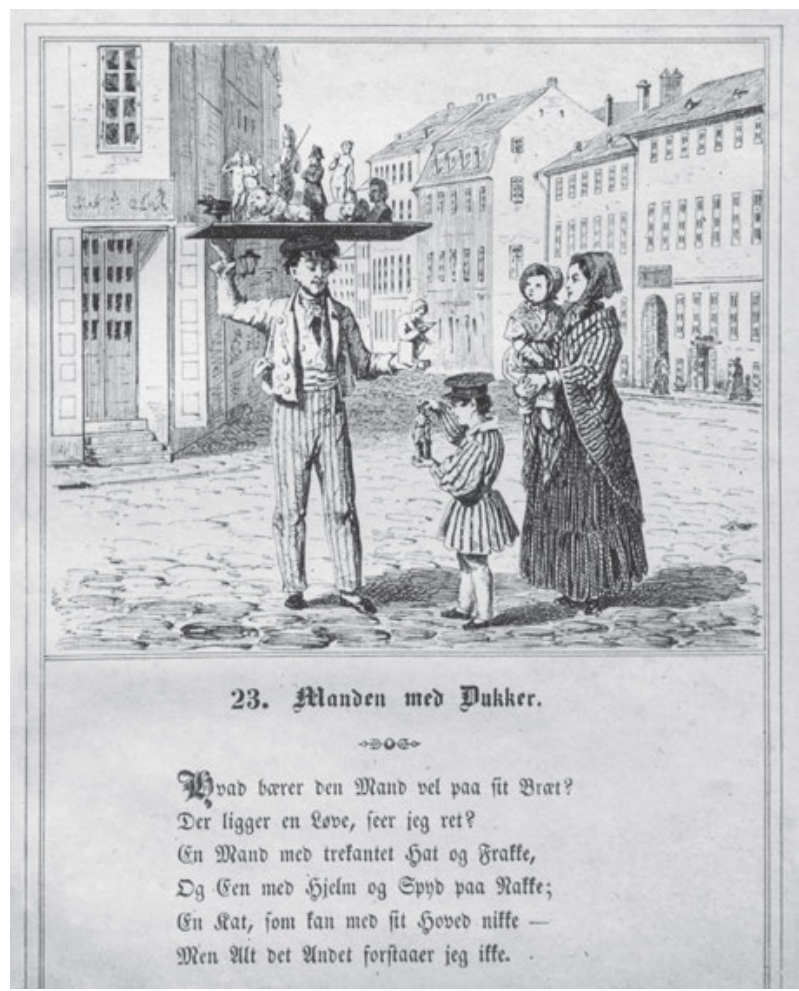

47_Martinus Rørbye, Manden med Dukker, 1846, in: Winther, C. 1846

von bildlichen Darstellungen und plastischen Kopien und Reproduktionen. Sie trugen zur Umwandlung von Thorvaldsens celebrity-Status in posthumen Ruhm bei. Ein besonders schönes Beispiel ist Rørbyes Illustration in dem 1846 publizierten Kinderbuch Fem og tyve Billeder for smaa Børn (Fünfundzwanzig Bilder für kleine Kinder): Unter dem Titel Manden med Dukker (Der Mann mit Puppen) zeigt Rørbye einen Straßenverkäufer und eine Mutter mit zwei Kindern (Abb. 47). Auf seinem Kopf trägt der Verkäufer ein großes Tablett mit Spielfiguren - der von Christian Winther verfasste Begleitvers zu dieser Illustration lautet übersetzt: „Was trägt der Mann wohl auf seinem Brett? / Da liegt ein Löwe, sehe ich richtig? / Ein Mann mit dreieckigem Hut und Mantel, / Und einer mit Helm und Speer auf dem Nacken; / Eine Katze, die mit ihrem Kopf nicken kann - / Aber alles andere verstehe ich nicht." 444

Bei den meisten der dargestellten Puppen handelt es sich um vereinfacht wiedergegebene Thorvaldsen-Skulpturen im Miniaturformat. So entsprechen der im Vers genannte

444 Winther, C. 1846, Nr. 23: „Hvad bærer den Mand vel paa sit Bræt? / Der ligger en Løve, seer jeg ret? / En Mand med trekantet Hat og Frakke, / Og Een med Hjelm og Spyd paa Nakke; / En Kat, som kan med sit Hoved nikke - / Men Alt det Andet forstaaer jeg ikke.“ 
Löwe Thorvaldsens Liegendem Löwen von 1825 und der Mann „mit Helm und Speer“ seinem Jason (Abb. 4). Weiter erkennt man auf dem Brett des Verkäufers Thorvaldsens Amor und Psyche (um 1807), Venus mit dem Apfel (1813-1816) sowie seine Selbstporträtbüste von 1810 (Abb. 31). Für den vorliegenden Kontext ist jedoch die Figur in den Händen des kleinen Jungen interessant, bei der es sich um Thorvaldsens Selbstbildnis mit der Statue der Hoffnung handelt. Obwohl dieses Werk nicht erwähnt wird und der Begleitvers stattdessen mit der Zeile schließt: „Aber alles andere verstehe ich nicht“, scheint sich der Junge besonders dafür zu interessieren. Damit zeigt Rørbyes Illustration, dass Thorvaldsens Selbstbildnis mit der Statue der Hoffnung in den Jahren nach dem Tod des Bildhauers so berühmt war, dass es sogar Kinder ansprach.

Im weiteren 19. Jahrhundert wurde Thorvaldsens Selbstbildnis mit der Statue der Hoffnung mehrfach und für verschiedene Kontexte nachgebildet. Beispielsweise ist noch aus der ersten Jahrhunderthälfte eine vergoldete Kaminuhr mit einem Aufsatz in Form dieser Skulptur erhalten, bei der jedoch die Göttin der Hoffnung durch die Porträtherme eines unbekannten Mannes ersetzt wurde. ${ }^{445}$ Außerdem schuf Harald Conradsen 1849 eine Medaille aus Silber, die auf der Vorderseite Thorvaldsens Selbstbildnisstatue sowie dessen Name, Geburts- und Todesdatum zeigt. Die Rückseite zieren das auf eine griechische Münze zurückgehende Bild der Nike auf einem Viergespann und der Name des Medailleurs. ${ }^{446}$ Diese Medaille bestätigte die verbreitete Betrachtung von Thorvaldsens Leben als einem einzigen Siegeszug. Eine leicht abgewandelte Version von Thorvaldsens Selbstbildnisstatue wurde 1856/1857 im Auftrag von Ludwig I. von Bayern durch Arnold Hermann Lossow für eine Nische in der Ostfassade der Münchner Glyptothek angefertigt (Abb. 48). ${ }^{447}$ Lossow änderte auf Ludwigs I. Wunsch hin Thorvaldsens Kleidung, indem er Schuhe, Strümpfe und Gürtelschnalle wegließ. Durch diese Antikisierung sollte sich Thorvaldsens Selbstporträtstatue besser in Gesamtprogramm und -auftrag der Glyptothek eingliedern. Ludwig I. begründete die Maßnahmen an Thorvaldsens Skulptur folgendermaßen: „So sehr ich gegen antike Darstellung Neuerer bin, muß dennoch, was in der Glyptothek, antik gehalten werden, soll Einklang nicht gestört seyn. "448 Aus dieser Aussage wird deutlich, dass Thorvaldsens Selbstbildnisstatue entgegen der gängigen Meinung in der Forschung durchaus Elemente aufweist, die nicht mit den klassizistischen Idealen vereinbar waren.

Im Jahr 1871 fertigte Emil Wolff eine Kopie des Selbstbildnisses mit der Statue der Hoffnung, die in Erinnerung an die römischen Werkstätten des Dänen noch immer vor dem

Diese Kaminuhr wurde am 2. Februar 2017 als Lot-Nr. 1705/1608 beim Kopenhagener Auktionshaus Bruun Rasmussen versteigert.

446 Kopenhagen, Thorvaldsens Museum (Inv.-Nr. F139). Siehe auch Kat. Köln 1977, 349.

447 Wünsche 1991, 323; Reichardt 2009, 200 - 201; Jørnæs 2011, 205.

448 Zit. nach Wünsche 1991, 323. Siehe auch Reichardt 2009, 104. 


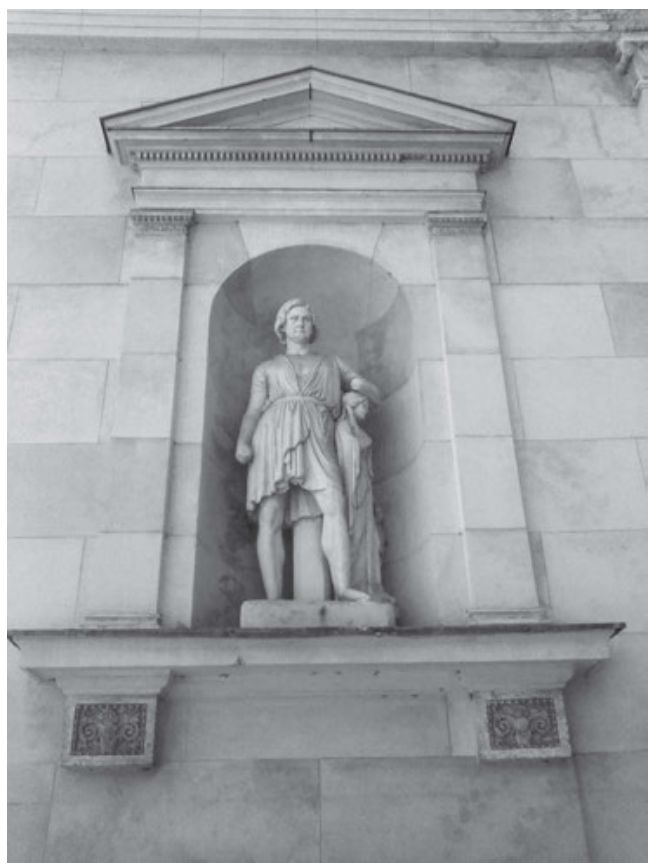

48_Arnold Hermann Lossow, Thorvaldsens Selbstbildnis mit der Statue der Hoffnung, 1856/1857, Marmor, nach Thorvaldsens Originalmodell in Gips von 1839, Höhe: ca. 2,35 m, München, Glyptothek, Ostfassade

Palazzo Barberini in Rom steht. ${ }^{449}$ Drei Jahre später erfolgte die Schenkung eines Bronzeabgusses der Skulptur durch die Stadt Kopenhagen an Island zu dessen 1000-jähriger Besiedlung. Das Monument wurde 1875 an Thorvaldsens Geburtstag, dem 19. November, auf dem Austurvöllur-Platz in Reykjavik feierlich enthüllt und 1931 an seinen heutigen Platz im Hljómskálagarðurinn-Park überführt. ${ }^{450}$ Ein weiterer Bronzeabguss von Thorvaldsens Selbstbildnis mit der Statue der Hoffnung wurde 1892 von amerikanischen Bürgern dänischer Abstammung bestellt und steht seit 1894 im Central Park in New York. ${ }^{451}$ Ferner gab es noch in den 1930er Jahren den Vorschlag, eine vergrößerte Bronzeversion des Werks auf dem Platz vor dem Kopenhagener Rathaus aufzustellen. ${ }^{452}$ Diese posthum ausgeführten oder zumindest geplanten Kopien der Skulptur für so unterschiedliche Orte wie München, Rom, Reykjavik, New York und Kopenhagen veranschaulichen nicht nur Thorvaldsens Status als internationale Berühmtheit. Gleichzeitig wird aus dem Nachleben des Selbstbildnisses mit der Statue der Hoffnung auch deutlich, dass das Werk - wohl gerade

449 Rosenberg 1901, 46; Jørnæs 1991c, 92 (datiert das Werk jedoch auf 1874); Tesan 1991a, 265.

450 Eldjárn 1982, 19 und 29. Im Rahmen der Festlichkeiten zu diesem Anlass wurde die bis heute existierende Thorvaldsensfélagið (Thorvaldsen-Gessellschaft) gegründet.

451 Bech 2009b.

452 Magnussen 1939, 63-64. 
wegen seiner Referenzen auf die klassische Antike einerseits und die nordische Mythologie andererseits - für verschiedene inhaltliche Kontexte und geografische Regionen passend erschien und darüber hinaus das Stilisierungsbedürfnis im Rahmen des Künstlerund celebrity-Kults um Thorvaldsen offenbar zu erfüllen vermochte. 
